\title{
The Emerging role of HDACs: Pathology and Therapeutic targets in Diabetes Mellitus
}

Saikat Dewanjee ${ }^{1 *}$, Jayalakshmi Vallamkondu ${ }^{2}$, Pratik Chakraborty ${ }^{1}$, Rajkumar Singh Kalra ${ }^{3}$, Moumita Gangopadhyay ${ }^{4}$, Ranabir Sahu ${ }^{5}$, Vijaykrishna Medala ${ }^{6}$, Albin John ${ }^{7}$, P. Hemachandra Reddy ${ }^{8,-12}$, Vincenzo De Feo ${ }^{13 *}$ Ramesh Kandimalla ${ }^{14 *}$

1. Advanced Pharmacognosy Research Laboratory, Department of Pharmaceutical Technology, Jadavpur University, Kolkata 700032, India. saikat.dewanjee@jadavpuruniversity.in

2. National Institute of Technology, Warangal 506004, Telangana, India. vlakshmij@ gmail.com

3. School of Life Science and Biotechnology, ADAMAS University, Barasat, Kolkata 700126, West Bengal, India. moumita.gangopadhyay@adamasuniversity.ac.in

4. AIST-INDIA DAILAB, National Institute of Advanced Industrial Science \& Technology (AIST), Higashi 1-1-1, Tsukuba, 305 8565, Japan. rajkumar.singh@ oist.jp

5. Department of Pharmaceutical Technology, University of North Bengal, Darjeeling 734013, West Bengal, India.ranaju4u@yahoo.co.in

6. Applied Biology, CSIR-Indian Institute of Technology, Uppal Road, Tarnaka, Hyderabad 500007, India. vijaykrishna079@gmail.com

7. Texas Tech University Health Sciences Center, Lubbock, TX, USA. Email: Albin.John@ttuhsc.edu

8. Professor of Internal Medicine, Texas Tech University Health Sciences Center, Lubbock, TX, USA. hemachandra.reddy@ttuhsc.edu

9. Neuroscience \& Pharmacology, Texas Tech University Health Sciences Center, Lubbock, TX, USA.

10. Neurology, Departments of School of Medicine, Texas Tech University Health Sciences Center, Lubbock, TX, USA.

11. Public Health Department of Graduate School of Biomedical Sciences, Texas Tech University Health Sciences Center, Lubbock, TX, USA.

12. Department of Speech, Language and Hearing Sciences, School Health Professions, Texas Tech University Health Sciences Center, Lubbock, TX, USA.

13. Department of Pharmacy, University of Salerno, 84084 Fisciano, Italy. defeo@unisa.it

14. Applied Biology, CSIR-Indian Institute of Technology, Uppal Road, Tarnaka, Hyderabad 500007, Department of Biochemistry, Kakatiya Medical College, Warangal 506007, Telangana, India.

* Correspondence: saikat.dewanjee@jadavpuruniversity.in; defeo@unisa.it; ramesh.kandimalla@gmail.com

\section{Running Title: HDACs: Therapeutic targets in diabetes}




\section{Highlights-}

- HDACs regulate crucial pathological functions/events in diabetes mellitus.

- HDACs have emerged as the potential therapeutic targets in diabetes.

- HDACs are at the crossroads of pathogenesis and therapeutics in diabetes. 


\begin{abstract}
:
Diabetes mellitus (DM) is one of the principal manifestations of metabolic syndrome and its prevalence with modern lifestyle is increasing incessantly. Chronic hyperglycemia can induce several vascular complications that were referred to be the major cause of morbidity and mortality in DM. Although several therapeutic targets have been identified and accessed clinically, the imminent risk of DM and its prevalence are still ascending. Substantial pieces of evidence revealed that histone deacetylase (HDAC) isoforms can regulate various molecular activities in DM via epigenetic and post-translational regulation of several transcription factors. To date, 18 HDAC isoforms have been identified in mammals that were categorized into 4 different classes. Classes I, II, and IV are regarded as classical HDACs, which operate through a Zn-based mechanism. In contrast, class III HDACs or Sirtuins depend on nicotinamide adenine dinucleotide (NAD+) for their molecular activity. Functionally, most of the HDAC isoforms can regulate $\beta$ cell fate, insulin release, insulin expression and signaling, and glucose metabolism. Moreover, the roles of HDAC members have been implicated in the regulation of oxidative stress, inflammation, apoptosis, fibrosis, and other pathological events, which substantially contribute to diabetes-related vascular dysfunctions. Therefore, HDACs could serve as the potential therapeutic target in DM towards developing novel intervention strategies. This review sheds light on the emerging role of HDACs/isoforms in diabetic pathophysiology and emphasized the scope of their targeting in DM for constituting the novel interventional strategies for metabolic disorders/complications.
\end{abstract}

Keywords: Diabetes mellitus; Glucose metabolism; Histone deacetylase; HDACs; Histone deacetylase inhibitor; HDACi, Insulin release; Sirtuins, Sirtuin activation 


\section{Introduction}

Diabetes mellitus (DM), a group of chronic metabolic disorders, is chiefly characterized by the persistently elevated blood glucose level due to deficiency and/or responsiveness of insulin [1]. Among two main types of diabetes mellitus, type 1 DM (T1DM) is caused by the absolute insulin deficiency due to damage of insulin-producing pancreatic $\beta$ cells, whereas type 2 DM (T2DM) is associated with insulin resistance, which ultimately may give rise to a relative deficiency of insulin [2]. In both cases, interactions between the genes and the environment are responsible for developing the syndrome [3, 4]. Also, some extracellular inflammatory factors in the islets of Langerhans have been revealed to be involved in diabetic pathogenesis despite their different genetic backgrounds [5]. Insulin deficiency in diabetic subjects can result in divergences of substrate metabolism [1]. This metabolic imbalance is not only restricted to carbohydrate metabolism but can also hamper protein and lipid metabolisms [6]. The TIDM is characterized by the lack of circulating insulin levels but in T2DM, the circulating insulin levels are either normal or slightly elevated, or mildly reduced. The pathological basis of the metabolic imbalance in diabetic subjects is an absolute or relative insulin deficiency in the blood [7]. Thus, maintaining the healthy mass of pancreatic $\beta$ cells can be a useful therapeutic aspect in DM [6, 7]. Umpteen studies revealed that the restoration of pancreatic $\beta$ cell population can restore normal substrate metabolism via triggering insulin Signaling and subsequently reduce the chance of developing DM [8, 9]. However, the mechanism underlying the alteration of insulin Signaling in pancreatic $\beta$ cells remains unclear.

Recent reports revealed that the role of epigenetic regulation in the development of diabetes $[10,11]$. However, this field of research field is still very young. Histone acetylation and deacetylation are important events for epigenetic gene regulation, which maintain a balance between physiological and pathological states $[12,13]$. Histone deacetylases (HDACs) comprise a group of enzymes, which catalyze the deacetylation of histone [13]. In the DM, activation of HDACs is rather pathogenic causing disruption of insulin turnover and glucose metabolism in different tissues by multiple mechanisms [6]. HDACs and Histone Acetyltransferases (HATs) are involved in chromatin remodeling by catalyzing Histone deacetylation and acetylation respectively. 
[14]. The combined activities of these two groups of enzymes play a vital role in gene transcription, cell growth, and apoptosis [14]. Cellular Signaling and gene expression can be mediated by controlling the HDACs-mediated deacetylation of histone and non-histone proteins [15]. The deacetylation process plays an important role in regulating the metabolism of glucose and maintaining glucose homeostasis both at the cellular and tissue level in active biological systems. For instance, PGC1 $\alpha$ undergoes deacetylation by epigenetic action of SIRT6, eventually promotes the production of glucose in the liver by repressing hepatic gluconeogenesis [\#185].

\section{HDACs: A general overview}

Histones are special proteins playing a role in the regulation of transcription by helping DNA to condense into its compact nucleosome form [16]. A histone octamer is made of 8 subunits namely two each of $\mathrm{H} 2 \mathrm{~A}, \mathrm{H} 2 \mathrm{~B}, \mathrm{H} 3$, and $\mathrm{H} 4$ [16]. DNA typically wraps around the histone octamer and the acetylation and methylation of the histone proteins regulate the tightness of this wrapping $[16,17]$. HDACs are the enzymes responsible for the removal of the acetyl group from histone proteins, thereby promoting tight wrapping that makes the DNA less accessible to the transcription factors [17]. The regulation of histone acetylation and deacetylation is achieved by the antagonistic action of HATs and HDACs [14, 18]. HDACs are closely associated with glucose metabolism by regulating insulin dynamics [6]. On the other hand, the mechanism of cell Signaling and gene expressions is regulated by the HATs by transferring acetyl groups to the lysine residue on histone and non-histone proteins [14, \#191]. A comparative analysis of lysyl residues modified by posttranslational modifications earlier identified 3600 acetylated sites on the 1750 proteins in human cells [\#307]. The basic phenomenon of this acetylation is to neutralize the positive charge at the histone and restrict its local association with the negatively charged DNA [19]. Once the acetyl group is bound to the histone, it serves as a docking site for protein bromodomain [20]. Bromodomains can aid in the remodeling of chromatin, or they can recruit other proteins to do the same [20]. The aforementioned gene function and activity are regulated by histone acetylation and deacetylation, but the net effect of the acetylation status of histone reflects in the regulation of target genes transcription. Thus, histone acetylation can be regarded as an important process for many biological or pathological functions. 


\section{The HDAC family: classes and inhibitors}

HDACs are the enzymes responsible for the deacetylation of lysine residues at histone proteins and thus regulates their post-translational acetylation [18]. In addition to histone deacetylation, HDACs can also regulate the activities of many non-histone proteins [21, 22]. Based on their sequence identity and catalytic activities, 18 HDACs were identified in mammals to date, which have been categorized into 4 different classes [13] (Table 1). Classes I, II, and IV are also known as classical HDACs operate through a mechanism based on $\mathrm{Zn}^{2+}$; while, class III HDACs or sirtuins (SIRTs) include SIRT1-7, which depend on nicotinamide adenine dinucleotide (NAD+) for their function [23].

Class I HDACs comprise HDAC1, 2, 3, and 8, which are structurally homologous to yeast RPD3 protein [13]. These HDACs can epigenetically regulate cell proliferation, differentiation, and cell cycle progression [24]. Interestingly, the members of HDACs principally contain a nuclear localization signal (NLS) but not the nuclear export signal (NES), so they are localized mainly in the nucleus [14]. However, HDAC3 is an exception in HDAC class I, which also contains NES [13]. The functions of class I HDACs are mediated through the formation of multi-protein complexes. HDAC1-HDAC2 conjugates form a catalytic core of several large complexes, such as co-repressing RE1 silencing transcription factor/neural restrictive silencing factor (CoREST), nucleosome remodelling and deacetylase (NuRD), nuclear receptor co-repressor/silencing mediator for retinoid and thyroid receptor (NCoR/SMRT), and switch-independent 3A (Sin3A) complexes [24]. HDAC3 is found to be conjugated with HDAC4, 5, and 7, and others. In contrast, HDAC8 is the only exception in class I, which can function singly [24]. Class II HDACs comprises HDAC4-7, 9, and 10 and they are homologous to yeast HDA1 protein [24]. Unlike class I HDACs, each member of class II HDACs contains an NLS, an NES, and an extra-regulatory domain [14]. However, depending on the photophosphorylation state, the class II HDACs can move in and away from the nucleus and cytoplasm aided by the presence of both NLS and NES [14]. Class II HDACs can deacetylate both histone and non-histone proteins [24]. Class II HDACs are further subdivided into class IIa (HDAC4, 5, 7, and 9) and class IIb (HDAC6 and 10) based on the organization and orientation in different domains within the proteins [13]. Also, Class IIa HDACs can handle only a specific and restricted set of natural substrates [14]. They generally act by recruiting corepressors or co-activators. Generally, class IIa HDACs exhibit poor deacetylation potential unless associated with class I HDACs. For example, the catalytic activity of HDAC4 depends on its association with HDAC3 within a larger NCoR-SMRT complex and NcoR-SMRT-HDAC3- 
mediated transcriptional regulation of target genes [25]. In contrast, class IIb HDACs are ultimately involved in non-classical epigenetic roles [26]. Unlike the other classical HDACs, HDAC6 is primarily cytoplasmic and involves cytoskeleton regulation via deacetylating $\alpha$-tubulin [25, 26 ]. Class III HDACs comprising SIRT1-7 mimic structural homology with yeast Sir2 protein and also belongs to the family of $\mathrm{NAD}^{+}$-dependent deacetylases [27]. SIRTs are responsible for the post-translational modifications of many intracellular proteins either by acetylation or by ribosylation of adenosine diphosphate (ADP) [14]. Nevertheless, SIRTs, facilitate the deacetylation of proteins with the help of energy gained through the hydrolysis of $\mathrm{NAD}^{+}$[14]. SIRT1 can regulate the expression of various genes either directly by recruiting other SIRTs by targeting several transcription factors and co-activator/repressor proteins or indirectly through structural modulation of chromatin [28]. SIRTs were found to have a close association with the development of cancer, metabolic dysregulation, and drug resistance through multiple levels of transcriptional regulation $[14,28]$. HDAC11, a sole member of class IV, is predominantly located in the perinuclear compartment of lymphoblastoid cells and cytosol of resting CD4 ${ }^{+} \mathrm{T}$ cells [29]. HDAC11 mainly regulates diverse immune functions, sensitivity in $\mathrm{CD}^{+} \mathrm{T}$ cells, and inflammation [13, 23, 29]. Also, HDAC11 contains a catalytic domain at the N-terminal region [29]. Similar to the first two classes, class IV HDACs also act by the $\mathrm{Zn}^{2+}$-dependent mechanism [23]. Unlike class I and II HDACS, HDAC11 does not interact with NCoR and SMRT; however, it interacts with HDAC6 [29].

Overexpression of HDACs is involved in various forms of cancer and some forms of neurological, inflammatory, and vascular disorders [15, 18, 23, 30]. Based on chemical structures, HDAC inhibitors (HDACis) are classified into five groups: hydroxamic acid derivates, such as 
trichostatin A, belinostat, practinostat, panabiostat, vorinostat, rocilinostat; short-chain fatty acids, like phenylbutyric acid, butyric acid, valproic acid; cyclic peptides, namely romidepsin; benzamides, such as tubastatin A, tacedinaline, 4SC202, entinostat, mocetinostat; and SIRT inhibitors, like sirtinol, camabinol, EX-527 [24, 31]. However, most HDACis are found to be effective against multiple isoforms of HDACs by targeting the $\mathrm{Zn} 2+$ domain [24]. In contrast, SIRT inhibitors comprise entirely different their different mechanisms of action [31, 32]. Mechanistically, this class of HDACis bind non-covalently to the SIRT active site and block the substrate-binding [32]. Indeed, most of the other HDACis comprise a common 'pharmacophore' with a 'Zn-binding domain' (for docking in the active site) and a 'surface recognition domain' to interact with the residues near the active site and gain entry [33]. Pharmacophore with the domains is joined by a linker or spacer allowing the molecule to lie on the catalytic tunnel of the enzyme [33]. Inhibitors of the classical HDACs, the $\mathrm{Zn}^{2+}$-dependent HDACs, have shown promising activity in the intervention of DM and associated complications [34-36]. Among the classical HDAC inhibitors, vorinostat, belinostat, romidepsin, panobinostat were approved by the US Food and Drugs Administration (FDA) and Chidamide has been approved by China FDA for therapeutic interventions [24]. Also, many of HDACis are under different stages of clinical trials [31]. Most of the aforementioned HDACis are active against multiple isoforms of HDAC and possibly enhancing the chances of developing several untoward effects [24]. In contrast, novel class/isoformselective HDACis could offer enhanced therapeutic efficacy as compared to non-selective HDACis [24]. Several HDACis have been mentioned to be useful against DM by multiple mechanisms (Fig. 1).

\section{HDACs and DM}

Both T1DM and T2DM are polygenetic disorders with multifactorial etiologies. Histone acetylation is among the epigenetic processes, which has been revealed to be an important regulatory role in DM [21]. Thus, HDACs can impart significant influence in both types of DM by regulating $\beta$ cell viability, insulin production, insulin resistance, glucose intolerance, and inflammation [21]. 
All members of Class I HDACs have been revealed to be associated with insulin resistance [21]. HDAC1 acts as a suppressor of glucose transport through glucose transporter (GLUT) 4 and can interrupt peripheral glucose uptake [21]. The role of HDAC2 in the development of diabetes and associated vascular complications has been well established [37-39]. Also, it has been pointed out that a significant association between $6 \mathrm{q} 21$, the chromosomal location of HDAC2, and DM [38]. HDAC3 has been proposed to trigger hepatic gluconeogenesis [21]. Also, single nucleotide polymorphic variants in the HDAC3 gene, such as rs2547547AG and rs2530223CC have been proposed to increase the risk of developing T2DM among the Hans population in China by potentiating HDAC3-mediated aberration in lipid metabolism [40]. In contrast, variant rs11741808AG can lower the risk of type 2 DM by antagonizing HDAC3 [40]. HDAC8 was found to endorse insulin resistance [21]. Also, class I HDACs, such as HDAC1 and 3, have been revealed to endorse inflammation in pancreatic $\beta$ cells [21].

Class II HDACs have been found to regulate the transcription of genes involved in glucose homeostasis and hepatic gluconeogenesis [41]. Activation of class IIa HDACs can endorse the transcription of gluconeogenic genes by deacetylation of forkhead box protein O1 (FOXO1) [41]. HDAC4, 5, 7, and 9 were found to act as metabolic regulators contributing to glucose homeostasis by deacetylation of FOXO1 [42]. Also, HDAC4 and HDAC5 can suppress the GLUT4 gene and contribute to insulin resistance, while HDAC7 has been reported to contribute to the impairment of insulin secretion and trigger $\beta$-cell apoptosis [21]. Earlier reports revealed a close association between HDAC9 activation and the development of vascular complications in DM [43, 44]. Among class IIb HDACs, HDAC6 has been revealed to be an agonist of glucocorticoids and endorse glucocorticoid-induced hepatic gluconeogenesis [45]. Also, HDAC6 can endorse glucoseprovoked ROS (reactive oxygen species) generation by regulating acetylation of peroxiredoxin-1 (Pdrx1) and thioredoxin-1 (Trx-1) [46]. HDAC10 deacetylates forkhead box P3 (FOXP3) and thus, can regulate FOXP3-dependent metabolic and inflammatory gene expression [47]. Also, HDAC10 in the hypothalamus has been claimed to regulate appetite [21]. Class II HDACs can also associate with GLUT4 at the promoter region and suppress the transcription of the GLUT4 gene 
in the adipose tissue [48]. It has been shown that GLUT4 transcription can be inhibited due to the loss of histone acetylation of GLUT4 promoter in adult muscle tissues [49]. In contrast, HDAC inhibition can improve GLUT4 transcription resulting in improvement in glucose tolerance and insulin sensitivity [50].

Class III HDACs, SIRTS, are known to regulate energy metabolism and glucose homeostasis [51, 52]. The roles of SIRTs in DM remain enigmatic. In most cases, SIRT1, 2, 3, and 6 have been proposed to regulate the genes which trigger insulin responsiveness and glucose homeostasis [52]. Also, SIRT1, 2, 3, and 6 have been mentioned to impart beneficial effects by reducing inflammation, suppressing oxidative stress, and restoring mitochondrial functions in the pancreas, skeletal muscle, and adipose tissues [53]. SIRT6 has been revealed to regulate insulin sensitivity and glucose utilization in a positive manner by regulating transient receptor potential vallinoid 1 (TRPV1), calcitonin gene-related peptide (CGRP), and GLUT4 genes [54]. In contrast, SIRT4 and SIRT7 suppress insulin secretion, insulin sensitivity, and fatty acid oxidation by epigenetic regulation. A recent report revealed that increase expression of SIRT5 is associated with the development of DM [55]. However, some contradictory shreds of evidence also exist; genetic polymorphisms of SIRT1 and SIRT2 were found to be associated with the development of DM [52]. Polymorphic variants rs 10823108 of the SIRT1 gene have been regarded to contribute to the pathogenesis of T2DM [56] and the human SIRT2 gene localized in the 19q13 region of the chromosome is found to contribute as a risk factor in developing T2DM [57]. In a report, SIRT4 expression has been mentioned to reciprocate diabetic nephropathy by reducing oxidative stress and apoptosis [58].

Class IV HDAC, HDAC11, is a relatively new member of the HDAC family, which can preferentially remove fatty acid residues from lysine side chains of a protein or peptide [59]. HDAC11 has been regarded to regulate metabolism and obesity [60]. Deletion of HDAC11 can enhance glucose tolerance, insulin sensitivity, and lipid metabolism [60, 61]. Also, HDAC11 deletion has been reported to reduce dyslipidemia, oxidative stress, inflammation, and apoptosis in the heart of diabetic mice [62].

Besides T1DM and T2DM, HDACs-suppressed histone acetylation is also related to one form of monogenic autosomal diabetes namely maturity-onset diabetes of the young 
[38]. Different subtypes of diabetes are associated with the mutation of genes [63]. However, most of these genes encode transcription factors associated with HDACs and HATs and regulate insulin transcription and hepatic gluconeogenesis [63]. Mutations or chromosomal aberration of these genes alter the extent of interaction of transcription factors with HATs and HDACs [64].

\subsection{Role of HDACs in the endocrine fate of pancreas}

The endocrine cells in the islets of Langerhans of the pancreas consist of mainly $\alpha, \beta, \delta$, and PP cells producing glucagon, insulin, somatostatin, and pancreatic polypeptide hormones, respectively [65]. The cascades of transcription factors and several Signaling pathways regulate the growth, development, and fate of the endocrine cells of the pancreas [66]. For the proper development of the pancreas, it involves a precise regulation and synchronization of a huge number of transcription factors [66]. Pancreatic and duodenal homeobox 1 (Pdx1) plays a central role in the early development of the pancreas [66]. At an early stage of development, Pdx1-expressing progenitor cells differentiate into endocrine and exocrine cells [66]. Neurogenin 3 (Ngn3) can trigger the initiation of endocrine differentiation from Pdx1-expressing progenitor cells [67]. Ngn3 expressing cells are the islet progenitors [67]. Furthermore, the developments of $\beta$ and $\delta$ cells are linked with the expression of paired box gene 4 (Pax4) [68].

HDACs have been regarded to regulate the differentiation of pancreatic progenitor cells and endocrine fates by interfering with the acetylation of histone residues [69]. HDAC1 can silence the expression of $\beta$ cell-specific Pdx1, which simultaneously obstructs $\beta$ cell development [70]. HDACis are found to enhances the expression of $\mathrm{Ngn} 3$, which consequently enhances the pool of endocrine progenitor cells [71]. The association of HDAC1 with sex-determining region Y box 6 (Sox6) can also prevent $\beta$ cell proliferation by Sox6 [38]. Among the various HDACis, trichostatin A (TSA) is found to enhance $\beta / \delta$ cell differentiation, while valproic acid is reported to suppress the same [71]. HDAC2 can also interact with Pdx1 at C-terminus [72]. HDAC3 can bind to the C/EBP homologous protein (Chop) and activating transcription factor 4 (Atf3) promoters in response to hyperlipidemia associated with T2DM and 
can induce apoptosis to $\beta$ cells by endorsing endoplasmic reticulum (ER) stress [73]. On the contrary, Xie and co-authors demonstrated that class I HDACs can promote $\beta$ and $\delta$ cell differentiation from endocrine progenitor cells [69].

Among class IIa HDACs, HDAC4, 5 and 9, can bind with myocyte enhancer factor 2A (MEF2A) to block the transcriptional activity of MEF2A target genes and consequently restrict the development of pancreatic endocrine cells [74] [75]. MC1568, a specific class IIa HDACi, treatment to pancreatic explant was reported to increase $\beta$ and $\delta$ cell population by regulating the stability of HDAC-MEF2A complex [75].

Several pieces of evidence revealed the key role of SIRTs in regulating the fates of the endocrine pancreas. Activation of SIRT1 was regarded to promote $\beta$-Cell regeneration by triggering endocrine progenitor cells through 5' AMP-activated protein kinase (AMPK)-mediated activation of Ngn3 and fatty acid oxidation [76]. Also, SIRT1 facilitates $\beta$-cell formation by endorsing the transcription of Pdx 1 mediated through deacetylation of FOXA2 on the promoter of the Pdx1 gene [77]. A recent report revealed that the expression of SIRT3 is required for restoring $\beta$ cell physiology [78]. SIRT5 has been regarded to regulate the proliferation of pancreatic $\beta$ cells negatively through suppressing the transcription of Pdx1 by histone H4K16 deacetylation [79] [55]. SIRT6 was found to impede the expression of a thioredoxin-interacting protein (Txnip) in pancreatic $\beta$ cells by deacetylating histone $\mathrm{H} 3$, thereby it plays an important role in restoring the $\beta$ cell population [80]. HDAC11 was revealed to function downstream of cytokines in human islets and could endorse distraction of pancreatic $\beta$ cells [81]. Thus, it was suggested that HDACs can be the therapeutic target to restore the structural physiology of the pancreas.

\subsection{Role of HDACs in regulating $\beta$ cell function and insulin secretion}

The function of $\beta$ cells is to release insulin to maintain glucose homeostasis [82]. An abnormal metabolic milieu can affect $\beta$ cell development by modifying key regulatory genes, such as Pdx1 and GLUT4 in muscle [83]. Transcription of preproinsulin mRNA from DNA is principally controlled by three specific transcription factors, such as Pdx1, neurogenic differentiation 1 (NeuD1), and V-maf musculoaponeurotic fibrosarcoma oncogene homolog A (MafA) [84] [85] (Fig. 2). This cycle of transcription and subsequent insulin release from the cells is controlled by glucose itself. The expression of insulin in $\beta$ cells is regulated by its acetylation [84]. HDACs can negatively regulate transcription [84].

$\mathrm{Pdx} 1$ is known to endorse glucose-provoked insulin gene activation [86]. In hyperglycemic conditions, Pdx1 can recruit p300 and triggers the acetylation of H4 protein [86] (Fig. 2). The 
hyperacetylation of $\mathrm{H} 4$ at the proximal promoter region causes the hypertrophy of $\beta$ cells, which subsequently sets off the transcription of preproinsulin in the insulin promoter region to produce high levels of insulin [38]. High glucose can also trigger the acetylation of H4 at the GLUT2 promoter region [38]. Pdx1 recruits HDAC1 and HDAC2 to the insulin promoter in the hypoglycemic condition, which apprehends $\mathrm{H} 4$ acetylation and led to the shutdown of insulin production [86] (Fig. 2). Recruitment of HDAC1 conjugated with the co-repressor Sin3A to the proximal promoter of Pdx1 can cause suppression of Pdx1 expression [38]. HDAC1-Sin3A conjugate can further recruit histone demethylase in a self-propagating epigenetic sequence to suppress histone $\mathrm{H} 3$ on lysine 4 trimethylation (H3K4me3), which can suppress Pdx 1 transcription [38]. NeuD1 plays a vital role in insulin gene expression through the acetylation of p300-associated factor (PCAF) [87]. Eventually, it serves to promote the binding of the transcription factors to the insulin promoter [87]. Phosphorylation of MafA can facilitate the binding of insulin promoters [87]. Precisely, phosphorylated MafA can interact with PCAF (p300/CBP-associated factor) to increase the transcriptional activity and simultaneously promotes the degradation of MafA [87]. However, the phosphorylation-mediated proteasomal degradation of MafA is delayed in hyperglycemic condition, which allows an extended period of insulin transcription [84] (Fig. 2). Cyclin-dependent kinase inhibitor 2A (CDKN2A) encoding cell cycle inhibitor genes, such as $\mathrm{p} 16^{\mathrm{INK} 4 \mathrm{~A}}$ can epigenetically regulate regeneration and proliferation $\beta$ cells at the transcriptional and post-translational levels of Cdkn2a locus [88]. HDAC1 can recruit $\mathrm{p} 16^{\mathrm{INK} 4 \mathrm{~A}}$ by regulating E2F1 release [89]. HDAC3 is activated through forming stable complexes NCoR1 and SMRT and subsequently suppress glucose-provoked insulin secretion through regulating several genes [90]. Both pharmacological and genetic inhibition of HDAC3 has been shown to protect $\beta$ cells and improve insulin gene transcription by triggering suppressors of cytokine 
Signaling 3 (SOCS3) and endorses glucose-provoked insulin secretion [90-92].

Class IIa HDACs, namely HDAC4, 5, and 9 possess distinct ability to hinder the replication of $\beta / \delta$ cell types in the pancreas without affecting $\alpha$ cell mass [74]. Increased expression of HDAC7 has been observed in the pancreatic islets of T2DM patients [92]. HDAC7 has been revealed to inhibit insulin secretion by triggering transcription factor 7-like 2 (Tcf712) expression and suppressing the expression of genes regulating DNA replication in $\beta$ cells [92]. Some reports proposed that the inhibition of HDAC4, 5, 7, and 9 can be fruitful to facilitate insulin production in $\beta$ cells $[38,74,92]$. On the contrary, Makinistoglu and Karsenty reported a positive correlation between HDAC4 expression in osteoblasts and circulatory insulin [93]. A recent study by McCann and co-workers revealed that HDAC4 and 5 can not influence insulin production under normal or hyperglycemic conditions [94]. In another study, mutations in the HDAC4 gene have been revealed to impede $\beta$ cell functions including insulin production by disrupting the FOXO1 and downregulating $\beta$ cell-specific transcriptional factors [95]. HDAC inhibition has been reported to increase the expression of insulin 1, insulin 2, GLUT2, and Ogg1 genes [96]; while, high dose of HDACis has been implicated to affect negatively in insulin secretory mechanism of pancreatic $\beta$ cell line [97].

Class III HDACs, SIRT isoforms, have been described to be the distinct regulators in DM, which can also regulate insulin secretion by pancreatic $\beta$ cells. SIRT1 can trigger the secretion of insulin by suppressing the uncoupling protein 2 (UCP2) gene and endorsing ATP production in pancreatic $\beta$ cells [51]. It could also activate the transcription of NeuD, MafA, insulin 1, and insulin 2 to facilitate insulin secretion [51]. Decreased expression of SIRT3 mRNA in pancreatic islets has been correlated to the suppression of Pdx1, MafA, insulin 1, and GLUT2 genes, which consequently results in $\beta$ cell dysfunction and suppression of insulin secretion [78]. Ectopic SIRT5 expression can inhibit insulin secretion in T2DM by suppressing Pdx1 through H4K16 deacetylation [79]. SIRT6 deficiency has been implicated to impair glucose-induced insulin secretion via deacetylation of FOXO1 and subsequent activation of Pdx1 and GLUT2 expressions $[98,99]$. SIRT4 gene in pancreatic islets has been 
proposed to abrogate insulin secretion via interaction with adenine nucleotide translocator 2/3(ANT2/3) and insulin-degrading enzymes under a calorie-sufficient state [51]. SIRT4 has also been revealed to remove three acyl moieties, such as methylglutaryl, hydroxymethylglutaryl, and 3methylglutaconyl from lysine residues and impede insulin secretion by controlling leucine metabolism [100]. On the other hand, the SIRT7 gene has been anticipated to regulate insulin secretion negatively [52].

To date, substantial evidence is absent regarding the regulatory effect of class IV, HDAC11, on insulin secretion; however, deletion of HDAC11 has been mentioned to suppress high fat-induced hyperinsulinemia in mice [61]. Considering the regulatory effect of HDACs in $\beta$ cell function and insulin secretion, it could be said that HDACs can be the therapeutic target to alleviate DM.

\subsection{Role of HDACs in glucose homeostasis}

Insulin and glucagon play vital roles in maintaining equilibrium between hepatic glucose production and glucose uptake by the peripheral tissues [101]. Normally, after diet insulin lowers blood glucose by promoting the uptake of glucose by the peripheral tissues and inhibiting hepatic gluconeogenesis [101]. In contrast, glucagon induces endogenous gluconeogenesis and glycogenolysis in the liver [101]. Mechanistically, insulin, after binding to the insulin receptor on the cell surface, promotes autophosphorylation of tyrosine kinases on the $\beta$ subunit of the receptor and recruits insulin receptor substrate 1 (IRS-1) signal transduction [102] (Fig. 3; Table 2). Eventually, IRS-1 undergoes conformational changes to accommodate phosphatidylinositol 3 kinase $(\mathrm{PI} 3 \mathrm{~K})$ by the activated insulin receptor. PI3K is responsible to convert membrane phosphatidylinositol bisphosphate (PIP2) into phosphatidylinositol trisphosphate (PIP3) by phosphorylation [102]. PIP3 phosphorylates protein kinase B (Akt) with the help of PIP3 dependent kinase (PDK) and subsequently triggers the Akt Signaling, which further activates GLUT4 by allowing it to translocate to the plasma membrane [102](Fig. 3). The GLUT4 translocation endorses glucose uptake by glycogenesis [82, 102]. On the flipside, activated Akt can also suppress the gluconeogenic genes, such as phosphoenolpyruvate carboxykinase (PEPCK) and glucose-6-phosphatase [103]. The suppression of PEPCK and glucose-6-phosphatase transcriptions is mainly carried out as a result of the FOXO1 [104]. Also, activated Akt causes 
increased uptake of glucose into the cell and converts into glycogen by glycogenesis [105]. So, Akt simultaneously deactivates glycogen synthase kinase $3 \beta$ (GSK-3 $\beta$ ) for converting glucose to glycogen by glycogen synthase without any interruption [106] [107]. Finally, gluconeogenesis and glycogenolysis are downregulated, whereas glycogenesis is upregulated. Activation of Akt can also ensure cell survival via inhibition of pro-apoptotic BAD genes [108]. In contrast, glucagon promotes hepatic gluconeogenesis by upregulating the expressions of PEPCK and glucose-6phosphatase [109] (Fig. 3).

The regulation of glucose metabolism is largely controlled by post-translational modifications of histones [110]. Acetylation and deacetylation of histone proteins are governed by HATs and HDACs, which are the key players to control gene expressions [110]. HDACs can epigenetically regulate fatty acid and carbohydrate metabolism by regulating the transcription of several genes [14]. Classical HDACs can also influence the deacetylation of non-histone protein, signal transducer, and activator of transcription 3 (STAT3), which results in suppression of gluconeogenic enzyme expression [14]. Kimura et al reported that classical HDAC inhibitors can suppress hepatic gluconeogenic enzymes via ER stress inhibition mediated through Janus kinase 2 (JAK2)/STAT3-dependent pathway [111]. Hence, HDACs are the key factors in regulating hepatic gluconeogenesis (Fig. $3 \& 4$ ).

All members of class I HDACs, are regarded as positive regulators in developing insulin resistance [21]. HDAC1 and 2 can suppress insulin Signaling by inhibiting the Pdx1 gene [112] [113]. Also, HDAC1 can suppress GLUT4 and impede glucose utilization. HDAC1, through induction of hepatocyte nuclear factor $4 \alpha$ (HNF4 $\alpha$ ), induces PEPCK expression and gluconeogenesis in the liver [114]. HDAC2 can also bind to IRS-1 and reduce its phosphorylation as seen in mouse hepatic cells [115]. Activation of HDAC3 epigenetic signature can contribute to developing insulin resistance in T2DM [116]. HDAC3 is known to deacetylate peroxisome proliferator-activated receptor gamma (PPAR $\gamma)$ and subsequently inhibits PPAR $\gamma$ action [117]. On the other hand, HDAC3 inhibition has been shown to reciprocate insulin resistance in adipocytes by activation of PPAR $\gamma$ through its acetylation [117] (Fig. 5). Also, HDAC3 can endorse FOXO1 deacetylation to facilitate DNA binding of FOXO1 
resulting in activation of gluconeogenic genes [118]. Sterol regulatory element-binding protein-1 (SREBP1) can bind to and recruits HDAC8 [119]. Activated HDAC8 can endorse Wnt Signaling components resulting development of insulin resistance and glucose accumulation [119] (Table 2).

In a fasting state, class IIa HDACs get dephosphorylated under the influence of glucagon [120] [121]. However, on dephosphorylation, class IIa HDACs translocates to the nucleus from the cytoplasm and endorse HDAC3 [14]. HDAC3, in turn, deacetylates FOXO1/3 which facilitates DNA binding of FOXO and increases gluconeogenic gene expressions [14] (Fig. 4). Thus, it becomes evident that class IIa HDACs trigger hepatic gluconeogenesis [118]. HDAC4 and 5 are known to impair GLUT4 expression because of their deacetylation capacity and thus can establish insulin resistance [122]. Deletion of HDAC9 in a hyperglycemic state has been reported to improve glucose tolerance in mice [123]. HDAC6 has been regarded as an essential modifier of glucocorticoid-induced hepatic gluconeogenesis and impair glucose metabolism by regulating nuclear translocation of the glucocorticoid receptor [45]. Thus, inhibition of class II HDACs has been shown to ameliorate insulin resistance and glucose intolerance.

SIRTs, the class III HDACs, is regarded as the key regulators in energy metabolism. In the hyperglycemic condition, SIRT1 can promote insulin-mediated glucose uptake by improving mitochondrial functions and deacetylating of FOXO1 and peroxisome proliferator-activated receptor gamma coactivator 1-alpha $(\mathrm{PGC1} \alpha)$ of muscle cells and [52]. Also, SIRT1 can improve insulin sensitivity by suppressing uncoupling protein 2 (UCP2) and protein tyrosine phosphatase 1b (PTP1B) [52]. SIRT1 plays a dual role in hepatic glucose production either suppression of hepatic gluconeogenesis by degradation of CREB-regulated transcription co-activator 2 (CRTC2) or activation of hepatic gluconeogenesis by FOXO/PGC1 $\alpha$ deacetylation [51]. Unlike SIRT1, SIRT3 can activate PGC1 $\alpha$ indirectly, through activating cAMP response element-binding protein (CREB) and AMPK expression [52]. Deletion of SIRT3 has been proposed to develop insulin resistance in mice [55]. In high glucose conditions, SIRT2 can sustain insulin sensitivity and glucose metabolism through augmenting mitochondrial functions and Akt activation [1 124 ]. SIRT2 can interact with Akt and subsequently activate Akt 
Signaling in insulin-responsive cells [125]. In another report, activation of SIRT2 has been proposed to improve glucose tolerance and hepatic glucose uptake in the hyperglycemic state via deacetylation K126 of glucokinase regulatory protein in diabetic mice [55]. Also, SIRT2 can prevent hepatic gluconeogenesis by inhibiting ubiquitylation of PEPCK through endorsing deacetylation [55]. However, the effect of SIRT2 in insulin Signaling is controversial. Arora and dey claimed that SIRT2 can endorse insulin resistance in $\mathrm{C} 2 \mathrm{C} 12$ skeletal muscle cells by interfering with the phosphorylation of Akt and GSK-3 $\beta$ [126] Deletion of SIRT5 has been reported to hamper glucose homeostasis by impairing mitochondrial function via hyper-acetylation of metabolic enzymes in brown adipose tissue [127]. SIRT6 deficiency has been revealed to endorse food-induced obesity and insulin resistance [128]. SIRT4 and 7 have been proposed to impede insulin Signaling and thus, can contribute to the pathogenesis of type 2 diabetes [21]. SIRT4-mediated dysregulation of AMPK Signaling has been implicated to induce insulin resistance by imparting oxidative stress, inflammation, and autophagy deactivation [129]. Yu and coworkers reported a positive association between SIRT7 activation and impairment of insulin Signaling. SIRT7 can deacetylate FK506binding protein 51 (FKBP51) and hinder FKBP51-mediated Akt activation by blocking the interaction between the pleckstrin homology domain and leucine-rich repeat protein phosphatase (PHLPP) and Akt [130].

Class IV HDAC, HDAC11 is also proposed to regulate metabolic fate by impairing adiponectin-AMPK Signaling in the liver [61]. HDAC11 deficiency has been regarded to improve insulin sensitivity by triggering UCP-2 and PGC1 $\alpha$ genes [131]. Association between HDAC11 and bromodomain-containing 2 (BRD2) has been implicated to form a regulatory complex to abrogate thermogenic program in brown adipose tissue. Considering the regulatory effect of HDACs in glucose homeostasis and insulin Signaling, it may be suggested that targeting HDACs can be the therapeutic option to alleviate metabolic disorders.

\section{HDACs: the possible therapeutic targets in DM}

Clinical interventions in DM are not only restricted in targeting glucose metabolism but also target many other intermediate processes of substrate metabolism. Apart from the rare exceptions of aberration in the insulin Signaling cascade, DM can be ceased by normalizing insulin release from pancreatic $\beta$ cells [38]. Thus, the preservation of 
functional $\beta$ cell mass can be a promising approach to therapeutic interventions of DM. Individual HDACs, including SIRTs, have distinct regulatory roles in pancreatic endocrine development, $\beta$ cell functions, insulin secretion, and metabolic fates.

Therefore, these are regarded as novel therapeutic targets in DM. Inhibition of classical HDACs has been mentioned to be useful in developing interventional strategies against DM [118]. HDACis can inhibit enzymatic activities of classical HDACs (not SIRTs) and thus, influence the transcription of several genes by promoting histone acetylation [132]. Also, HDACis can possess secondary effects on other regulatory transcription factors [132]. Inhibition of HDACs has been regarded to regulate the expression of more than 50 histone and non-histone transcription factors. On the other hand, SIRT-boosting therapies have been regarded to be promising interventions against metabolic diseases including DM [133].

\section{Improving $\beta$ cell generation: via targeting HDACs}

Restoration of the functioning pool of $\beta$ cells has been regarded to be the principal therapeutic approach in T2DM. Classical HDACis have been found to enhance Pdx1 expressing pancreatic precursors toward Ngn3 expressing pro-endocrine linage and then, HDACis behave in distinct manners based on the inhibition properties [71]. Pan-HDACis (inhibit both classes I and II HDACs), such as sodium butyrate $(\mathrm{NaB})$ and TSA have been revealed to promote the differentiation of pro-endocrine linage into $\beta$ cells [71]. In contrast, class I selective HDACis, such as valproic acid and MS275, were found to suppress $\beta$ cell differentiation [71]. In another report, Khan and Jena revealed that valproic acid can improve glucose homeostasis by triggering $\beta$ cell proliferation, function, and protection [134]. A class IIa HDACi, MC1568, has been found to endorse differentiation and amplification of $\beta$ cells by enhancing the expression of Pax4 [74]. BRD3308, an isoform-selective inhibitor of HDAC3, has been reported to BRD3308 to endorse $\beta$ cell proliferation in non-obese female diabetic mice [135].

Harnessing the utility of HDACis has been revealed to have a significant impact on tissue engineering [17]. The inclusion of HDACi, TSA, has been shown to improve the rejuvenating capacity of the pancreatic islet in vitro [96]. Thus, HDACis have been proven to be the key agents in $\beta$ cell replacement therapy. $\mathrm{NaB}$ stimulates early events in embryonic stem cells differentiation to achieve pancreas-like specification; while TSA can 
facilitate trans-differentiation of bone marrow-derived stem cells to achieve physiological similarity as islet-like clusters [38]. In an ex vivo study, HDAC inhibition by $\mathrm{NaB}$ was found to trigger the differentiation of embryonic stem cells into islet-like clusters expressing insulin, glucagon, and somatostatin genes [136]. Recent reports revealed that HDACis can enhance the differentiation of embryonic stem cells into insulin-producing cells [137, 138]. In a recent study, valproic acid, an HDACi, was claimed to trigger the differentiation of adipose-derived stem cells into insulinproducing cells which were claimed to be clinically effective against type 1 diabetes [139]. Valproic acid can increase pancreatic endoderm formation [140]. HC toxin, a cyclin peptide HDACi, is reported to promote induced pluripotent stem cell-derived $\beta$ cells generation by activating the differentiation markers, such as Pdx1, NeuD1, and insulin [140]. The roles of SIRT1, 3, and 6 in restoring $\beta$ cell mass have been discussed earlier. SRT1720, a SIRT1 agonist, has been shown to endorse differentiation of endocrine progenitor cells in vitro via triggering AMPK-mediated fatty acid oxidation [76]. Suberanilohydroxamic acid (SAHA; vorinostat), a pan-HDACi, can promote the differentiation of stem cells into insulin-secreting cells via activation of SRY-box (SOX17), NK6 homeobox 1 (Nkx6.1), and MafA genes [138].

Activation of SIRT1 by SRT3025 has been reported to cause islet expansion as a consequence of enhancement in $\beta$ cell mass [141]. $\gamma$-Aminobutyric acid (GABA) is known to trigger $\beta$ cell proliferation via activation of SIRT1 [142]. Resveratrol can promote $\beta$-like cell formation from porcine pancreatic stem cells by triggering $\mathrm{Wnt} / \beta$-catenin signal transductionmediated through SIRT1 activation [143]. Several naturally occurring small molecules, such as resveratrol, dihydromyricetin, honokiol, 7-hydroxy-3-(4'-methoxyphenyl) coumarin have been reported to activate SIRT3 [127, 144, 145]. On the other hand, long-chain free fatty acids can trigger the deacetylation capacity of SIRT6 [146]. Thus, these compounds could be tested for their $\beta$ cell regeneration capacity. SIRT5 is known to negatively regulate $\beta$ cell proliferation [79. Kalbas and co-workers developed several peptide-based selective SIRT5 antagonists which could be tested for their effect on $\beta$ cell proliferation [\#339].

\section{2. $\beta$ cell protection and promotion of insulin secretion: via targeting HDACs}

Pro-inflammatory mediators, such as interleukin $1 \beta$ (IL-1 $\beta$ ), tumor necrosis factor $\alpha$ (TNF $\alpha$ ), and interferon $\gamma(\mathrm{INF}-\gamma)$ were found to endorse apoptosis of the $\beta$ cells by triggering several Signaling pathways and contribute to the pathogenesis of DM [147]. Pro-inflammatory cytokines have been found to hinder the survival of the transplanted islet grafts in vivo by endorsing inflammation [148]. 
Pancreatic $\beta$ cell expresses all 11 classical HDACs, which are differentially regulated by the proinflammatory cytokines [81]. Thus, HDACs could be the possible therapeutic targets to prevent structural and functional loss of $\beta$ cells.

HDACis, such as TSA and SAHA are useful in reciprocating cytokine-induced $\beta$ cell death and reducing insulin secretion [149]. THS-78-5, a polyaminobenzamide pan-HDACi, has been shown to protect against the IL-1 $\beta$-mediated loss of $\beta$ cell viability by attenuating inducible nitric oxide synthases (iNOS) expression and NF- $\mathrm{B}$ (nuclear factor kappa-light-chain-enhancer of activated B cells) trans-activation [150]. ITF2357, a non-specific inhibitor of class I and II HDACs, can protect pancreatic $\beta$ cells from self-inflicted injury and can promote insulin production by inhibiting endogenous cytokines in the hyperglycemic condition [151]. HC toxin, a class I HDACi, can enhance $\beta$ cell function and simultaneously promote insulin-triggered glucose uptake via IRS1/PI3K/Akt activation [140, 152]. Phenylbutyrate, a pan-HDACi, was found to protect $\beta$ cells by suppressing ER stress and simultaneously improved $\beta$ cell function to revert insulin resistance [153]. NaB can alleviate metabolic impairments by preventing structural and functional loss of $\beta$ cells by suppressing IL-1 $\beta / \mathrm{NF}-\kappa \mathrm{B} / \mathrm{MAPK}$ (mitogen-activated protein kinase) suppression [154]. Inhibitors of class I, IIb, and IV HDACs, such as HC toxin, CI-994, PCI24781, LAQ824, PCI34051, and SAHA were found to rescue $\beta$ cells against cytokine-mediated destruction. On the other hand, isoform-selective inhibitors of HDAC8, PCI34051, and Class IIa-selective HDACis did not offer any protective effect to $\beta$ cells against cytokine-mediated injury [155]. In contrast, MC1568, a class IIa selective HDACi, has been reported to enhance insulin secretion in islets obtained from humans with T2DM [92]. It can produce this effect by reciprocating $\beta$ cell dysfunction and apoptosis caused by HDAC7 activation as observed in HDAC7-overexpressed murine $\beta$ cells [92]. MGCD0103, an isoform-selective HDACi for HDAC1, 2, and 3, and 11, exhibited a protective effect on $\beta$ cells again 
oxidative stress, inflammation, and apoptosis by activating SOD (superoxide dismutase) genes mediated through histone acetylation of specificity protein 1 and recruitment of RNA polymerase II [156]. MS-275 and CI-994, selective inhibitors of HDAC1, 2, and 3, have been found to inhibit cytokine-induced apoptosis of murine $\beta$ cells and enhance glucose-triggered insulin production [157, 158]. Plaisance and coworkers revealed that MS-275 can alleviate cytokine-elicited $\beta$ cell dysfunction and apoptosis caused by a lipotoxic agent, palmitate, by suppressing ER stress [73]. However, the genetic inhibition approach revealed that only HDAC3 inhibition is sufficient to prevent cytokine-induced $\beta$ cell damage [73, 157]. A highly selective HDAC3 inhibitor, BRD3308, can protect pancreatic $\beta$ cells against cytokine-provoked apoptosis in vitro and in vivo and promotes insulin release in a hyperglycemic state $[135,159]$. Also, selective HDAC3 inhibitor was claimed to be safe as compared to the inhibitors of HDAC1 and 2 [159].

Class III HDACs, SIRTs, have been regarded to be the key regulators in T2DM by regulating inflammation, oxidative stress, and mitochondrial function [53]. SIRT1, 2, 3, and 6 were revealed to suppress inflammation and oxidative stress [53]. Thus, strategies of activating SIRT1, 2, 3, and 6 can offer attractive therapies in T2DM. SIRT1 deficiency has been reported to cause functional impairment of $\beta$ cells mediated through the activation of UCP2 $[51,160]$. In contrast, SIRT1 overexpression can completely prevent cytokine-mediated $\beta$ cell destruction by impairing the NF- $\kappa$ B Signaling pathway [161]. Activation of SIRT1 expression via resveratrol has been found to prevent cytokine-mediated $\beta$ cell damage and maintained glucose-induced insulin secretion [161]. Another SIRT1 activator, fucoidan, can also prevent oxidative stress-mediated $\beta$ cell apoptosis and elevates insulin biosynthesis via upregulating glucagon-like peptide-1 receptor (GLP-1R) and Pdx1 [162]. Camel milk-derived lactoferrin has been found to activate SIRT1 along with PPAR- $\gamma$ and exhibit hypoglycemic and insulin-sensitizing effects in patients with T2DM [163]. 3-(4-methanesulfonylphenoxy)-N-[1-(2-methoxy-ethoxymethyl)-1H-pyrazol-3-yl]-5-(3methyl pyridin-2-yl)-benzamide, a glucokinase activator useful in attenuating hyperglycemia associated with T2DM in mice, can prevent cytokine-provoked $\beta$ cell apoptosis via SIRT1 activation [164]. Artesunate can prevent cytokine-induced $\beta$ cell apoptosis via activation of SIRT1 and inhibiting NF- $\mathrm{B}$, iNOS, NO activities [165]. 
Nicotinamide mononucleotide, a SIRT1 activator, has been reported to prevent cytokine-induced $\beta$ cell dysfunction and facilitates insulin secretion. Suppression of SIRT3 in diabetic islet is known to be associated with $\beta$ cell dysfunction mediated through enhancement of ROS production, IL-1 $\beta$ synthesis, MAPK activation [166]. SIRT3 activation has been shown to prevent $\beta$ cell dysfunction and thus, small molecule SIRT3 activators could be the prospective therapeutic agents to treat DM. Earlier reports suggested that SIRT6 activation can improve glucose-induced insulin secretion and thus, pharmacological activation of SIRT6 may serve as the potential therapeutic approach to attenuate DM [55, 98]. MDL-800, a selective SIRT6 activator, has been reported to enhance its deacetylation activity to 22 -fold by binding to the allosteric site [105]. Cyanidin, a naturally occurring anthocyanidin, can increase SIRT6 activity to almost 55 -fold by binding to the $\beta 6 / \alpha 6$ loop at the acetyl-lysine binding tunnel [167]. Also, longchain free fatty acids, UBCS039, fluvastatin, methysticin have been reported to activate SIRT6 $[146,168,169]$. Thus, these compounds may be targeted to find out their potency in improving insulin secretion in response to hyperglycemia. SIRT5 and SIRT7 have been regarded to regulate insulin secretion negatively. Thus, pharmacological inhibition of SIRT5 and SIRT7 could promote insulin secretion. However, the inhibitors of SIRT5 and SIRT7 were also found to inhibit other SIRTs, which necessitate developing isoform-selective inhibitors of SIRT5 and SIRT7 [170]. As discussed earlier, the specific role of HDAC11 in $\beta$ cell function and insulin secretion has not been revealed; however, HDAC11 activation was found to be associated with elevated cytokine levels in pancreatic islets [81]. Also, HDAC11 can result in insulin resistance in high fat-induced hyperinsulinemic mice [61]. Thus, HDAC11 inhibition may have a protective role in DM.

\section{Improving glucose homeostasis: via targeting HDACs}

In recent times, HDACs have emerged as potential new molecular targets for the mitigation and intervention of DM as they play a regulatory role in insulin Signaling [35]. HDACs can regulate glucose homeostasis through epigenetic regulation of IRS2 expression and controlling IRS2 activity by regulating $\mathrm{H} 3 \mathrm{~K} 9$ promoter acetylation [113]. IRS2 can also regulate $\beta$ cell proliferation [113]. Pan-HDACis, SAHA, and TSA can promote H3K9 acetylation in the IRS2 promoter by HDAC1 inhibition [113]. 
CREB-binding protein and $\mathrm{p} 300$ are the critical cofactors in driving $\beta$ cell genesis, $\beta$ cell proliferation, and maintaining glucose homeostasis [171]. Also, CREB-binding protein and p300 can inhibit hepatic gluconeogenic genes by inhibiting the DNA binding capacity and transcriptional activity of FOXO1 through its acetylation [118]. HDACis, TSA and NaB, can endorse transactivation CREB-binding protein/p300 and thus, may be beneficial in improving glycemic status in DM [172]. Valproic acid can inhibit hyperglycemia by suppressing hepatic gluconeogenic genes, such as glucose-6-phosphatase, fructose-1,6-bis-phosphatase, and phosphoenolpyruvate carboxykinase by inhibiting transcriptional activation of glucocorticoid receptor-mediated through its acetylation [173]. In this study, it has been shown that only class I HDACs, specifically HDAC1 and 3 can interact with glucocorticoid receptor and thus, panHDACi and class I selective HDACi were found to be effective in inhibiting glucocorticoid receptor activation, while class IIa selective HDACi possessed only a marginal effect [173]. Class I selective HDACi, such as MS275 can enhance oxidative metabolism in skeletal muscle and adipose tissue by the mitochondrial mechanism mediated through the activation of PGC $\alpha$ and PPAR $\gamma / P G C 1 \alpha$ Signaling in skeletal muscle and adipose tissue, respectively [174]. Chromatin immunoprecipitation assay revealed that the observed effect is associated with HDAC3 inhibition by class I selective HDACi [174]. In contrast, class II selective HDACi, MC1568, was found to be ineffective in regulating energy-dependent oxidative metabolism [174]. Remsberg and coresearchers reported that the selective inhibition HDAC3 has been revealed to improve glucose tolerance by increasing insulin secretion [90]. In another report, inhibition of HDAC3 by butyrate was shown to prevent the development of insulin resistance and obesity in high fat-fed mice via triggering PGC1 $\alpha$ /AMPK activation and increasing adaptive thermogenesis and fatty acid oxidation in skeletal muscle and brown fat [175]. HDAC inhibition by TSA, a pan-HDACi, has been regarded to abrogate HDAC2-IRS-1 interaction and trigger tyrosine phosphorylation via IRS1 acetylation [176]. This observation suggested that specific inhibitors of HDAC2 can improve insulin-dependent glucose transport via IRS-1/Akt activation [176]. HDAC8 can promote insulin resistance [119]. Thus, isoform-selective inhibitors of HDAC8, such as PCI34051, PCI-34058, ITF3056 (givinostat), N-hydroxy-3-[1-(phenylthio) methyl-1H-1,2,3-triazol-4-yl]benzamide (NCC149) derivatives etc. [177] [178] [179]could provide the possible therapeutic options in T2DM by improving insulin sensitivity.

Class IIa HDACs, HDAC4, 5, and 7 are known to activate hepatic gluconeogenesis through dephosphorylation followed by their nuclear translocation, where they can associate with the 
promoters of gluconeogenic genes [120,180,181]. HDAC4 and 5 can also cause transcriptional induction of these genes via HDAC3 recruitment and HDAC3-mediated activation of FOXO1 and FOXO3 [120]. Thus, inhibition of class I and IIa or pan-HDACis can suppress hepatic gluconeogenesis. HDAC5 can repress the GLUT4 gene and genetic inhibition of HDAC5 has been shown to improve glucose utilization and insulin sensitivity in skeletal muscle cells by endorsing GLUT4 activation [182]. Scriptaid, a pan-HDACi exhibiting IC $_{50}$ of 2 and $0.6 \mu \mathrm{M}$ for HDAC5 and Class I HDACs, respectively, has been shown to correct glucose metabolism in skeletal muscle by restoring GLUT4 activity [182]. However, it is not worthy to mention that the effect is directly associated with HDAC5 inhibition [182]. HDAC9 together with HDAC3 can promote hepatic gluconeogenesis provoked by the hepatitis $\mathrm{C}$ virus via FOXO1 activation and thus, pharmacological inhibition of HDAC9 has been proposed to be a therapeutic strategy to attenuate hepatitis C virus-induced metabolic abnormality as well as T2DM [42]. Class IIb HDAC, HDAC6, has been revealed to endorse glucocorticoid receptor activation and simultaneously trigger hepatic gluconeogenesis resulting in an impairment of glucose metabolism [45]. In contrast, HDAC6 selective inhibitor, tubacin, can suppress gluconeogenic gene expression in the liver via hyperacetylation of heat shock protein 90 (hsp90) and suppression of glucocorticoid receptor translocation [45]. Thus, selective pharmacological inhibition of HDAC6 can mitigate the diabetogenic effect of glucocorticoids [45]. The comparison between class I and class II HDACis revealed that the class I specific HDACis are superior in regulating energy metabolism and improving insulin sensitivity over class II specific inhibitors, which may be associated with PPAR $\gamma$ activation by class I HDACs [174] (Fig. 5).

Class III HDACs or SIRTs are regarded to be the important regulators of glucose and lipid metabolism through interacting with several factors, such as is regarded to regulate PGCla, SREBP, PPAR $\gamma$, FOXO1, hypoxia-inducible factor $1 \alpha$ (HIF-1 $\alpha$ ), CREB-regulated transcription coactivator 2 (CRTC2), AMPK [51]. SRT1720, a small molecule 
SIRT1 activator can promote glucose homeostasis (whole-body) and insulin sensitivity in adipose tissue, skeletal muscle, and liver as observed in multiple in vivo models of T2DM [183]. Interestingly, SRT1720 was found to inhibit hepatic gluconeogenesis [183]. In contrast, Park and co-workers reported that SRT1720 recruits AMPK to improve glucose homeostasis in a SIRT1 independent manner [184]. In another report, SRT1720-mediated activation of SIRT1 has been proposed to promote insulin sensitivity, glucose tolerance, and lipid metabolism by endorsing angiogenic factors in pre-adipocytes to induce adipose tissue angiogenesis [185]. Vitamin K supplements can reverse hyperglycemia and insulin resistance in patients with T2DM [186]. This effect has been proposed to be mediated through activation of SIRT1/AMPK Signaling of glucose metabolism in the liver [186]. SRT501, a less effective SIRT1 activator, can also possess a significant hypoglycemic effect in T2D mice [183]. MHY2233 is a potent SIRT1 activator exhibiting better activation potential than resveratrol and SRT1720 [187]. MHY2233 is a potential pharmaceutical agent in DM, which can improve glucose tolerance by suppressing SREBP1 expression and improves insulin Signaling by the IRS-1/Akt pathway [187].

AS101, a tellurium compound, has been found to reverse insulin resistance and attenuate T2DM in rats by triggering SIRT1 activation and deacetylation function [188]. Naltrexone, a TLR4 antagonist, has been found to diminish hyperinsulinemia-mediated insulin resistance via activation of SIRT1 [189].

As discussed earlier, SIRT2 can impart characteristic and even opposing roles in insulin-mediated glucose metabolism. Genetic deletion of SIRT2 has been revealed to reduce insulin responsiveness in the liver and muscle [190]. Nicotinamide mononucleotide (NMN) was found to enhance hepatic glucose uptake by activating SIRT2-mediated deacetylation of K126 of glucokinase regulatory protein in hyperglycemic conditions [191]. In contrast, inhibition of SIRT2 by sirtinol can prevent hepatic gluconeogenesis by suppressing PEPCK1 mediated through hyperacetylation [192]. SIRT3 is an important regulator in metabolism and insulin sensitivity and SIRT3 inhibition is regarded to impair insulin sensitivity and augment oxidative stress in skeletal muscle [193]. Celastrol is known to suppress redox stress by endorsing SIRT3 activation along with the recruitment of AMPK/PGC1 $\alpha$ signal transduction in the skeletal muscle under diabetic conditions [194]. Honokiol, a SIRT3 activator, has been regarded to reduce oxidative stress and trigger AMPK/CREB/PGC1 $\alpha$ activation in Chinese hamster ovarian cells [195]. Thus, it may be effective in reciprocating insulin insensitivity in T2DM. In contrast, inhibition of SIRT3 by berberine has been claimed to reduce hepatic gluconeogenesis by hindering mitochondrial pyruvate import in 
mitochondria [196]. Similarly, Zhang et al. reported that berberine can promote glucose uptake and inhibit gluconeogenesis by suppressing SIRT3 inhibition [103]. As discussed earlier, several reports claimed that SIRT6 can promote insulin sensitivity and glucose consumption. Anderson et al. revealed a positive association between SIRT6 expression and insulin sensitivity in skeletal muscle and liver in T2DM [197]. SIRT6 activation can also inhibit hepatic gluconeogenesis found to be a potential therapeutic target to develop an interventional strategy against T2DM [198]. Fluvastatin can recruit SREBP-1 and AMPK Signaling by direct activation of SIRT6. Thus, it suggests that fluvastatin may serve as a pharmacotherapeutic agent to treat T2DM [169]. Similarly, other SIRT6 activators, such as fucoidan, MDL-800, quercetin, luteolin, pyrrolo-[1,2a]quinoxaline analogs may be assessed preclinically for the therapeutic potential to correct metabolic abnormalities in T2DM [199].In contrast, selective SIRT6 inhibitor has also been shown to endorse GLUT1 activation in pancreatic cells and increases glucose uptake by skeletal muscle cells [200]. Social and co-workers reported that 2,4-dioxo-N-(4-(pyridin-3-yloxy)phenyl)-1,2,3,4tetrahydroquinazoline-6-sulfonamide, a pharmacological inhibitor of SIRT6, can improve oral glucose tolerance, activate the glycolytic process, and endorse GLUT1 and GLUT4 activation in muscle [201]. Thus, SIRTs serve to be the mystic targets as therapeutic negotiators in regulating glucose homeostasis and insulin sensitivity.

HDAC11 deficiency abrogates obesity and obesity-provoked metabolic syndrome, such as T2DM. Inhibition of HDAC11 is regarded to promote energy expenditure by triggering UCP1 activation in brown adipose tissue [61]. Several small molecules, such as elevenostat, FT895, 2carboxamidothiophene-based zinc ion chelating carbohydrazides, etc. can selectively inhibit HDAC11 [59]. Also, some pan-HDACs, such as romidepsin and TSA have been shown to inhibit HDAC11 in nM concentration [59]. Thus, these compounds could probably be potential agents to correct T2DM by HDAC11 inhibition. 


\section{Improving diabetic complications: via targeting HDACs}

\subsubsection{HDAC-mediated therapeutic options in diabetic nephropathy}

Persistent hyperglycemia can affect various tissues and organs resulting in their structural and functional loss [202]. Epigenetic studies revealed that all classes of HDACs play critical roles in diabetic complications by histone modifications [203]. HDAC2, 4, 5 were found to be upregulated in the diabetic kidney [204]. Thus, HDACs can be the potential therapeutic targets in attenuating diabetic nephropathy.

HDACs regulate the development and progression of diabetic nephropathy by maintaining acetylation balance on chromatin remodeling and regulating the transcription of genes [204] Longterm oral treatment of SAHA, a pan-HDACi, was found to reduce glomerular hypertrophy, mesangial collagen IV deposition, and albuminuria in diabetic mice by suppressing endothelial nitric oxide synthase (eNOS)-mediated oxidative stress [205]. Also, SAHA can reduce diabetesmediated kidney enlargement by downregulating epidermal growth factor receptor (EGFR) expression [206]. NaB, pan-HDACi, can inhibit diabetic-associated retinotoxicity by suppressing hyperglycemia, oxidative stress, fibrosis, inflammation, DNA damage, and apoptosis in the diabetic kidney [154]. NaB was found to suppress eNOS, iNOS, $\alpha$-smooth muscle actin ( $\alpha$-SMA), collagen I, fibronectin, transforming growth factor $\beta 1$ (TGF- $\beta 1$ ), NF- $\kappa$ B expression and endorses nuclear factor erythroid 2-related factor 2 (Nrf2), heme oxygenase 1 (HO-1), and NAD(P)H dehydrogenase quinone 1 activation [154, 207]. HDACis, such as TSA, valproic acid, and SK7041 were found to suppress epithelial-to-mesenchymal transition (EMT) in renal tubular cells and inhibit the expression of extracellular matrix (ECM) components in both transcriptional and translational levels in diabetic kidneys [37]. Further study concluded that the effect was mainly associated with HDAC2 inhibition by pan and class I selective HDACis [37]. Among all classical HDACs, NaB was found to suppress only HDAC2 in kidney cells under high glucose conditions and attenuates hyperglycemia-triggered oxidative stress and apoptosis in renal cells [208]. Valproic acid can ameliorate high glucose-induced myofibroblast activation, fibrogenesis, and ER stress in the kidneys of diabetic rats by promoting histone acetylation through HDAC inhibition [209] [210]. High glucose and advanced glycation end products (AGEs) can endorse HDAC4 activation, which contributes to the podocyte injury by impairing autophagy and inducing 
inflammation [204]. HDAC4 silencing has been proven to attenuate diabetic renal injury, which suggests that pharmacological inhibition of HDAC4 with isoform-selective inhibitor could be a therapeutic option in diabetic nephropathy [204] (Fig. 6).

Class III HDACs, SIRTs, can also play a crucial role in regulating diabetic nephropathy. SIRT1 has been regarded as a key epigenetic regulator in diabetic kidneys, which regulates the transcription of NF- $\mathrm{B}, \mathrm{STAT} 3, \mathrm{p} 53, \mathrm{FOXO} 4$, and PGC1 $\alpha$ genes [211]. Increased SIRT1 expression either by genetically inducing SIRT1 expression in podocytes or by pharmacological activation through an isoform-selective SIRT1 agonist, BF175, can attenuate albuminuria, oxidative stress in glomeruli, and podocyte injury via multiple downstream Signalings [211]. Srivastava and co-workers reported that fibrogenic programming in diabetic kidneys is associated with the abnormal glycolysis caused by SIRT3 downregulation [212]. Also, SIRT3 overexpression was found to facilitate ameliorate diabetic nephropathy in engrafted amniotic fluid stem cells of T2D mice by restoring mitochondrial homeostasis and modulating mitophagy [213]. Thus, restoration of SIRT3 expression or pharmacological activation of SIRT3 may mitigate renal fibrosis in diabetic conditions [212]. Pharmacological activation of SIRT3 by liraglutide has been reported to suppress the intrinsic pathway of apoptosis and restore mitochondrial function in renal mesangial cells in the diabetic kidney [214]. Nicotinamide riboside, a SIRT3 agonist, treatment can prevent renal damage in diabetic mice [215]. Aucubin, a naturally occurring glycoside, can reduce oxidative stress and inflammation in renal tissue of T2D rats by endorsing Nrf2 and FOXO3a activation and suppressing NF- $\mathrm{B}$ Signaling, which has been proposed to be mediated through the activation of SIRT1 and SIRT3 [216]. SIRT4 activation was found to inhibit high glucose-led free radical production, inflammation, and apoptosis in podocytes and represents a therapeutic option in diabetic nephropathy [58]. Similarly, SIRT6 overexpression is associated with high glucose-induced podocyte injury by inhibiting oxidative stress, inflammation, and apoptosis [217]. Thus, pharmacological activation of SIRT4 and SIRT6 can be regarded as therapeutic strategies in attenuating diabetic nephropathy (Fig. 6).

\subsection{HDAC-mediated therapeutic options in diabetic cardiomyopathy}

High glucose-induced oxidative stress, AGEs accumulation, inflammation, ER stress, apoptosis, and a myriad of pathological Signaling events have been implicated to contribute in 
development and progression of diabetic cardiomyopathy [218]. All four classes of HDACs are implicated in the epigenetic regulation of associated Signalings and gene transcription in diabetic cardiomyopathy $[133,219]$. Thus, targeting of HDACs and SIRTs can be the novel therapeutic approach against diabetic cardiomyopathy.

$\mathrm{NaB}$, a pan-HDACi, can attenuate diabetic cardiomyopathy, as validated by the reduction in cardiac hypertrophy and inhibition of interstitial fibrosis by enhancing redox defense, suppressing apoptosis, improving angiogenesis, activating GLUT1 and GLUT4 in diabetic myocardium in T1D mice [34]. Also, $\mathrm{NaB}$ has been reported to attenuate diabetic cardiomyopathy by activating MAPK kinase 3 (MKK3)/P38/p38-regulated protein kinase (PRAK) Signaling [220]. HDACs inhibition by TSA can prevent hyperglycemia-provoked myocardial ischemia/reperfusion injury through inhibition of intrinsic apoptosis pathway in diabetic rats via Akt-modulated activation and suppression of FOXO3a and Bim, respectively [221]. Magnesium valproate can alleviate cardiomyopathy-associated with T1DM by reducing cardiac hypertrophy, improving hemodynamic functions, restoring estrogen receptor expression, and regulating hypoglycemic status [222]. MPT0E014, a pan-HDACi, has been reported to attenuate diabetic cardiomyopathy by modulating cardiac peroxisome proliferator-activated receptors (PPARS), fatty acid metabolism, and proinflammatory cytokines. Also, MPT0E014 can improve cardiac function by modulating myocardial autophagy and insulin Signaling in T2D rats [223, 224]. HDACs inhibition by SAHA is regarded to counteract the oxidative stress and functional changes in cardiomyocytes during the early stage of DM [225]. RGFP966, a specific inhibitor of HDAC3, was found to abrogate the initiation of diabetic cardiomyopathy by endorsing dual-specificity phosphatase 5 (DUSP5) activation by acetylating histone H3 on the DUSP5 primer region leading to an extracellular-signal-regulated kinase (Erk)1/2 activation [143]. Gene therapeutic method to inhibit HDAC4 has been revealed to restrict the progression of diabetic cardiomyopathy [226]. In contrast, Kronlage and co-workers reported that HDAC4 silencing can develop heart failure in T1DM and T2DM, which indicates the protective role of HDAC4 in the diabetic heart [227].

HDAC6 is revealed to be associated with diabetic-induced myocardial ischemia/reperfusion injury mediated through increased oxidative stress by suppressing acetylation of Prdx1, an antioxidant protein [46]. Tubastatin A, an isoform-selective HDAC6 inhibitor, can 
mitigate hyperglycemia-provoked cardiac dysfunction, cardiac infarction, and free radical generation by facilitating the Prdx1 acetylation [46]. Genetic deletion of HDAC11 was found to attenuate DM-associated cardiac apoptosis, inflammation, and dyslipidemia by attenuating cardiac oxidative stress [62]. Thus, pharmacological inhibition of HDAC11 may be a possible therapeutic strategy in diabetic cardiomyopathy.

SIRTs activator, resveratrol, has been reported to improve diabetes-provoked cardiac dysfunction via activation of SIRT1 and SIRT3 [228-232]. SIRT1 activation by resveratrol can alleviate myocardial injuries in diabetic cardiomyopathy via regulation of mitochondrial function mediated through SIRT1-triggered PGC1 $\alpha$ deacetylation and Nrf2 activation [230] [231]. Also, resveratrol was found to recruit sarcoplasmic $\mathrm{Ca}^{2+}$ ATPase (SERCA2a) in the diabetic hearts by SIRT1-mediated restoration of SERCA2 promoter activity and improves cardiac functions in diabetic cardiomyopathy [228] (Fig. 7). Resveratrol can also attenuate oxidative insult myocardial tissue of diabetic mice by triggering autophagic flux by SIRT1-provoked FOXO1 DNA binding at the Rab7 promoter [229]. Bagul and co-workers reported that resveratrol-mediated SIRT1 activation can reduce the oxidative stress alternatively via deacetylation of NF- $\kappa \mathrm{B}$ (p65) and histone 3 [233]. Resveratrol can also endorse SIRT3 activation and can prevent collagen deposition in the heart and improved cardiac functions [234]. Also, SIRT3 activation has been proposed to inhibit high glucose-provoked mitochondrial injury and cardiomyocyte apoptosis by recruiting FOXO3A/Parkin-mediated activation of mitophagy in vitro [235]. Thus, resveratrol can also prevent cardiac fibrosis via SIRT3 activation. SIRT3 activation by resveratrol has been revealed to preserve mitochondrial oxidative phosphorylation, mitochondrial function, and cellular size in the myocardial tissue of diabetic rats by endorsing deacetylation of a mitochondrial transcription factor by augmenting the mitochondrial DNA binding ability to mitochondrial transcription factor [232]. Phloretin, a dihydrochalcone, has been found to prevent high glucose-induced myocardial damage by inhibiting inflammation and fibrosis in vivo and in vitro by restoring SIRT1 expression in cardiac tissue [236]. L-arginine has been proposed to trigger cardiac SIRT1 expression in diabetic rats and ensured defense against diabetes-mediated fibrosis, apoptosis, and inflammation in myocardial tissue [237]. Apelin, an endogenous peptide ligand of 
the human G-protein-coupled apelin receptor, gene therapy can correct microvascular insufficiency, cardiac hypertrophy, and heart dysfunction in diabetic cardiomyopathy by endorsing SIRT3 expression [238]. Apelin-mediated SIRT3 activation can also suppress high glucoseprovoked oxidative insult and endothelial cell apoptosis in diabetic mice [238]. Polydatin, a naturally occurring small molecule, has been proposed to alleviate high glucose-induced cardiac dysfunction by endorsing autophagy flux and improving mitochondrial bioenergetics through SIRT3 activation in the heart of diabetes mice [239]. Kanwal and colleagues reported that SIRT6 and SIRT3 restore each other's activity and prevent the development of diabetic cardiomyopathy [99]. SIRT3 has been proposed to maintain SIRT6 expression by reducing oxidative stress; while SIRT6 can restore SIRT3 expression by endorsing Nrf2-dependent transcription of the SIRT3 gene in T2D mice. Among other SIRTs, SIRT5 has been regarded to restore normal metabolism and function of the heart by regulating lysine succinylation [240]; while SIRT2 can regulate microtubule stabilization in diabetic cardiomyopathy in T1D rats [241]. Thus, regulation of SIRT expression may be an alternative therapeutic approach in diabetic cardiomyopathy.

\subsubsection{HDAC-mediated therapeutic options in diabetic retinopathy}

Posttranslational modifications of histones have been regarded to play a key role in developing diabetic retinopathy by regulating the genes affected by chromatin structure [242]. Hyperglycemia can endorse HDAC (HDAC1, 2, 6, and 8) activation in the retina and its capillary cells in diabetic animals, which suppresses histone H3 acetylation [243] [242]. Abnormality in H3 acetylation can trigger oxidative stress, apoptosis, and cyto-structural abnormality in retinal tissue [243]. In contrast, Kadiyala and coworkers claimed that acetylation of histones and other proteins in the diabetic retina can trigger pro-inflammatory proteins and contribute to the development of diabetic retinopathy [244]. However, the majority of reports revealed that inhibition of classical HDACs can mitigate diabetic retinopathy. TSA, a pan-HDACi, has been regarded to improve transepithelial resistance in retinal pigment epithelium (RPE) cells in vitro and RPE fluid transport in vivo in hyperglycemic rats. In the same study, specific inhibition of HDAC6 by tubastatin-A exhibited a similar effect in maintaining normal fluid homeostasis in the diabetic retina as observed with TSA, which proposed that HDAC6 inhibition could be a potential therapeutic intervention in diabetic retinopathy [242]. In another report, HDAC6 activation 
in the diabetic retina, has been regarded to promote oxidative stress through suppression of the Trx-1 [245]. However, HDAC6 inhibition by tubastatin-A was found to alleviate high glucoseprovoked oxidative stress in retinal tissue by upregulating Trx-1 [245]. HDAC6 inhibition by TSA or tubacin (an HDAC6 selective inhibitor) can also prevent ischemia and reperfusion-induced retinal neurodegeneration [246]. GLP-1 treatment has been reported to alleviate diabetic retinopathy by inhibiting hyperglycemia-provoked autophagy in the retina of T2D rats mediated through the restoration of GLP-1R expression and HDAC6 inhibition [247]. 5-aza-2'deoxycytidine and TSA, two pan-HDACis, were found to protect human retinal endothelial cells and retinal pigment epithelial cells from toxic effects of hyperglycemic stimuli in vitro by reciprocating high glucose-induced suppression of pigment epithelium-derived factor and counteracting with inflammatory factors [248].

SIRTs are highly expressed in the retina and were inferred as novel therapeutic targets in diabetic retinopathy [249]. SIRT1 activation has been found to prevent the development of diabetic retinopathy by modulating acetylation of NF- $\mathrm{B}$ (p65), suppression of matrix metalloproteinase-9 (MMP-9), and regulating the transcription of several genes involved in inflammation, vascular growth, oxidative stress, fibrosis, and apoptosis [250-252]. Chronic treatment of SRT1720, an isoform-selective SIRT1 activator, has been reported to alleviate diabetic retinopathy by preventing cholesterol accumulation, inflammation, visual dysfunction, vascular degeneration, and neuro-degeneration in the retina of T2D mice [253]. Diabetic rats overexpressing the SIRT1 gene exhibited protection against oxidative stress and apoptosis in retinal tissue, which has been proposed to be mediated through the suppression of hyperglycemia-provoked p66shc activation by SIRT1 [254]. Resveratrol can attenuate high glucose-provoked apoptosis in retinal capillary endothelial cells by activating SIRT1/AMPK/PGC1 $\alpha$ signal transduction and proposed to be an effective therapeutic agent to prevent the pathogenesis in the early stage of diabetic retinopathy [254]. Forskolin can promote SIRT1 activation, which subsequently triggers protein kinase Amediated suppression of cytoplasmic high mobility group box 1 (HMGB1) in high glucoseexposed human retinal endothelial cells [255]. HMGB1 inhibition can reduce inflammation in the retina vasculature [255]. Fenofibrate was found to attenuate diabetic retinopathy by 
endorsing SIRT1 activation to reduce the NF- $\kappa$ B activity in the retinal tissues of diabetic rats [256]. Retinal SIRT3 activation has been implicated in the protection of retinal capillary endothelial cells against hyperglycemia-induced damage in vitro and in vivo by endorsing redox defense via deacetylating manganese superoxide dismutase (MnSOD) and suppression of poly (ADP-ribose) polymerase [257]. Genetic deletion of both SIRT3 and SIRT5 in diabetic mice revealed significant evidence in developing inner retinal dysfunction [258]. SIRT6 deficiency in the diabetic retina has been regarded to initiate neurodegenerative processes in diabetic retinopathy by changing glycolytic gene expressions and inducing apoptosis [259]. In contrast, SIRT6 overexpression can ensure neuroprotection in high glucose-exposed Müller glial cells by impeding the acetylation of H3K9 and H3K56 [259]. Thus, pharmacological activation of SIRT3, 5, and 6 may offer therapeutic options in attenuating diabetic retinopathy.

\section{HDAC-mediated therapeutic options in diabetic neuropathy}

Histone H3 and H4 acetylation is regarded to play important roles in painful diabetic neuropathy [47]. HDAC inhibition is regarded to be a therapeutic option for diabetic peripheral neuropathy. Several preclinical assays claimed that HDACis can be useful in attenuating neuropathic pain by targeting specific epigenetic loci; however, very little literature is available regarding the therapeutic potential of HDACi specifically in diabetic neuropathy. Regenacy Pharmaceuticals, LLC patented (U.S. Patent No. 10,040,769) the use of HDACis for diabetic peripheral neuropathy [260]. Ricolinostat (ACY-1215), an isoform-selective and orally effective HDAC6 inhibitor, was reported to attenuate neuropathic pain and reciprocate metabolic defects in rats with diabetic peripheral neuropathy [260]. Also, it can improve mitochondrial transport in the high glucose-exposed neurons in vitro [260]. Inhibition of STAT3 phosphorylation by AG490 results in HDAC1 inhibition which can subsequently upregulate high glucose-mediated defect in Schwann cell autophagy in vitro by triggering the activation of autophagy markers, autophagyrelated 3 (Atg3), and microtubule-associated protein 1a/1b-light chain 3 (LC3)-I/II [261].

Several SIRTs, the class III HDACs, activators have been reported to play important therapeutic potential in alleviating diabetic neuropathy. SIRT1 can regulate neuronal cell fate in diabetic neuropathy by regulating metabotropic glutamate receptor (mGluR). Several preclinical 
studies revealed that SIRT1 overexpression/activation can prevent diabetic neuropathy in experimental animals [109, 262-264]. SIRT1 has been reported to attenuate neuropathic pain in diabetes through suppression of mGluR1/5 by facilitating $\mathrm{H} 3$ acetylation at the promoter region of mGluR1/5-encoding Grm1/5 [262]. On the other hand, mGluR2/3 activation of the SIRT1 axis can protect dorsal root ganglia by preserving mitochondrial oxidative phosphorylation [263, 264]. SIRT1 activation by SRT1720 has been found to relieve pain behavior and trigger spinal neuronal activation in rats having painful diabetic neuropathy [262]. Also, SRT1720-provoked spinal SIRT1 activation can reduce structural synaptic plasticity of spinal dorsal horn neurons via suppression of growth-associated protein 43 (GAP43), postsynaptic density protein 95 (PSD95), and synaptophysin [109]. Also, SRT1720 can reciprocate cognitive dysfunction in T2D rats by suppressing oxidative stress, apoptosis, and inflammation in hippocampal tissue via SIRT1/Nrf2/NF-кB/AMPK-dependent mechanisms [265]. SIRT1 activation by isoliquiritigenin can alleviate oxidative stress and mitochondrial impairment in vitro and in vivo by endorsing PGC1 $\alpha /$ FOXO3a/AMPK Signaling in experimentally induced diabetic neuropathy [266]. Resveratrol can prevent neurotoxicity by improving redox status and impairing inflammation in diabetic neuropathy by endorsing SIRT1 activation [267]. Also, SIRT1 activation by resveratrol has been reported to prevent hyperglycemia-provoked hippocampal neuronal apoptosis via deacetylation of p53 [268]. Li and coworkers reported that berberine can attenuate diabetic encephalopathy by endorsing SIRT1 protein activation and suppressing ER stress in the hippocampus of T2D mice [269]. Also, berberine imparts a neuroprotective effect by rescuing synapse and nerve-related protein (postsynaptic density protein 95, nerve growth factor, synaptin) expression, suppressing inflammatory factors, reducing hyperglycemia, and improving lipid metabolism in $\mathrm{db} / \mathrm{db}$ mice [269]. Nicotinamide treatment can reduce the nuclear expression of SIRT2 and slightly activate the nuclear expression of SIRT1 in the brain of diabetic rats and suppressing the development of brain dysfunctions [270]. SIRT2 isoforms 2.1 and 2.2 remain downregulated in the dorsal root ganglia in hyperglycemic conditions, which impair axon regeneration potential [271,272]. Downregulation of SIRT2 or activation of a negative mutant of SIRT2 
(SIRT2-H150) can hamper neurite outgrowth. In contrast, SIRT2 activation by nicotinamide adenine dinucleotide can potentiate neurite outgrowth and thus, inhibits diabetic sensory neuropathy [271]. Salvianolic acid A can prevent morphological and functional deficits in peripheral nerves by activation of the SIRT3/PGC1 $\alpha /$ AMPK axis in diabetic rats [273]. SIRT3 has also been revealed to prevent axonal apoptosis [274]. Thus, SIRTs may serve as the potential targets to develop a therapeutic regime for diabetic neuropathy.

\subsection{HDAC-mediated therapeutic options in diabetic endothelial dysfunctions}

Persistent hyperglycemia is implicated in vascular endothelial dysfunctions resulting in lethal complications, such as angiopathy, vascular diseases, stroke, heart disease, chronic kidney failure, venous thrombosis, and others [275]. Inhibition of classical HDACs is regarded to protect human vascular endothelial cells by promoting angiogenesis [276]. HDAC2 can suppress MnSOD expression by binding to MnSOD promoter in hyperglycemic condition and contributes to endothelial dysfunction by endorsing oxidative stress and apoptosis [39]. HDAC2 deletion has been found to prevent high glucose-induced toxic manifestation in human umbilical cord veins endothelial cells in vitro [39]. Thus, pharmacological inhibition of HDAC2 may be a potential therapeutic approach to attenuate diabetes-provoked vascular diseases [39]. High glucose was found to trigger HDAC1 and HDAC2 expressions in aortic smooth muscle cells in vitro and in vivo, which consequently endorse NADPH oxidase (NOX) activation and stimulate ROS formation [277]. The interactions of p300 and HDAC1 and HDAC2 with NOX1, NOX4, and NOX5 promoters have been detected at the active transcription sites in luciferase assays [277]. In contrast, SAHA, a broad spectrum HDACi, has been found to protect aortic smooth muscle cells by preventing ROS formation via inhibition of HDACs [277]. HDAC inhibition by NaB has been reported to mitigate diabetes-provoked oxidative damage in aortic endothelial cells by triggering Nrf2 activation through improving aryl hydrocarbon receptor (AHR) and p300 occupancy at the Nrf2 promoter [278]. SIRT1 activation was found to prevent hyperglycemia-induced endothelial dysfunction via multiple mechanisms. Hyperglycemia causes lysine K81 and histone H3 acetylation of Src homology 2 domain-containing protein (p66Shc), which simultaneously triggers endogenous hydrogen peroxide production and induces redox stress-provoked dysfunction endothelial cells $[279,280]$. SIRT1 can prevent high glucose-induced endothelial dysfunction by 
inhibiting oxidative stress in the vascular endothelium mediated through deacetylation of p66Shc [279] [280, 281]. 2,6-diisopropylphenol (propofol) has been found to reciprocate hyperglycemiatriggered P66shc activation in human umbilical vein endothelial cells through SIRT1 activation and can prevent endothelial ROS accumulation, inflammation, and apoptosis [282]. SIRT1 activation by resveratrol has been reported to mitigate hyperglycemia-induced oxidative stress and aging in endothelial cells by recruiting mitochondrial antioxidant enzymes by recruiting DNA binding capability of FOXO1 and suppressing acetylation capacity of p300 [283]. Hydroxytyrosol nitric oxide has been found to prevent endothelial dysfunction by decreasing ROS production and improving nitric oxide release mediated through an augmentation in SIRT1 expression in high glucose-exposed human umbilical vein endothelial cells [282]. Trans- $\delta$-viniferin, a phenolic compound, can attenuate endothelial oxidative stress and mitochondrial dysfunction by endorsing SIRT1 activation in high glucose-exposed human umbilical vein endothelial cells [284]. SIRT1 has also been found to inhibit hyperglycemia-provoked apoptosis in endothelial cells in vitro by inhibiting mitochondrial fission factor (Mff)-mediated mitochondrial fission, suppressing c.Jun Nterminal kinase (JNK) activation, and sustaining Factin homeostasis [285]. SIRT1 prevents endothelial senescence and dysfunction by preventing p53 activation mediated through p53 deacetylation [286-288]. SIRT1 activators, resveratrol, and SRT2104, can alleviate diabetesassociated endothelial apoptosis by suppressing p53 activation via SIRT1-led p53 deacetylation [287, 288]. Resveratrol can also prevent high glucose-triggered apoptosis by reducing oxidative stress and mitochondrial dysfunction in human endothelial cells through SIRT1 activation [289]. Also, SIRT1 can attenuate diabetes vasculopathy by suppressing the NF- $\kappa \mathrm{B}$ activation through its deacetylation, and thus, inhibits inflammatory disorder [290]. Mesenchymal stem cell-conditioned media can ameliorate diabetes-provoked endothelial dysfunction by improving mitochondrial function by the SIRT1-dependent PI3K/Akt/AMPK/PGC1 $\alpha$ pathway [291]. Bone marrow-derived early outgrowth cell-mediated repairing of diabetic endothelial dysfunction requires SIRT1 to improve angiogenesis in vitro and in vivo [292]. Similar to SIRT1, SIRT6 expression is required to maintain endothelial homeostasis [290]. Persistent hyperglycemia can produce oxidative stress to the endothelial cells causing cell senescence, 
which has been implicated in the pathogenesis of vascular complications in DM. SIRT6 suppression can induce diabetic vascular complications by potentiating oxidative stress-induced endothelial cell senescence [293]. Also, SIRT6 inhibition has been proposed to cause DNA damage, cell-cycle arrest, and angiogenic defects [294]. Thus, the SIRT6 activator might serve as a therapeutic option in attenuating diabetes vasculopathy.

\subsubsection{HDAC-mediated therapeutic options in other diabetic complications}

Diabetic foot syndrome is an end-stage complication in T2DM. Overexpression of HDAC2 has been observed in patients with diabetic foot ulcers, which mainly contributes to endothelial progenitor cell dysfunction and the production of ROS and pro-inflammatory factors in endothelial progenitor cells in hyperglycemic conditions [295]. On the other hand, HDAC2 silencing showed protection against impaired cell proliferation, tube formation, oxidative stress, and inflammation [295]. HDAC2 inhibition can also upregulate SIRT1 expression and ensure SIRT1-mediated protection against diabetic foot ulcers [295]. Resveratrol has been proposed to suppress inflammation, inhibit circulatory disorder, reduce ulceration, improve neuroprotection, and enhance tissue generation capacity in diabetic foot syndrome by SIRT1 activation [296]. The C allele of SIRT1 rs12778366 polymorphism has been regarded as a protective factor in foot complications in patients with T2DM [297]. Poor wound healing contributes in the progression of diabetic foot ulcer disease [298].

Impairment in the wound healing process is a serious concern in diabetes, which often leads to the amputation of limbs in diabetic patients. Inhibition of classical HDACs has been claimed to promote diabetic wound healing [299]. Homeobox protein Hox-A3 (Hoxa3)-treated diabetesderived macrophages exhibited HDAC inhibition, which quickens the wound healing process by inhibiting inflammatory factors [299]. HDACi, valproic acid, was found to accelerate wound healing in high glucose-exposed porcine corneas and hyperglycemia-suppressed wound closure in T1DM rats by upregulating $\mathrm{H} 3$ acetylation [300]. $\mathrm{NaB}$, an HDACi, in combination with epidermal growth factor and platelet-derived growth factor-BB can facilitate the healing of acute cutaneous the wound in diabetic mice [301]. SIRT1, 2, 3, and 6 have been reported to promote wound healing in DM. SIRT1 can promote hyperglycemia-provoked corneal epithelial wound healing involving insulin-like growth factor binding protein-3 (IGFBP3)/insulin-like growth 
factor-1 (IGF-1)/Akt Signaling pathway by p53 deacetylation [302]. SIRT3 loss has been proposed to delay the wound healing process in insulin-resistant mice model of T2DM [303]. SIRT6 depletion in cutaneous wounds has been reported to aggravate the wound healing process by promoting NF- $\kappa \mathrm{B}$ activation, inducing oxidative stress, and decreasing angiogenesis in diabetic mice [304]. MC2562, a SIRT1, 2, and 3 activators, was shown to accelerate wound repair [305]. SIRT1 activation by resveratrol endorsed its endothelial protection and pro-angiogenic effects, facilitating diabetic wound healing by inhibition of FOXO1 and endorsing c-Myc expression [306]. Inclusion of SRT1720, a SIRT1 agonist, in an embryonic artery CD133+ cell-seeded dressing material composed of poly (lactic-co-glycolic acid), collagen, and silk has been found to accelerate the wound healing process and induces angiogenesis in diabetic ischemic ulcers [307]. SRT1720 inclusion can potentiate embryonic artery $\mathrm{CD}_{133^{+}}$cell proliferation, enhancing the secretion of vascular endothelial growth factor (VEGF) A, basic fibroblast growth factor, IL-8 and, and inhibiting the TNF- $\alpha$ secretion [307]. Localized use of SRT1720 can promote wound healing and angiogenesis in T1D mice. The effect has been proposed to be associated with the suppression of high glucose-induced oxidative stress as observed in in vitro assay performed in human umbilical vein endothelial cells [308]. Micro-RNA-92a inhibition was reported to promote skin repair in diabetic wound healing by SIRT1 activation [309].

HDACs are known to regulate several pathological events in cardiometabolic diseases including atherosclerosis by inducing inflammation and oxidative stress [310]. Significant upregulation of HDACs was reported in atherosclerotic arterial specimens in diabetic and hypercholesterolemic mice [277, 310]. Also, HDAC9 can endorse atherogenic plaque formation by suppressing cholesterol efflux and generating activated macrophages in atherosclerosis [311]. Also, HDAC9 can enhance the progression of vascular diabetic calcification that can contribute to diabetic atherosclerosis [43]. Inhibition of classical HDACs has been regarded as a therapeutic option in treating atherosclerosis [310]. SAHA, a pan-HDACi, has been found to alleviate atherosclerotic lesions by impeding NOX expressions, reducing oxidative stress, and suppressing inflammation in diabetic and apolipoprotein E-deficient hypercholesterolemic mice [277, 310]. Inhibition of HDAC2 and HDAC3 
by valproic acid can prevent cholesterol absorption by inhibiting NPC1L1 expression, which has been implicated in the development of atherosclerosis-associated with DM [312]. RGFP-966, an isoform-selective HDAC3 inhibitor, can significantly reduce diabetic liver damage and aortic pathologies in T1D mice by restoring the synthesis of hepatic fibroblast growth factor 21 through hepatic Nrf2 activation [114]. Among all SIRTs, SIRT1 and SIRT6 are characterized for their protective mechanism against inflammation, vascular aging, and atherosclerosis in DM [313]. SIRT1 expression in peripheral blood mononuclear cells is negatively correlated with proinflammatory cytokines level in T2DM patients with coronary artery diseases [314]. Thus, there may be a regulatory role of SIRT1 in developing atherosclerotic lesions [314]. SS-31, a mitochondrial antioxidant, can enhance SIRT1 level and ameliorates leukocyte-endothelium interactions, inflammation, and oxidative stress in T2DM to prevent the risk of developing diabetic cardiovascular diseases, including atherosclerosis [315]. Vascular calcification has been implicated in the risk of cardiovascular disease in DM, which accelerates atherosclerotic plaque development [316]. SIRT1 can negatively regulate vascular calcification in diabetes [316]. SIRT1 activation by SRT1720 can suppress osteogenic differentiation of human vascular smooth muscle cells by inhibiting RUNX2 Signaling and preventing senescence [316]. SIRT6 has been revealed to be a negative regulator in endothelial dysfunction and atherosclerosis development [317]. SIRT6-knocked down and apolipoprotein E-deficient hypercholesterolemic mice tend to develop atherosclerosis by increasing inflammation in the endothelial cells [317]. Incretin treatment attenuates diabetic atherosclerosis in T2DM patients; however, SIRT6-attenuated inflammation in atherosclerotic lesions was regarded to potentiate the therapeutic effect of incretin [318].

Cerebral ischemia yields severe morbidity and high mortality in diabetic patients. Classical HDACs are implicated in the neurological disorder, including ischemic stroke by inducing oxidative stress, ER stress, apoptosis, inflammation, and blood-brain barrier breakdowns, which have been reported to be reciprocated by classical HDACis, such as TSA, valproic acid, butyrates, and SAHA [319]. HDAC3 has been regarded to be a positive regulator in developing diabetic stroke, which remains upregulated in the brain of diabetic subjects [320]. Inhibition of HDAC3 by a specific inhibitor, RGFP966, can prevent hyperglycemia-induced cerebral ischemia-reperfusion injury in vivo and in vitro by suppressing oxidative stress, inhibiting apoptosis, and improving autophagy [320]. Tubacin, a selective HDAC6 inhibitor, was found to alleviate ischemic brain injury in T2D mice with focal cerebral ischemia by endorsing eNOS expression in an HDAC6dependent mechanism [321]. Class III HDACs are also considered as the key regulators in 
diabetes-triggered ischemic brain injury. SIRT1 imparts a neuroprotective role in the brain against cerebral ischemia and neurodegeneration [214, 322]. Dexmedetomidine attenuates diabetesexacerbated cerebral ischemia/reperfusion injury in vitro and in vivo [323]. Dexmedetomidine can alleviate oxidative stress, inflammation, and apoptosis in high glucose-exposed mouse hippocampal neurons and middle cerebral artery region in diabetic mice by endorsing SIRT1, Nrf2, and nuclear factor of activated T-cells 5 (NFAT5) expression [323]. N-palmitoylethanolamideoxazoline attenuates ischemia/reperfusion brain injury and cognitive impairment in diabetic rats by SIRT1 activation resulting in attenuation of cerebral inflammation and oxidative stress [324]. Hyperglycemia can suppress SIRT3 expression in the cerebral tissue, which augments neural oxidative stress, inflammation, and apoptosis [325]. Honokiol, a pharmacological activator of SIRT3, was shown to abolish neural dysfunctions after intracerebral hemorrhage in T1D rats by decreasing PYD domains-containing protein 3 inflammasome activation, suppressing IL-1 $\beta$ level, and by potentiating SOD2 deacetylation and ROS scavenging [325].

\section{Challenges and prospects}

HDACs have emerged as potential targets for the treatment of DM. HDACs-mediated epigenetic and post-translational regulation of several transcription factors that modulate multiple Signaling events in DM and the pathological development of diabetic complications serve as the potential mechanism(s) to intervene. Substantial shreds of evidence revealed that HDACs can regulate $\beta$ cell fate, insulin release, insulin expression, insulin Signaling, and glucose metabolism. HDACs have also been implicated in the regulation of oxidative stress, inflammation, apoptosis, fibrosis, and other pathological events that essentially contributes to the diabetes-provoked pathogenesis in several tissues. The enhanced expression of the majority of classical HDAC isoforms has been regarded to play pathogenic roles in developing DM and DM-associated complications. In contrast, most of the class III HDACs, such as SIRT1, 2, 3, and 6 were claimed to impede insulin resistance and impart 
beneficial effects by suppressing inflammation, oxidative stress, and mitochondrial dysfunctions in the DM-affected tissues. Simultaneously, several controversial claims are also reported. However, the targeting of HDACs can provide a theoretical basis to intervene in DM and its associated complications. Emerging evidence revealed the preclinical success of several classical HDACis and SIRT activators in the experimentally induced T1DM, T2DM, and DM-led vascular complications in vitro and in vivo. However, the majority of the studies employed non-selective inhibitors and activators of HDACs and SIRTs respectively. Despite some preclinical studies that included genetically mutant cells or animals to predict the exact HDAC isoform for the observed effect, but these are too insignificant to portrait the specific roles of the individual members in all four classes of HDACs. Thus, the majority of the evaluations remain confined within the preclinical level.

Metabolic aberration and consequent pathological events in DM are generally manifested by multiple molecular mechanisms involving several transcription factors. All 18 HDACs are implicated in the removal of the acetyl group from the $\varepsilon$-lysine residue of proteins and thereby, HDACs can not only impact transcriptional machinery but can also concurrently endorse posttranslational modifications of proteins. Substantial evidence revealed that modifications in histone acetylation status can regulate the activity of several transcription factors that play a vital part in the pathological or preventive events in DM. Expression of individual HDAC in diabetic patients followed by preclinical assays predicted the regulatory mechanism(s) of different HDAC isoforms in the DM. However, the precise role of individual HDACs is yet to be categorically understood. Also, the complex regulatory network of HDACs, all together, must be precisely elucidated. Once the complete understanding of HDACs regulation is characterized, it can potentially serve as a novel therapeutic target for DM and associated pathological complications.

\section{Conclusion}

This review provides insights into the emerging roles of all four classes of HDACs in the developmental and pathogenetic pathways associated with DM. This report provides an up-to-date account of details on the involvement of HDACs in DM etiology and pathology. The molecular insights behind the HDAC-mediated epigenetic regulation in endocrine islet fate, insulin expression, insulin Signaling, and glucose homeostasis are comprehensively accentuated. It also 
discussed the targeting of HDACs for the potential treatment of DM and diabetes-associated complications, such as nephropathy, cardiomyopathy, retinopathy, neuropathy, vasculopathy, foot syndrome, poor wound healing, and cerebral strokes. Largely, the inhibition of classical HDACs and the activation of class III HDACs or SIRTs were described and its therapeutic potential for the $\mathrm{DM}$ and associated complications were further extensively discussed, while several controversial pieces of evidence were also conferred. Although, these evidences so far distinctly underlined the crucial part HDACs play in DM and associated complications, the complete functional map of HDACs is yet to be revealed. Conclusively, further extensive efforts are warranted to reveal the distinct role of individual HDAC family members in disease pathology towards developing effective HDACs-targeted therapeutic interventions for DM.

\section{Acknowledgments}

The authors are thankful to the Council of Scientific and Industrial Research, New Delhi, India, for awarding the research project (grant number 02(0275)/16/EMR-II) to Dr. Saikat Dewanjee. The authors sincerely acknowledge Jadavpur University, India for providing the necessary facilities.

\section{Conflicts of interest}

None.

\section{Authors' contribution}

SD, VDF, RK designed and wrote the manuscript. JV, RJK, PC, RS, MM, VM, AJ, Reddy PH edited and corrected the manuscript. The final correction and editing were done by Reddy PH.

\section{References}

1. Advani, A.; Huang, Q.; Thai, K.; Advani, S.L.; White, K.E.; Kelly, D.J.; Yuen, D.A.; Connelly, K.A.; Marsden, P.A.; Gilbert, R.E. Long-term administration of the histone deacetylase inhibitor vorinostat attenuates renal injury in experimental diabetes through an endothelial nitric oxide synthase-dependent mechanism. Am J Pathol 2011, 178, 2205-2214, doi:10.1016/j.ajpath.2011.01.044.

2. Alrdahe, S.; Al Sadoun, H.; Torbica, T.; McKenzie, E.A.; Bowling, F.L.; Boulton, A.J.M.; Mace, K.A. Dysregulation of macrophage development and phenotype in diabetic human macrophages can be rescued by Hoxa3 protein transduction. PLoS One 2019, 14, e0223980, doi:10.1371/journal.pone.0223980.

3. Anderson, J.G.; Ramadori, G.; Ioris, R.M.; Galie, M.; Berglund, E.D.; Coate, K.C.; Fujikawa, T.; Pucciarelli, S.; Moreschini, B.; Amici, A., et al. Enhanced insulin sensitivity in skeletal muscle and liver by physiological overexpression of SIRT6. Mol Metab 2015, 4, 846-856, doi:10.1016/j.molmet.2015.09.003. 
4. Anderson, K.A.; Huynh, F.K.; Fisher-Wellman, K.; Stuart, J.D.; Peterson, B.S.; Douros, J.D.; Wagner, G.R.; Thompson, J.W.; Madsen, A.S.; Green, M.F., et al. SIRT4 Is a Lysine Deacylase that Controls Leucine Metabolism and Insulin Secretion. Cell Metab 2017, 25, 838855 e815, doi:10.1016/j.cmet.2017.03.003.

5. Arora, A.; Dey, C.S. SIRT2 negatively regulates insulin resistance in C2C12 skeletal muscle cells. Biochim Biophys Acta 2014, 1842, 1372-1378, doi:10.1016/j.bbadis.2014.04.027.

6. Assar, M.E.; Angulo, J.; Rodriguez-Manas, L. Diabetes and ageing-induced vascular inflammation. J Physiol 2016, 594, 2125-2146, doi:10.1113/JP270841.

7. Astratenkova, I.V., Rogozkin, V.A. The Role of Acetylation/Deacetylation of Histones and Transcription Factors in Regulating Metabolism in Skeletal Muscles. Neurosci Behav Physi 2019, 49, 281-288

8. Bae, E.J. Sirtuin 6, a possible therapeutic target for type 2 diabetes. Arch Pharm Res 2017, 40, 1380-1389, doi:10.1007/s12272-017-0989-8.

9. Bagchi, R.A.; Ferguson, B.S.; Stratton, M.S.; Hu, T.; Cavasin, M.A.; Sun, L.; Lin, Y.H.; Liu, D.; Londono, P.; Song, K., et al. HDAC11 suppresses the thermogenic program of adipose tissue via BRD2. JCI Insight 2018, 3, doi:10.1172/jci.insight.120159.

10. Bagchi, R.A.; Weeks, K.L. Histone deacetylases in cardiovascular and metabolic diseases. J Mol Cell Cardiol 2019, 130, 151-159, doi:10.1016/j.yjmcc.2019.04.003.

11. Bagul, P.K.; Deepthi, N.; Sultana, R.; Banerjee, S.K. Resveratrol ameliorates cardiac oxidative stress in diabetes through deacetylation of NFkB-p65 and histone 3. J Nutr Biochem 2015, 26, 1298-1307, doi:10.1016/j.jnutbio.2015.06.006.

12. Bagul, P.K.; Katare, P.B.; Bugga, P.; Dinda, A.K.; Banerjee, S.K. SIRT-3 Modulation by Resveratrol Improves Mitochondrial Oxidative Phosphorylation in Diabetic Heart through Deacetylation of TFAM. Cells 2018, 7, doi:10.3390/cells7120235.

13. Balestrieri, M.L.; Rizzo, M.R.; Barbieri, M.; Paolisso, P.; D'Onofrio, N.; Giovane, A.; Siniscalchi, M.; Minicucci, F.; Sardu, C.; D'Andrea, D., et al. Sirtuin 6 expression and inflammatory activity in diabetic atherosclerotic plaques: effects of incretin treatment. Diabetes 2015, 64, 1395-1406, doi:10.2337/db14-1149.

14. Bartoli-Leonard, F.; Wilkinson, F.L.; Schiro, A.; Inglott, F.S.; Alexander, M.Y.; Weston, R. Suppression of SIRT1 in Diabetic Conditions Induces Osteogenic Differentiation of Human Vascular Smooth Muscle Cells via RUNX2 Signaling. Sci Rep 2019, 9, 878, doi:10.1038/s41598-018-37027-2.

15. Bastidas-Ponce, A.; Scheibner, K.; Lickert, H.; Bakhti, M. Cellular and molecular mechanisms coordinating pancreas development. Development 2017, 144, 2873-2888, doi:10.1242/dev.140756.

16. Bayley, J.S.; Pedersen, T.H.; Nielsen, O.B. Skeletal muscle dysfunction in the db/db mouse model of type 2 diabetes. Muscle Nerve 2016, 54, 460-468, doi:10.1002/mus.25064.

17. Benerofe, S.A., Carrillo-Sepulveda, M.A. Downregulation of Histone Deacetylase 9 (HDAC9) is Associated with Vascular Calcification in Diabetic Mice. The FASEB Journal 2017, 31, 673.679-673.679.

18. Bhaskara, S. Histone deacetylase 11 as a key regulator of metabolism and obesity. EBioMedicine 2018, 35, 27-28, doi:10.1016/j.ebiom.2018.08.008.

19. Bhattacharjee, N.; Barma, S.; Konwar, N.; Dewanjee, S.; Manna, P. Mechanistic insight of diabetic nephropathy and its pharmacotherapeutic targets: An update. Eur J Pharmacol 2016, 791, 8-24, doi:10.1016/j.ejphar.2016.08.022.

20. Bhattacharjee, N.; Dua, T.K.; Khanra, R.; Joardar, S.; Nandy, A.; Saha, A.; De Feo, V.; Dewanjee, S. Protocatechuic Acid, a Phenolic from Sansevieria roxburghiana Leaves, Suppresses Diabetic Cardiomyopathy via Stimulating Glucose Metabolism, Ameliorating Oxidative Stress, and Inhibiting Inflammation. Front Pharmacol 2017, 8, 251, doi:10.3389/fphar.2017.00251.

21. Bilokapic, S.; Strauss, M.; Halic, M. Structural rearrangements of the histone octamer translocate DNA. Nat Commun 2018, 9, 1330, doi:10.1038/s41467-018-03677-z.

22. Blanter, M.; Sork, H.; Tuomela, S.; Flodstrom-Tullberg, M. Genetic and Environmental Interaction in Type 1 Diabetes: a Relationship Between Genetic Risk Alleles and Molecular Traits of Enterovirus Infection? Curr Diab Rep 2019, 19, 82, doi:10.1007/s11892-019-1192- 
8.

23. Bocchi, L.; Motta, B.M.; Savi, M.; Vilella, R.; Meraviglia, V.; Rizzi, F.; Galati, S.; Buschini, A.; Lazzaretti, M.; Pramstaller, P.P., et al. The Histone Deacetylase Inhibitor Suberoylanilide Hydroxamic Acid (SAHA) Restores Cardiomyocyte Contractility in a Rat Model of Early Diabetes. Int J Mol Sci 2019, 20, doi:10.3390/ijms20081873.

24. Boniakowski, A.E., Kimball, A., Joshi, A., Kunkel, S., Gallagher, K. PC200 A Deacetylase Enzyme, Sirtuin 3, Plays a Major Role in Macrophage Inflammation and Wound Healing. Journal of Vascular Surgery 2017, 65, 193S-194S.

25. Boni-Schnetzler, M.; Meier, D.T. Islet inflammation in type 2 diabetes. Semin Immunopathol 2019, 41, 501-513, doi:10.1007/s00281-019-00745-4.

26. Bonnefond, A.; Froguel, P.; Vaxillaire, M. The emerging genetics of type 2 diabetes. Trends Mol Med 2010, 16, 407-416, doi:10.1016/j.molmed.2010.06.004.

27. Bramswig, N.C.; Kaestner, K.H. Epigenetics and diabetes treatment: an unrealized promise? Trends Endocrinol Metab 2012, 23, 286-291, doi:10.1016/j.tem.2012.02.002.

28. Cai, X.; Li, J.; Wang, M.; She, M.; Tang, Y.; Li, J.; Li, H.; Hui, H. GLP-1 Treatment Improves Diabetic Retinopathy by Alleviating Autophagy through GLP-1R-ERK1/2-HDAC6 Signaling Pathway. Int J Med Sci 2017, 14, 1203-1212, doi:10.7150/ijms.20962.

29. Cao, J.; Yu, Y.; Zhang, Z.; Chen, X.; Hu, Z.; Tong, Q.; Chang, J.; Feng, X.H.; Lin, X. SCP4 Promotes Gluconeogenesis Through FoxO1/3a Dephosphorylation. Diabetes 2018, 67, 46-57, doi: $10.2337 / \mathrm{db} 17-0546$.

30. Cao, Q.; Rong, S.; Repa, J.J.; St Clair, R.; Parks, J.S.; Mishra, N. Histone deacetylase 9 represses cholesterol efflux and alternatively activated macrophages in atherosclerosis development. Arterioscler Thromb Vasc Biol 2014, 34, 1871-1879, doi:10.1161/ATVBAHA.114.303393.

31. Caton, P.W.; Richardson, S.J.; Kieswich, J.; Bugliani, M.; Holland, M.L.; Marchetti, P.; Morgan, N.G.; Yaqoob, M.M.; Holness, M.J.; Sugden, M.C. Sirtuin 3 regulates mouse pancreatic beta cell function and is suppressed in pancreatic islets isolated from human type 2 diabetic patients. Diabetologia 2013, 56, 1068-1077, doi:10.1007/s00125-013-2851-y.

32. Chandrasekaran, K.; Muragundla, A.; Demarest, T.G.; Choi, J.; Sagi, A.R.; Najimi, N.; Kumar, P.; Singh, A.; Ho, C.Y.; Fiskum, G., et al. mGluR2/3 activation of the SIRT1 axis preserves mitochondrial function in diabetic neuropathy. Ann Clin Transl Neurol 2017, 4, 844858, doi:10.1002/acn3.484.

33. Chandrasekaran, K.; Salimian, M.; Konduru, S.R.; Choi, J.; Kumar, P.; Long, A.; Klimova, N.; Ho, C.Y.; Kristian, T.; Russell, J.W. Overexpression of Sirtuin 1 protein in neurons prevents and reverses experimental diabetic neuropathy. Brain 2019, 142, 3737-3752, doi:10.1093/brain/awz324.

34. Chatterjee, T.K.; Basford, J.E.; Knoll, E.; Tong, W.S.; Blanco, V.; Blomkalns, A.L.; Rudich, S.; Lentsch, A.B.; Hui, D.Y.; Weintraub, N.L. HDAC9 knockout mice are protected from adipose tissue dysfunction and systemic metabolic disease during high-fat feeding. Diabetes 2014, 63, 176-187, doi:10.2337/db13-1148.

35. Chen, C.; Cohrs, C.M.; Stertmann, J.; Bozsak, R.; Speier, S. Human beta cell mass and function in diabetes: Recent advances in knowledge and technologies to understand disease pathogenesis. Mol Metab 2017, 6, 943-957, doi:10.1016/j.molmet.2017.06.019.

36. Chen, H.; Wan, Y.; Zhou, S.; Lu, Y.; Zhang, Z.; Zhang, R.; Chen, F.; Hao, D.; Zhao, X.; Guo, Z., et al. Endothelium-specific SIRT1 overexpression inhibits hyperglycemia-induced upregulation of vascular cell senescence. Sci China Life Sci 2012, 55, 467-473, doi:10.1007/s11427-012-4329-4.

37. Chen, J.; Wang, N.; Dong, M.; Guo, M.; Zhao, Y.; Zhuo, Z.; Zhang, C.; Chi, X.; Pan, Y.; Jiang, J., et al. The Metabolic Regulator Histone Deacetylase 9 Contributes to Glucose Homeostasis Abnormality Induced by Hepatitis C Virus Infection. Diabetes 2015, 64, 40884098, doi:10.2337/db15-0197.

38. Chen, J.; Zhang, J.; Shaik, N.F.; Yi, B.; Wei, X.; Yang, X.F.; Naik, U.P.; Summer, R.; Yan, G.; Xu, X., et al. The histone deacetylase inhibitor tubacin mitigates endothelial dysfunction by up-regulating the expression of endothelial nitric oxide synthase. J Biol Chem 2019, 294, 19565-19576, doi:10.1074/jbc.RA119.011317. 
39. Chen, J.; Zhang, Z.; Wang, N.; Guo, M.; Chi, X.; Pan, Y.; Jiang, J.; Niu, J.; Ksimu, S.; Li, J.Z., et al. Role of HDAC9-FoxO1 Axis in the Transcriptional Program Associated with Hepatic Gluconeogenesis. Sci Rep 2017, 7, 6102, doi:10.1038/s41598-017-06328-3.

40. Chen, L.; Cao, J.; Cao, D.; Wang, M.; Xiang, H.; Yang, Y.; Ying, T.; Cong, H. Protective effect of dexmedetomidine against diabetic hyperglycemia-exacerbated cerebral ischemia/reperfusion injury: An in vivo and in vitro study. Life Sci 2019, 235, 116553, doi:10.1016/j.lfs.2019.116553.

41. Chen, N.; Jiang, K.; Yan, G.G. Effect of fenofibrate on diabetic retinopathy in rats via SIRT1/NF-kappaB signaling pathway. Eur Rev Med Pharmacol Sci 2019, 23, 8630-8636, doi:10.26355/eurrev_201910_19180.

42. Chen, T.; Li, J.; Liu, J.; Li, N.; Wang, S.; Liu, H.; Zeng, M.; Zhang, Y.; Bu, P. Activation of SIRT3 by resveratrol ameliorates cardiac fibrosis and improves cardiac function via the TGFbeta/Smad3 pathway. Am J Physiol Heart Circ Physiol 2015, 308, H424-434, doi:10.1152/ajpheart.00454.2014.

43. Chen, W.B.; Gao, L.; Wang, J.; Wang, Y.G.; Dong, Z.; Zhao, J.; Mi, Q.S.; Zhou, L. Conditional ablation of HDAC3 in islet beta cells results in glucose intolerance and enhanced susceptibility to STZ-induced diabetes. Oncotarget 2016, 7, 57485-57497, doi:10.18632/oncotarget.11295.

44. Chen, Y.; Du, J.; Zhao, Y.T.; Zhang, L.; Lv, G.; Zhuang, S.; Qin, G.; Zhao, T.C. Histone deacetylase (HDAC) inhibition improves myocardial function and prevents cardiac remodeling in diabetic mice. Cardiovasc Diabetol 2015, 14, 99, doi:10.1186/s12933-0150262-8.

45. Cheng, P.K.; Chen, X.L.; Su, X.X.; Su, X.J.; Hou, C.L. A novel dressing seeded with embryonic artery CD133(+) cells and loaded with the Sirt1 agonist SRT1720 accelerates the healing of diabetic ischemic ulcers. Exp Ther Med 2018, 15, 5243-5250, doi:10.3892/etm.2018.6099.

46. Cho, H.M.; Seok, Y.M.; Lee, H.A.; Song, M.; Kim, I. Repression of Transcriptional Activity of Forkhead Box O1 by Histone Deacetylase Inhibitors Ameliorates Hyperglycemia in Type 2 Diabetic Rats. Int J Mol Sci 2018, 19, doi:10.3390/ijms 19113539.

47. Chou, D.H.; Holson, E.B.; Wagner, F.F.; Tang, A.J.; Maglathlin, R.L.; Lewis, T.A.; Schreiber, S.L.; Wagner, B.K. Inhibition of histone deacetylase 3 protects beta cells from cytokineinduced apoptosis. Chem Biol 2012, 19, 669-673, doi:10.1016/j.chembiol.2012.05.010.

48. Choubey, A., Kar, A.K., Girdhar, K., Chattopadhyay, T., Dogra, S., Kushwaha, S., Medhi, B., Bhansali, A., Mantri, C.K., Kolthur-Seetharam, U., Ghosh, D., Mondal, P. Hyperinsulinemia promotes HMGB1 release leading to inflammation induced systemic insulin resistance: An interplay between pancreatic beta-cell and peripheral organs. bioRxiv 2019.

49. Christensen, D.P.; Dahllof, M.; Lundh, M.; Rasmussen, D.N.; Nielsen, M.D.; Billestrup, N.; Grunnet, L.G.; Mandrup-Poulsen, T. Histone deacetylase (HDAC) inhibition as a novel treatment for diabetes mellitus. Mol Med 2011, 17, 378-390, doi:10.2119/molmed.2011.00021.

50. Cieslak, M.; Wojtczak, A.; Cieslak, M. Role of pro-inflammatory cytokines of pancreatic islets and prospects of elaboration of new methods for the diabetes treatment. Acta Biochim Pol 2015, 62, 15-21, doi:10.18388/abp.2014_853.

51. Clemens Zwergel, G.S., Sergio Valente and Antonello Mai. Histone Deacetylase Inhibitors: Updated Studies in Various Epigenetic-Related Diseases. Journal of Clinical Epigenetics 2016, 2, doi:10.21767/2472-1158.100015.

52. Da Silva Xavier, G. The Cells of the Islets of Langerhans. J Clin Med 2018, 7, doi: $10.3390 / j \mathrm{~cm} 7030054$.

53. Dahllof, M.S.; Christensen, D.P.; Harving, M.; Wagner, B.K.; Mandrup-Poulsen, T.; Lundh, M. HDAC inhibitor-mediated beta-cell protection against cytokine-induced toxicity is STAT1 Tyr701 phosphorylation independent. J Interferon Cytokine Res 2015, 35, 63-70, doi:10.1089/jir.2014.0022.

54. Dai, Y.; Faller, D.V. Transcription Regulation by Class III Histone Deacetylases (HDACs)Sirtuins. Transl Oncogenomics 2008, 3, 53-65, doi:10.4137/tog.s483.

55. Daneshpajooh, M.; Eliasson, L.; Bacos, K.; Ling, C. MC1568 improves insulin secretion in 
islets from type 2 diabetes patients and rescues beta-cell dysfunction caused by Hdac7 upregulation. Acta Diabetol 2018, 55, 1231-1235, doi:10.1007/s00592-018-1201-4.

56. Davis, F.M.; Kimball, A.; Boniakowski, A.; Gallagher, K. Dysfunctional Wound Healing in Diabetic Foot Ulcers: New Crossroads. Curr Diab Rep 2018, 18, 2, doi:10.1007/s11892-0180970-z.

57. Desjardins, D.; Liu, Y.; Crosson, C.E.; Ablonczy, Z. Histone Deacetylase Inhibition Restores Retinal Pigment Epithelium Function in Hyperglycemia. PLoS One 2016, 11, e0162596, doi:10.1371/journal.pone.0162596.

58. Dewanjee, S.; Das, S.; Das, A.K.; Bhattacharjee, N.; Dihingia, A.; Dua, T.K.; Kalita, J.; Manna, P. Molecular mechanism of diabetic neuropathy and its pharmacotherapeutic targets. Eur J Pharmacol 2018, 833, 472-523, doi:10.1016/j.ejphar.2018.06.034.

59. Dihingia, A.; Ozah, D.; Ghosh, S.; Sarkar, A.; Baruah, P.K.; Kalita, J.; Sil, P.C.; Manna, P. Vitamin K1 inversely correlates with glycemia and insulin resistance in patients with type 2 diabetes (T2D) and positively regulates SIRT1/AMPK pathway of glucose metabolism in liver of T2D mice and hepatocytes cultured in high glucose. J Nutr Biochem 2018, 52, 103-114, doi:10.1016/j.jnutbio.2017.09.022.

60. Dirice, E.; Ng, R.W.S.; Martinez, R.; Hu, J.; Wagner, F.F.; Holson, E.B.; Wagner, B.K.; Kulkarni, R.N. Isoform-selective inhibitor of histone deacetylase 3 (HDAC3) limits pancreatic islet infiltration and protects female nonobese diabetic mice from diabetes. J Biol Chem 2017, 292, 17598-17608, doi:10.1074/jbc.M117.804328.

61. Dominy, J.E., Jr.; Lee, Y.; Jedrychowski, M.P.; Chim, H.; Jurczak, M.J.; Camporez, J.P.; Ruan, H.B.; Feldman, J.; Pierce, K.; Mostoslavsky, R., et al. The deacetylase Sirt6 activates the acetyltransferase GCN5 and suppresses hepatic gluconeogenesis. Mol Cell 2012, 48, 900913, doi:10.1016/j.molcel.2012.09.030.

62. Dong, W.; Jia, Y.; Liu, X.; Zhang, H.; Li, T.; Huang, W.; Chen, X.; Wang, F.; Sun, W.; Wu, H. Sodium butyrate activates NRF2 to ameliorate diabetic nephropathy possibly via inhibition of HDAC. J Endocrinol 2017, 232, 71-83, doi:10.1530/JOE-16-0322.

63. D'Onofrio, N.; Servillo, L.; Balestrieri, M.L. SIRT1 and SIRT6 Signaling Pathways in Cardiovascular Disease Protection. Antioxid Redox Signal 2018, 28, 711-732, doi:10.1089/ars.2017.7178.

64. Du, W.; Wang, N.; Li, F.; Jia, K.; An, J.; Liu, Y.; Wang, Y.; Zhu, L.; Zhao, S.; Hao, J. STAT3 phosphorylation mediates high glucose-impaired cell autophagy in an HDAC1-dependent and -independent manner in Schwann cells of diabetic peripheral neuropathy. FASEB J 2019, 33, 8008-8021, doi:10.1096/fj.201900127R.

65. Du, Y.; Tang, G.; Yuan, W. Suppression of HDAC2 by sodium butyrate alleviates apoptosis of kidney cells in db/db mice and HGinduced NRK52E cells. Int J Mol Med 2020, 45, 210222, doi:10.3892/ijmm.2019.4397.

66. Eckschlager, T.; Plch, J.; Stiborova, M.; Hrabeta, J. Histone Deacetylase Inhibitors as Anticancer Drugs. Int J Mol Sci 2017, 18, doi:10.3390/ijms18071414.

67. Elmallah, M.I.Y.; Micheau, O. Epigenetic Regulation of TRAIL Signaling: Implication for Cancer Therapy. Cancers (Basel) 2019, 11, doi:10.3390/cancers11060850.

68. Elsharkawi, I., Sandeep, D., El-Serafi, A. Investigating the role of the histone deacetylasesinhibitor suberanilohydroxamic acid in the differentiation of stem cells into insulin secreting cells. Hamdan Medical Journal 2019, 12, 10-14.

69. Escribano-Lopez, I.; de Maranon, A.M.; Iannantuoni, F.; Lopez-Domenech, S.; AbadJimenez, Z.; Diaz, P.; Sola, E.; Apostolova, N.; Rocha, M.; Victor, V.M. The Mitochondrial Antioxidant SS-31 Modulates Oxidative Stress, Endoplasmic Reticulum Stress, and Autophagy in Type 2 Diabetes. J Clin Med 2019, 8, doi:10.3390/jcm8091322.

70. Fan, J.; Krautkramer, K.A.; Feldman, J.L.; Denu, J.M. Metabolic regulation of histone posttranslational modifications. ACS Chem Biol 2015, 10, 95-108, doi:10.1021/cb500846u.

71. Fan, X.D.; Wan, L.L.; Duan, M.; Lu, S. HDAC11 deletion reduces fructose-induced cardiac dyslipidemia, apoptosis and inflammation by attenuating oxidative stress injury. Biochem Biophys Res Commun 2018, 503, 444-451, doi:10.1016/j.bbrc.2018.04.090.

72. Fang, W.J.; Wang, C.J.; He, Y.; Zhou, Y.L.; Peng, X.D.; Liu, S.K. Resveratrol alleviates diabetic cardiomyopathy in rats by improving mitochondrial function through PGC-1alpha 
deacetylation. Acta Pharmacol Sin 2018, 39, 59-73, doi:10.1038/aps.2017.50.

73. Feldman, J.L.; Baeza, J.; Denu, J.M. Activation of the protein deacetylase SIRT6 by longchain fatty acids and widespread deacylation by mammalian sirtuins. J Biol Chem 2013, 288, 31350-31356, doi:10.1074/jbc.C113.511261.

74. Feng, J.; Lu, C.; Dai, Q.; Sheng, J.; Xu, M. SIRT3 Facilitates Amniotic Fluid Stem Cells to Repair Diabetic Nephropathy Through Protecting Mitochondrial Homeostasis by Modulation of Mitophagy. Cell Physiol Biochem 2018, 46, 1508-1524, doi:10.1159/000489194.

75. Fenley, A.T.; Anandakrishnan, R.; Kidane, Y.H.; Onufriev, A.V. Modulation of nucleosomal DNA accessibility via charge-altering post-translational modifications in histone core. Epigenetics Chromatin 2018, 11, 11, doi:10.1186/s13072-018-0181-5.

76. Fessler, E.B.; Chibane, F.L.; Wang, Z.; Chuang, D.M. Potential roles of HDAC inhibitors in mitigating ischemia-induced brain damage and facilitating endogenous regeneration and recovery. Curr Pharm Des 2013, 19, 5105-5120, doi:10.2174/1381612811319280009.

77. Franks, P.W.; Pearson, E.; Florez, J.C. Gene-environment and gene-treatment interactions in type 2 diabetes: progress, pitfalls, and prospects. Diabetes Care 2013, 36, 1413-1421, doi:10.2337/dc12-2211.

78. Fu, Z.; Gilbert, E.R.; Liu, D. Regulation of insulin synthesis and secretion and pancreatic Betacell dysfunction in diabetes. Curr Diabetes Rev 2013, 9, 25-53.

79. Fusco, R.; Scuto, M.; Cordaro, M.; D'Amico, R.; Gugliandolo, E.; Siracusa, R.; Peritore, A.F.; Crupi, R.; Impellizzeri, D.; Cuzzocrea, S., et al. N-Palmitoylethanolamide-Oxazoline Protects against Middle Cerebral Artery Occlusion Injury in Diabetic Rats by Regulating the SIRT1 Pathway. Int J Mol Sci 2019, 20, doi:10.3390/ijms20194845.

80. Galmozzi, A.; Mitro, N.; Ferrari, A.; Gers, E.; Gilardi, F.; Godio, C.; Cermenati, G.; Gualerzi, A.; Donetti, E.; Rotili, D., et al. Inhibition of class I histone deacetylases unveils a mitochondrial signature and enhances oxidative metabolism in skeletal muscle and adipose tissue. Diabetes 2013, 62, 732-742, doi:10.2337/db12-0548.

81. Gao, J.; Wang, Y.; Li, W.; Zhang, J.; Che, Y.; Cui, X.; Sun, B.; Zhao, G. Loss of histone deacetylase 2 inhibits oxidative stress induced by high glucose via the HO-1/SIRT1 pathway in endothelial progenitor cells. Gene 2018, 678, 1-7, doi:10.1016/j.gene.2018.07.072.

82. Gao, J.; Zheng, Z.; Gu, Q.; Chen, X.; Liu, X.; Xu, X. Deacetylation of MnSOD by PARPregulated SIRT3 protects retinal capillary endothelial cells from hyperglycemia-induced damage. Biochem Biophys Res Commun 2016, 472, 425-431, doi:10.1016/j.bbrc.2015.12.037.

83. Gao, Z.; Yin, J.; Zhang, J.; Ward, R.E.; Martin, R.J.; Lefevre, M.; Cefalu, W.T.; Ye, J. Butyrate improves insulin sensitivity and increases energy expenditure in mice. Diabetes 2009, 58, 1509-1517, doi:10.2337/db08-1637.

84. Gilbert, R.E.; Huang, Q.; Thai, K.; Advani, S.L.; Lee, K.; Yuen, D.A.; Connelly, K.A.; Advani, A. Histone deacetylase inhibition attenuates diabetes-associated kidney growth: potential role for epigenetic modification of the epidermal growth factor receptor. Kidney Int 2011, 79, 1312-1321, doi:10.1038/ki.2011.39.

85. Gilbert, R.E.; Thai, K.; Advani, S.L.; Cummins, C.L.; Kepecs, D.M.; Schroer, S.A.; Woo, M.; Zhang, Y. SIRT1 activation ameliorates hyperglycaemia by inducing a torpor-like state in an obese mouse model of type 2 diabetes. Diabetologia 2015, 58, 819-827, doi:10.1007/s00125014-3485-4.

86. Gomes, P.; Fleming Outeiro, T.; Cavadas, C. Emerging Role of Sirtuin 2 in the Regulation of Mammalian Metabolism. Trends Pharmacol Sci 2015, 36, 756-768, doi:10.1016/j.tips.2015.08.001.

87. Gomez, D.L.; O'Driscoll, M.; Sheets, T.P.; Hruban, R.H.; Oberholzer, J.; McGarrigle, J.J.; Shamblott, M.J. Neurogenin 3 Expressing Cells in the Human Exocrine Pancreas Have the Capacity for Endocrine Cell Fate. PLoS One 2015, 10, e0133862, doi:10.1371/journal.pone.0133862.

88. Gong, M.; Yu, Y.; Liang, L.; Vuralli, D.; Froehler, S.; Kuehnen, P.; Du Bois, P.; Zhang, J.; Cao, A.; Liu, Y., et al. HDAC4 mutations cause diabetes and induce beta-cell FoxO1 nuclear exclusion. Mol Genet Genomic Med 2019, 7, e602, doi:10.1002/mgg3.602.

89. Gray, S.G.; De Meyts, P. Role of histone and transcription factor acetylation in diabetes 
pathogenesis. Diabetes Metab Res Rev 2005, 21, 416-433, doi:10.1002/dmrr.559.

90. Guan, Y.; Cui, Z.J.; Sun, B.; Han, L.P.; Li, C.J.; Chen, L.M. Celastrol attenuates oxidative stress in the skeletal muscle of diabetic rats by regulating the AMPK-PGC1alpha-SIRT3 signaling pathway. Int J Mol Med 2016, 37, 1229-1238, doi:10.3892/ijmm.2016.2549.

91. Gurley, J.M.; Griesel, B.A.; Olson, A.L. Increased Skeletal Muscle GLUT4 Expression in Obese Mice After Voluntary Wheel Running Exercise Is Posttranscriptional. Diabetes 2016, 65, 2911-2919, doi:10.2337/db16-0305.

92. Guzyk M. M., T.T.M., Dyakun K. O., Yanitska L. V., Pryvrotska I. B., Kuchmerovska T. M. . Altered sirtuins 1 and 2 expression in the brain of rats induced by experimental diabetes and the ways of its correction. The Ukrainian Biochemical Journal 2019, 91, 21-29, doi:https://doi.org/10.15407/ubj91.01.021.

93. Hadden, M.J.; Advani, A. Histone Deacetylase Inhibitors and Diabetic Kidney Disease. Int J Mol Sci 2018, 19, doi:10.3390/ijms19092630.

94. Halperin-Sheinfeld, M.; Gertler, A.; Okun, E.; Sredni, B.; Cohen, H.Y. The Tellurium compound, AS101, increases SIRT1 level and activity and prevents type 2 diabetes. Aging (Albany NY) 2012, 4, 436-447, doi:10.18632/aging.100468.

95. Hammer, S.S.; Vieira, C.P.; McFarland, D.; Sandler, M.; Levitsky, Y.; Dorweiler, T.F.; Lydic, T.A.; Asare-Bediako, B.; Adu-Agyeiwaah, Y.; Sielski, M.S., et al. Fasting and fastingmimicking treatment activate SIRT1/LXRalpha and alleviate diabetes-induced systemic and microvascular dysfunction. Diabetologia 2021, 10.1007/s00125-021-05431-5, doi:10.1007/s00125-021-05431-5.

96. Hatting, M.; Tavares, C.D.J.; Sharabi, K.; Rines, A.K.; Puigserver, P. Insulin regulation of gluconeogenesis. Ann N Y Acad Sci 2018, 1411, 21-35, doi:10.1111/nyas.13435.

97. Haumaitre, C.; Lenoir, O.; Scharfmann, R. Histone deacetylase inhibitors modify pancreatic cell fate determination and amplify endocrine progenitors. Mol Cell Biol 2008, 28, 6373-6383, doi:10.1128/MCB.00413-08.

98. Haumaitre, C.; Lenoir, O.; Scharfmann, R. Directing cell differentiation with small-molecule histone deacetylase inhibitors: the example of promoting pancreatic endocrine cells. Cell Cycle 2009, 8, 536-544, doi:10.4161/cc.8.4.7610.

99. Helker, C.S.M.; Mullapudi, S.T.; Mueller, L.M.; Preussner, J.; Tunaru, S.; Skog, O.; Kwon, H.B.; Kreuder, F.; Lancman, J.J.; Bonnavion, R., et al. A whole organism small molecule screen identifies novel regulators of pancreatic endocrine development. Development 2019, 146, doi:10.1242/dev.172569.

100. Hong, Q.; Zhang, L.; Das, B.; Li, Z.; Liu, B.; Cai, G.; Chen, X.; Chuang, P.Y.; He, J.C.; Lee, K. Increased podocyte Sirtuin-1 function attenuates diabetic kidney injury. Kidney Int 2018, 93, 1330-1343, doi:10.1016/j.kint.2017.12.008.

101. Hossameldin Abdelmonem Abouhish, M.C.T., Ravirajsinh N Jadeja, Pamela M Martin, Mohamed Mhmoud Khriza, Manuela Bartoli. Activation of Histone Deacetylase 6 (HDAC6) in the diabetic retina and in retinal endothelial cells exposed to glucidic stress, promotes oxidative stress through suppression of the thioredoxin system. The FASEB Journal 2019, 33, lb337-lb337, doi: https://doi.org/10.1096/fasebj.2019.33.1_supplement.lb337.

102. Hossini, A.M.; Quast, A.S.; Plotz, M.; Grauel, K.; Exner, T.; Kuchler, J.; Stachelscheid, H.; Eberle, J.; Rabien, A.; Makrantonaki, E., et al. PI3K/AKT Signaling Pathway Is Essential for Survival of Induced Pluripotent Stem Cells. PLoS One 2016, 11, e0154770, doi:10.1371/journal.pone.0154770.

103. Hou, Q.; Hu, K.; Liu, X.; Quan, J.; Liu, Z. HADC regulates the diabetic vascular endothelial dysfunction by targetting MnSOD. Biosci Rep 2018, 38, doi:10.1042/BSR20181042.

104. Hu, J.; Jing, H.; Lin, H. Sirtuin inhibitors as anticancer agents. Future Med Chem 2014, 6, 945-966, doi:10.4155/fmc.14.44.

105. Huang, X.; Liu, G.; Guo, J.; Su, Z. The PI3K/AKT pathway in obesity and type 2 diabetes. Int J Biol Sci 2018, 14, 1483-1496, doi:10.7150/ijbs.27173.

106. Huang, X.; Sun, J.; Chen, G.; Niu, C.; Wang, Y.; Zhao, C.; Sun, J.; Huang, H.; Huang, S.; Liang, Y., et al. Resveratrol Promotes Diabetic Wound Healing via SIRT1-FOXO1-c-Myc Signaling Pathway-Mediated Angiogenesis. Front Pharmacol 2019, 10, 421, doi:10.3389/fphar.2019.00421. 
107. Huang, Z.; Zhao, J.; Deng, W.; Chen, Y.; Shang, J.; Song, K.; Zhang, L.; Wang, C.; Lu, S.; Yang, X., et al. Identification of a cellularly active SIRT6 allosteric activator. Nat Chem Biol 2018, 14, 1118-1126, doi:10.1038/s41589-018-0150-0.

108. Hull, E.E.; Montgomery, M.R.; Leyva, K.J. HDAC Inhibitors as Epigenetic Regulators of the Immune System: Impacts on Cancer Therapy and Inflammatory Diseases. Biomed Res Int 2016, 2016, 8797206, doi:10.1155/2016/8797206.

109. Iachettini, S.; Trisciuoglio, D.; Rotili, D.; Lucidi, A.; Salvati, E.; Zizza, P.; Di Leo, L.; Del Bufalo, D.; Ciriolo, M.R.; Leonetti, C., et al. Pharmacological activation of SIRT6 triggers lethal autophagy in human cancer cells. Cell Death Dis 2018, 9, 996, doi:10.1038/s41419-0181065-0.

110. Ikemoto, T.; Feng, R.; Iwahashi, S.I.; Yamada, S.; Saito, Y.; Morine, Y.; Imura, S.; Matsuhisa, M.; Shimada, M. In vitro and in vivo effects of insulin-producing cells generated by xenoantigen free 3D culture with RCP piece. Sci Rep 2019, 9, 10759, doi:10.1038/s41598-01947257-7.

111. Ikemoto, T.; Feng, R.; Shimada, M.; Saito, Y.; Iwahashi, S.; Morine, Y.; Imura, S. A New 2Step Acceleration Protocol Using a Histone Deacetylase Inhibitor to Generate InsulinProducing Cells From Adipose-Derived Mesenchymal Stem Cells. Pancreas 2018, 47, 477481, doi:10.1097/MPA.0000000000001017.

112. Jerram, S.T.; Dang, M.N.; Leslie, R.D. The Role of Epigenetics in Type 1 Diabetes. Curr Diab Rep 2017, 17, 89, doi:10.1007/s11892-017-0916-X.

113. Ji, L.; Chen, Y.; Wang, H.; Zhang, W.; He, L.; Wu, J.; Liu, Y. Overexpression of Sirt6 promotes M2 macrophage transformation, alleviating renal injury in diabetic nephropathy. Int J Oncol 2019, 55, 103-115, doi:10.3892/ijo.2019.4800.

114. Jia, G.; Hill, M.A.; Sowers, J.R. Diabetic Cardiomyopathy: An Update of Mechanisms Contributing to This Clinical Entity. Circ Res 2018, 122, 624-638, doi:10.1161/CIRCRESAHA.117.311586.

115. Jia Yin, F.X.Y. Role of Histone Acetylation in Corneal Epithelial Wound Healing and Diabetic Keratopathy. Investigative Ophthalmology \& Visual Science 2011, $52,5307$.

116. Jiang, J.; Au, M.; Lu, K.; Eshpeter, A.; Korbutt, G.; Fisk, G.; Majumdar, A.S. Generation of insulin-producing islet-like clusters from human embryonic stem cells. Stem Cells 2007, 25, 1940-1953, doi:10.1634/stemcells.2006-0761.

117. Jiang, X.; Ye, X.; Guo, W.; Lu, H.; Gao, Z. Inhibition of HDAC3 promotes ligand-independent PPARgamma activation by protein acetylation. J Mol Endocrinol 2014, 53, 191-200, doi:10.1530/JME-14-0066.

118. Jin, G.; Bausch, D.; Knightly, T.; Liu, Z.; Li, Y.; Liu, B.; Lu, J.; Chong, W.; Velmahos, G.C.; Alam, H.B. Histone deacetylase inhibitors enhance endothelial cell sprouting angiogenesis in vitro. Surgery 2011, 150, 429-435, doi:10.1016/j.surg.2011.07.001.

119. Jing, E.; Emanuelli, B.; Hirschey, M.D.; Boucher, J.; Lee, K.Y.; Lombard, D.; Verdin, E.M.; Kahn, C.R. Sirtuin-3 (Sirt3) regulates skeletal muscle metabolism and insulin signaling via altered mitochondrial oxidation and reactive oxygen species production. Proc Natl Acad Sci U S A 2011, 108, 14608-14613, doi:10.1073/pnas.1111308108.

120. Kadiyala, C.S.; Zheng, L.; Du, Y.; Yohannes, E.; Kao, H.Y.; Miyagi, M.; Kern, T.S. Acetylation of retinal histones in diabetes increases inflammatory proteins: effects of minocycline and manipulation of histone acetyltransferase (HAT) and histone deacetylase (HDAC). J Biol Chem 2012, 287, 25869-25880, doi:10.1074/jbc.M112.375204.

121. Kaiser, C.; James, S.R. Acetylation of insulin receptor substrate-1 is permissive for tyrosine phosphorylation. BMC Biol 2004, 2, 23, doi:10.1186/1741-7007-2-23.

122. Kane, A.E.; Sinclair, D.A. Sirtuins and $\mathrm{NAD}(+)$ in the Development and Treatment of Metabolic and Cardiovascular Diseases. Circ Res 2018, 123, 868-885, doi:10.1161/CIRCRESAHA.118.312498.

123. Kanwal, A., Dsouza, L.A. Sirtuins and diabetes: optimizing the sweetness in the blood. Translational Medicine Communications 2019, 4.

124. Kanwal, A.; Pillai, V.B.; Samant, S.; Gupta, M.; Gupta, M.P. The nuclear and mitochondrial sirtuins, Sirt6 and Sirt3, regulate each other's activity and protect the heart from developing obesity-mediated diabetic cardiomyopathy. FASEB J 2019, 33, 10872-10888, 
doi:10.1096/fj.201900767R.

125. Karbasforooshan, H.; Karimi, G. The role of SIRT1 in diabetic retinopathy. Biomed Pharmacother 2018, 97, 190-194, doi:10.1016/j.biopha.2017.10.075.

126. Karpac, J.; Jasper, H. Metabolic homeostasis: HDACs take center stage. Cell 2011, 145, 497499, doi:10.1016/j.cell.2011.04.017.

127. Kawada, Y.; Asahara, S.I.; Sugiura, Y.; Sato, A.; Furubayashi, A.; Kawamura, M.; Bartolome, A.; Terashi-Suzuki, E.; Takai, T.; Kanno, A., et al. Histone deacetylase regulates insulin signaling via two pathways in pancreatic beta cells. PLoS One 2017, 12, e0184435, doi:10.1371/journal.pone.0184435.

128. Kee, H.J.; Ryu, Y.; Seok, Y.M.; Choi, S.Y.; Sun, S.; Kim, G.R.; Jeong, M.H. Selective inhibition of histone deacetylase 8 improves vascular hypertrophy, relaxation, and inflammation in angiotensin II hypertensive mice. Clin Hypertens 2019, 25, 13, doi:10.1186/s40885-019-0118-8.

129. Keshava, R., Gope, R. Sodium butyrate plus EGF and PDGF-BB aids cutaneous wound healing in diabetic mice. Advances in Biology 2015.

130. Khan, S.; Jena, G. Sodium butyrate, a HDAC inhibitor ameliorates eNOS, iNOS and TGFbeta1-induced fibrogenesis, apoptosis and DNA damage in the kidney of juvenile diabetic rats. Food Chem Toxicol 2014, 73, 127-139, doi:10.1016/j.fct.2014.08.010.

131. Khan, S.; Jena, G. Valproic Acid Improves Glucose Homeostasis by Increasing Beta-Cell Proliferation, Function, and Reducing its Apoptosis through HDAC Inhibition in Juvenile Diabetic Rat. J Biochem Mol Toxicol 2016, 30, 438-446, doi:10.1002/jbt.21807.

132. Khan, S.; Jena, G.; Tikoo, K. Sodium valproate ameliorates diabetes-induced fibrosis and renal damage by the inhibition of histone deacetylases in diabetic rat. Exp Mol Pathol 2015, 98, 230-239, doi:10.1016/j.yexmp.2015.01.003.

133. Khan, S.; Komarya, S.K.; Jena, G. Phenylbutyrate and beta-cell function: contribution of histone deacetylases and ER stress inhibition. Epigenomics 2017, 9, 711-720, doi:10.2217/epi2016-0160.

134. Khanra, R.; Dewanjee, S.; T, K.D.; Sahu, R.; Gangopadhyay, M.; De Feo, V.; Zia-Ul-Haq, M. Abroma augusta L. (Malvaceae) leaf extract attenuates diabetes induced nephropathy and cardiomyopathy via inhibition of oxidative stress and inflammatory response. J Transl Med 2015, 13, 6, doi:10.1186/s12967-014-0364-1.

135. Khullar, M.; Cheema, B.S.; Raut, S.K. Emerging Evidence of Epigenetic Modifications in Vascular Complication of Diabetes. Front Endocrinol (Lausanne) 2017, 8, 237, doi:10.3389/fendo.2017.00237.

136. Kim, J.H.; Lee, J.M.; Kim, J.H.; Kim, K.R. Fluvastatin activates sirtuin 6 to regulate sterol regulatory element-binding proteins and AMP-activated protein kinase in HepG2 cells. Biochem Biophys Res Commun 2018, 503, 1415-1421, doi:10.1016/j.bbrc.2018.07.057.

137. Kim, M.J.; An, H.J.; Kim, D.H.; Lee, B.; Lee, H.J.; Ullah, S.; Kim, S.J.; Jeong, H.O.; Moon, K.M.; Lee, E.K., et al. Novel SIRT1 activator MHY2233 improves glucose tolerance and reduces hepatic lipid accumulation in db/db mice. Bioorg Med Chem Lett 2018, 28, 684-688, doi:10.1016/j.bmcl.2018.01.021.

138. Kimura, K.; Yamada, T.; Matsumoto, M.; Kido, Y.; Hosooka, T.; Asahara, S.; Matsuda, T.; Ota, T.; Watanabe, H.; Sai, Y., et al. Endoplasmic reticulum stress inhibits STAT3-dependent suppression of hepatic gluconeogenesis via dephosphorylation and deacetylation. Diabetes 2012, 61, 61-73, doi:10.2337/db10-1684.

139. Kitada, M.; Ogura, Y.; Monno, I.; Koya, D. Sirtuins and Type 2 Diabetes: Role in Inflammation, Oxidative Stress, and Mitochondrial Function. Front Endocrinol (Lausanne) 2019, 10, 187, doi:10.3389/fendo.2019.00187.

140. Kolluru, G.K.; Bir, S.C.; Kevil, C.G. Endothelial dysfunction and diabetes: effects on angiogenesis, vascular remodeling, and wound healing. Int J Vasc Med 2012, 2012, 918267, doi:10.1155/2012/918267.

141. Kong, Y.; Sharma, R.B.; Nwosu, B.U.; Alonso, L.C. Islet biology, the CDKN2A/B locus and type 2 diabetes risk. Diabetologia 2016, 59, 1579-1593, doi:10.1007/s00125-016-3967-7.

142. Kowluru, R.A.; Santos, J.M.; Zhong, Q. Sirt1, a negative regulator of matrix metalloproteinase-9 in diabetic retinopathy. Invest Ophthalmol Vis Sci 2014, 55, 5653-5660, 
doi:10.1167/iovs.14-14383.

143. Kronlage, M.; Dewenter, M.; Grosso, J.; Fleming, T.; Oehl, U.; Lehmann, L.H.; Falcao-Pires, I.; Leite-Moreira, A.F.; Volk, N.; Grone, H.J., et al. O-GlcNAcylation of Histone Deacetylase 4 Protects the Diabetic Heart From Failure. Circulation 2019, 140, 580-594, doi:10.1161/CIRCULATIONAHA.117.031942.

144. Kuang, J.; Chen, L.; Tang, Q.; Zhang, J.; Li, Y.; He, J. The Role of Sirt6 in Obesity and Diabetes. Front Physiol 2018, 9, 135, doi:10.3389/fphys.2018.00135.

145. Kumar, A.; Negi, G.; Sharma, S.S. Neuroprotection by resveratrol in diabetic neuropathy: concepts \& mechanisms. Curr Med Chem 2013, 20, 4640-4645, doi:10.2174/09298673113209990151.

146. Kumar, S.; Kim, Y.R.; Vikram, A.; Naqvi, A.; Li, Q.; Kassan, M.; Kumar, V.; Bachschmid, M.M.; Jacobs, J.S.; Kumar, A., et al. Sirtuin1-regulated lysine acetylation of p66Shc governs diabetes-induced vascular oxidative stress and endothelial dysfunction. Proc Natl Acad Sci U S A 2017, 114, 1714-1719, doi:10.1073/pnas.1614112114.

147. Kumar, S.; Lombard, D.B. Functions of the sirtuin deacylase SIRT5 in normal physiology and pathobiology. Crit Rev Biochem Mol Biol 2018, 53, 311-334, doi:10.1080/10409238.2018.1458071.

148. Kutil, Z.; Mikesova, J.; Zessin, M.; Meleshin, M.; Novakova, Z.; Alquicer, G.; Kozikowski, A.; Sippl, W.; Barinka, C.; Schutkowski, M. Continuous Activity Assay for HDAC11 Enabling Reevaluation of HDAC Inhibitors. ACS Omega 2019, 4, 19895-19904, doi:10.1021/acsomega.9b02808.

149. Lantier, L.; Williams, A.S.; Hughey, C.C.; Bracy, D.P.; James, F.D.; Ansari, M.A.; Gius, D.; Wasserman, D.H. SIRT2 knockout exacerbates insulin resistance in high fat-fed mice. PLoS One 2018, 13, e0208634, doi:10.1371/journal.pone.0208634.

150. Larsen, L.; Tonnesen, M.; Ronn, S.G.; Storling, J.; Jorgensen, S.; Mascagni, P.; Dinarello, C.A.; Billestrup, N.; Mandrup-Poulsen, T. Inhibition of histone deacetylases prevents cytokine-induced toxicity in beta cells. Diabetologia 2007, 50, 779-789, doi:10.1007/s00125006-0562-3.

151. Lawlor, L.; Yang, X.B. Harnessing the HDAC-histone deacetylase enzymes, inhibitors and how these can be utilised in tissue engineering. Int J Oral Sci 2019, 11, 20, doi:10.1038/s41368-019-0053-2.

152. Lee, H.A.; Kang, S.H.; Kim, M.; Lee, E.; Cho, H.M.; Moon, E.K.; Kim, I. Histone deacetylase inhibition ameliorates hypertension and hyperglycemia in a model of Cushing's syndrome. Am J Physiol Endocrinol Metab 2018, 314, E39-E52, doi:10.1152/ajpendo.00267.2017.

153. Lee, H.A.; Lee, E.; Do, G.Y.; Moon, E.K.; Quan, F.S.; Kim, I. Histone deacetylase inhibitor MGCD0103 protects the pancreas from streptozotocin-induced oxidative stress and beta-cell death. Biomed Pharmacother 2019, 109, 921-929, doi:10.1016/j.biopha.2018.10.163.

154. Lee, J.H.; Song, M.Y.; Song, E.K.; Kim, E.K.; Moon, W.S.; Han, M.K.; Park, J.W.; Kwon, K.B.; Park, B.H. Overexpression of SIRT1 protects pancreatic beta-cells against cytokine toxicity by suppressing the nuclear factor-kappaB signaling pathway. Diabetes $2009,58,344-$ 351, doi:10.2337/db07-1795.

155. Lee, T.I.; Bai, K.J.; Chen, Y.C.; Lee, T.W.; Chung, C.C.; Tsai, W.C.; Tsao, S.Y.; Kao, Y.H. Histone deacetylase inhibition of cardiac autophagy in rats on a highfat diet with lowdose streptozotocin-induced type 2 diabetes mellitus. Mol Med Rep 2018, 17, 594-601, doi:10.3892/mmr.2017.7905.

156. Lee, T.I.; Kao, Y.H.; Tsai, W.C.; Chung, C.C.; Chen, Y.C.; Chen, Y.J. HDAC Inhibition Modulates Cardiac PPARs and Fatty Acid Metabolism in Diabetic Cardiomyopathy. PPAR Res 2016, 2016, 5938740, doi:10.1155/2016/5938740.

157. Leng, Y.; Wu, Y.; Lei, S.; Zhou, B.; Qiu, Z.; Wang, K.; Xia, Z. Inhibition of HDAC6 Activity Alleviates Myocardial Ischemia/Reperfusion Injury in Diabetic Rats: Potential Role of Peroxiredoxin 1 Acetylation and Redox Regulation. Oxid Med Cell Longev 2018, 2018, 9494052, doi:10.1155/2018/9494052.

158. Lenoir, O.; Flosseau, K.; Ma, F.X.; Blondeau, B.; Mai, A.; Bassel-Duby, R.; Ravassard, P.; Olson, E.N.; Haumaitre, C.; Scharfmann, R. Specific control of pancreatic endocrine beta- and delta-cell mass by class IIa histone deacetylases HDAC4, HDAC5, and HDAC9. Diabetes 
2011, 60, 2861-2871, doi:10.2337/db11-0440.

159. Lewien, P., Levi, M., Wang, X., Myakala, K., Wang, D., Luo, Y. 340 Nad+-dependent deacetylase sirt3 activation inhibits diabetic kidney disease. Journal of Investigative Medicine. 2018, 66.

160. Lewis, E.C.; Blaabjerg, L.; Storling, J.; Ronn, S.G.; Mascagni, P.; Dinarello, C.A.; MandrupPoulsen, T. The oral histone deacetylase inhibitor ITF2357 reduces cytokines and protects islet beta cells in vivo and in vitro. Mol Med 2011, 17, 369-377, doi:10.2119/molmed.2010.00152.

161. Li, A.; Liu, Q.; Li, Q.; Liu, B.; Yang, Y.; Zhang, N. Berberine Reduces Pyruvate-driven Hepatic Glucose Production by Limiting Mitochondrial Import of Pyruvate through Mitochondrial Pyruvate Carrier 1. EBioMedicine 2018, 34, 243-255, doi:10.1016/j.ebiom.2018.07.039.

162. Li, G.E., Kim, H.-H. 201-LB: The Neuronal Sirt1 Regulate the Metabolic Imbalance in Ischemic Stroke. Diabetes 2019, 68.

163. Li, H.Y.; Wang, X.C.; Xu, Y.M.; Luo, N.C.; Luo, S.; Hao, X.Y.; Cheng, S.Y.; Fang, J.S.; Wang, Q.; Zhang, S.J., et al. Berberine Improves Diabetic Encephalopathy Through the SIRT1/ER Stress Pathway in db/db Mice. Rejuvenation Res 2018, 21, 200-209, doi:10.1089/rej.2017.1972.

164. Li, J.; Yu, S.; Ying, J.; Shi, T.; Wang, P. Resveratrol Prevents ROS-Induced Apoptosis in High Glucose-Treated Retinal Capillary Endothelial Cells via the Activation of AMPK/Sirt1/PGC1alpha Pathway. Oxid Med Cell Longev 2017, 2017, 7584691, doi:10.1155/2017/7584691.

165. Li, P.; Zhang, L.; Zhou, C.; Lin, N.; Liu, A. Sirt 1 activator inhibits the AGE-induced apoptosis and p53 acetylation in human vascular endothelial cells. J Toxicol Sci 2015, 40, 615-624, doi:10.2131/jts.40.615.

166. Li, S.; Fossati, G.; Marchetti, C.; Modena, D.; Pozzi, P.; Reznikov, L.L.; Moras, M.L.; Azam, T.; Abbate, A.; Mascagni, P., et al. Specific inhibition of histone deacetylase 8 reduces gene expression and production of proinflammatory cytokines in vitro and in vivo. $\mathrm{J}$ Biol Chem 2015, 290, 2368-2378, doi:10.1074/jbc.M114.618454.

167. Li, S.; Zheng, W. Mammalian Sirtuins SIRT4 and SIRT7. Prog Mol Biol Transl Sci 2018, 154, 147-168, doi:10.1016/bs.pmbts.2017.11.001.

168. Li, X.; Wu, G.; Han, F.; Wang, K.; Bai, X.; Jia, Y.; Li, Z.; Cai, W.; Zhang, W.; Su, L., et al. SIRT1 activation promotes angiogenesis in diabetic wounds by protecting endothelial cells against oxidative stress. Arch Biochem Biophys 2019, 661, 117-124, doi:10.1016/j.abb.2018.11.016.

169. Li, Y.; Ni, J.; Guo, R.; Li, W. In Patients with Coronary Artery Disease and Type 2 Diabetes, SIRT1 Expression in Circulating Mononuclear Cells Is Associated with Levels of Inflammatory Cytokines but Not with Coronary Lesions. Biomed Res Int 2016, 2016, 8734827, doi:10.1155/2016/8734827.

170. Lin, J.B.; Lin, J.B.; Chen, H.C.; Chen, T.; Apte, R.S. Combined SIRT3 and SIRT5 deletion is associated with inner retinal dysfunction in a mouse model of type 1 diabetes. Sci Rep 2019, 9, 3799, doi:10.1038/s41598-019-40177-6.

171. Ling, C.; Ronn, T. Epigenetics in Human Obesity and Type 2 Diabetes. Cell Metab 2019, 29, 1028-1044, doi:10.1016/j.cmet.2019.03.009.

172. Liu, F.; Zong, M.; Wen, X.; Li, X.; Wang, J.; Wang, Y.; Jiang, W.; Li, X.; Guo, Z.; Qi, H. Silencing of Histone Deacetylase 9 Expression in Podocytes Attenuates Kidney Injury in Diabetic Nephropathy. Sci Rep 2016, 6, 33676, doi:10.1038/srep33676.

173. Liu, L.; Patel, P.; Steinle, J.J. PKA regulates HMGB1 through activation of IGFBP-3 and SIRT1 in human retinal endothelial cells cultured in high glucose. Inflamm Res 2018, 67, 1013-1019, doi:10.1007/s00011-018-1196-x.

174. Liu, R.; Liu, H.; Ha, Y.; Tilton, R.G.; Zhang, W. Oxidative stress induces endothelial cell senescence via downregulation of Sirt6. Biomed Res Int 2014, 2014, 902842, doi:10.1155/2014/902842.

175. Liu, T.; Yang, W.; Pang, S.; Yu, S.; Yan, B. Functional genetic variants within the SIRT2 gene promoter in type 2 diabetes mellitus. Diabetes Res Clin Pract 2018, 137, 200-207, doi:10.1016/j.diabres.2018.01.012.

176. Liu, Z.; Wang, J.; Huang, X.; Li, Z.; Liu, P. Deletion of sirtuin 6 accelerates endothelial 
dysfunction and atherosclerosis in apolipoprotein E-deficient mice. Transl Res 2016, 172, 1829 e12, doi:10.1016/j.trsl.2016.02.005.

177. Lorenzo, P.I.; Juarez-Vicente, F.; Cobo-Vuilleumier, N.; Garcia-Dominguez, M.; Gauthier, B.R. The Diabetes-Linked Transcription Factor PAX4: From Gene to Functional Consequences. Genes (Basel) 2017, 8, doi:10.3390/genes8030101.

178. Lu, J.; Zhang, H.; Chen, X.; Zou, Y.; Li, J.; Wang, L.; Wu, M.; Zang, J.; Yu, Y.; Zhuang, W., et al. A small molecule activator of SIRT3 promotes deacetylation and activation of manganese superoxide dismutase. Free Radic Biol Med 2017, 112, 287-297, doi:10.1016/j.freeradbiomed.2017.07.012.

179. Lucas, T.; Schafer, F.; Muller, P.; Eming, S.A.; Heckel, A.; Dimmeler, S. Light-inducible antimiR-92a as a therapeutic strategy to promote skin repair in healing-impaired diabetic mice. Nat Commun 2017, 8, 15162, doi:10.1038/ncomms15162.

180. Lundh, M.; Christensen, D.P.; Damgaard Nielsen, M.; Richardson, S.J.; Dahllof, M.S.; Skovgaard, T.; Berthelsen, J.; Dinarello, C.A.; Stevenazzi, A.; Mascagni, P., et al. Histone deacetylases 1 and 3 but not 2 mediate cytokine-induced beta cell apoptosis in INS-1 cells and dispersed primary islets from rats and are differentially regulated in the islets of type 1 diabetic children. Diabetologia 2012, 55, 2421-2431, doi:10.1007/s00125-012-2615-0.

181. Lundh, M.; Christensen, D.P.; Rasmussen, D.N.; Mascagni, P.; Dinarello, C.A.; Billestrup, N.; Grunnet, L.G.; Mandrup-Poulsen, T. Lysine deacetylases are produced in pancreatic beta cells and are differentially regulated by proinflammatory cytokines. Diabetologia 2010, 53, 2569-2578, doi:10.1007/s00125-010-1892-8.

182. Ma, B., Zhu, Z., Zhang, J., Ren, C., Zhang, Q. Aucubin alleviates diabetic nephropathy by inhibiting NF- $\kappa$ B activation and inducing SIRT1/SIRT3-FOXO3a signaling pathway in highfat diet/streptozotocin-induced diabetic mice. Journal of Functional Foods 2020, 64, 103702.

183. Ma, S.; Feng, J.; Zhang, R.; Chen, J.; Han, D.; Li, X.; Yang, B.; Li, X.; Fan, M.; Li, C., et al. SIRT1 Activation by Resveratrol Alleviates Cardiac Dysfunction via Mitochondrial Regulation in Diabetic Cardiomyopathy Mice. Oxid Med Cell Longev 2017, 2017, 4602715, doi:10.1155/2017/4602715.

184. Ma, Y.; Fei, X. SIRT5 regulates pancreatic beta-cell proliferation and insulin secretion in type 2 diabetes. Exp Ther Med 2018, 16, 1417-1425, doi:10.3892/etm.2018.6301.

185. Maghbooli, Z.; Emamgholipour, S.; Aliakbar, S.; Amini, M.; Gorgani-Firuzjaee, S.; HosseinNezhad, A. Differential expressions of SIRT1, SIRT3, and SIRT4 in peripheral blood mononuclear cells from patients with type 2 diabetic retinopathy. Arch Physiol Biochem 2020, 126, 363-368, doi:10.1080/13813455.2018.1543328.

186. Magnifico, S.; Saias, L.; Deleglise, B.; Duplus, E.; Kilinc, D.; Miquel, M.C.; Viovy, J.L.; Brugg, B.; Peyrin, J.M. NAD+ acts on mitochondrial SirT3 to prevent axonal caspase activation and axonal degeneration. FASEB J 2013, 27, 4712-4722, doi:10.1096/fj.13-229781.

187. Makinistoglu, M.P.; Karsenty, G. The class II histone deacetylase HDAC4 regulates cognitive, metabolic and endocrine functions through its expression in osteoblasts. Mol Metab 2015, 4, 64-69, doi:10.1016/j.molmet.2014.10.004.

188. Malhotra, P., Muthusamy, S., Gavin, D.P., Luo, A.Y., Saksena, S., Gill, R.K., Dudeja, P.K., Alrefai, W.A. Mo1760 Histone Deacetylase Inhibition Decreases the Expression of Intestinal Cholesterol Transporter Niemann Pick-C1-Like 1 (NPC1L1). Gastroenterology 2014, 146, S$653,$.

189. Manea, S.A.; Antonescu, M.L.; Fenyo, I.M.; Raicu, M.; Simionescu, M.; Manea, A. Epigenetic regulation of vascular NADPH oxidase expression and reactive oxygen species production by histone deacetylase-dependent mechanisms in experimental diabetes. Redox Biol 2018, 16, 332-343, doi:10.1016/j.redox.2018.03.011.

190. Manea, S.A.; Vlad, M.L.; Fenyo, I.M.; Lazar, A.G.; Raicu, M.; Muresian, H.; Simionescu, M.; Manea, A. Pharmacological inhibition of histone deacetylase reduces NADPH oxidase expression, oxidative stress and the progression of atherosclerotic lesions in hypercholesterolemic apolipoprotein E-deficient mice; potential implications for human atherosclerosis. Redox Biol 2020, 28, 101338, doi:10.1016/j.redox.2019.101338.

191. McCann, J.; Ellis, M.; McGee, S.L.; Aston-Mourney, K. Class IIa HDACs do not influence beta-cell function under normal or high glucose conditions. Islets 2019, 11, 112-118, 
doi:10.1080/19382014.2019.1617621.

192. Mei, Z.; Zhang, X.; Yi, J.; Huang, J.; He, J.; Tao, Y. Sirtuins in metabolism, DNA repair and cancer. J Exp Clin Cancer Res 2016, 35, 182, doi:10.1186/s13046-016-0461-5.

193. Mihaylova, M.M.; Vasquez, D.S.; Ravnskjaer, K.; Denechaud, P.D.; Yu, R.T.; Alvarez, J.G.; Downes, M.; Evans, R.M.; Montminy, M.; Shaw, R.J. Class IIa histone deacetylases are hormone-activated regulators of FOXO and mammalian glucose homeostasis. Cell 2011, 145, 607-621, doi:10.1016/j.cell.2011.03.043.

194. Milne, J.C.; Lambert, P.D.; Schenk, S.; Carney, D.P.; Smith, J.J.; Gagne, D.J.; Jin, L.; Boss, O.; Perni, R.B.; Vu, C.B., et al. Small molecule activators of SIRT1 as therapeutics for the treatment of type 2 diabetes. Nature 2007, 450, 712-716, doi:10.1038/nature06261.

195. Mohamed, W.A.; Schaalan, M.F. Antidiabetic efficacy of lactoferrin in type 2 diabetic pediatrics; controlling impact on PPAR-gamma, SIRT-1, and TLR4 downstream signaling pathway. Diabetol Metab Syndr 2018, 10, 89, doi:10.1186/s13098-018-0390-x.

196. Mortuza, R.; Chen, S.; Feng, B.; Sen, S.; Chakrabarti, S. High glucose induced alteration of SIRTs in endothelial cells causes rapid aging in a p300 and FOXO regulated pathway. PLoS One 2013, 8, e54514, doi:10.1371/journal.pone.0054514.

197. Mortuza, R.; Feng, B.; Chakrabarti, S. SIRT1 reduction causes renal and retinal injury in diabetes through endothelin 1 and transforming growth factor beta1. J Cell Mol Med 2015, 19, 1857-1867, doi:10.1111/jcmm.12557.

198. Mosley, A.L.; Ozcan, S. The pancreatic duodenal homeobox-1 protein (Pdx-1) interacts with histone deacetylases Hdac-1 and Hdac-2 on low levels of glucose. J Biol Chem 2004, 279, 54241-54247, doi:10.1074/jbc.M410379200.

199. Mottamal, M.; Zheng, S.; Huang, T.L.; Wang, G. Histone deacetylase inhibitors in clinical studies as templates for new anticancer agents. Molecules 2015, 20, 3898-3941, doi:10.3390/molecules20033898.

200. Nawaz, A.; Mehmood, A.; Kanatani, Y.; Kado, T.; Igarashi, Y.; Takikawa, A.; Yamamoto, S.; Okabe, K.; Nakagawa, T.; Yagi, K., et al. Sirt1 activator induces proangiogenic genes in preadipocytes to rescue insulin resistance in diet-induced obese mice. Sci Rep 2018, 8, 11370, doi:10.1038/s41598-018-29773-0.

201. Noh, H.; Oh, E.Y.; Seo, J.Y.; Yu, M.R.; Kim, Y.O.; Ha, H.; Lee, H.B. Histone deacetylase-2 is a key regulator of diabetes- and transforming growth factor-beta1-induced renal injury. Am J Physiol Renal Physiol 2009, 297, F729-739, doi:10.1152/ajprenal.00086.2009.

202. Oh, Y.S.; Seo, E.; Park, K.; Jun, H.S. Compound 19e, a Novel Glucokinase Activator, Protects against Cytokine-Induced Beta-Cell Apoptosis in INS-1 Cells. Front Pharmacol 2017, 8, 169, doi:10.3389/fphar.2017.00169.

203. Olga Golonzhka, M.B.J. HDAC inhibitors for the treatment of diabetic peripheral neuropathy. US10040769B2, 2018.

204. Olson, A.L. Regulation of GLUT4 and Insulin-Dependent Glucose Flux. ISRN Mol Biol 2012, 2012, 856987, doi:10.5402/2012/856987.

205. Orimo, M.; Minamino, T.; Miyauchi, H.; Tateno, K.; Okada, S.; Moriya, J.; Komuro, I. Protective role of SIRT1 in diabetic vascular dysfunction. Arterioscler Thromb Vasc Biol 2009, 29, 889-894, doi:10.1161/ATVBAHA.109.185694.

206. Ormazabal, V.; Nair, S.; Elfeky, O.; Aguayo, C.; Salomon, C.; Zuniga, F.A. Association between insulin resistance and the development of cardiovascular disease. Cardiovasc Diabetol 2018, 17, 122, doi:10.1186/s12933-018-0762-4.

207. Pacifici, F.; Di Cola, D.; Pastore, D.; Abete, P.; Guadagni, F.; Donadel, G.; Bellia, A.; Esposito, E.; Salimei, C.; Sinibaldi Salimei, P., et al. Proposed Tandem Effect of Physical Activity and Sirtuin 1 and 3 Activation in Regulating Glucose Homeostasis. Int J Mol Sci 2019, 20, doi:10.3390/ijms20194748.

208. Parenti, M.D.; Grozio, A.; Bauer, I.; Galeno, L.; Damonte, P.; Millo, E.; Sociali, G.; Franceschi, C.; Ballestrero, A.; Bruzzone, S., et al. Discovery of novel and selective SIRT6 inhibitors. J Med Chem 2014, 57, 4796-4804, doi:10.1021/jm500487d.

209. Park, J.H.; Stoffers, D.A.; Nicholls, R.D.; Simmons, R.A. Development of type 2 diabetes following intrauterine growth retardation in rats is associated with progressive epigenetic silencing of Pdx1. J Clin Invest 2008, 118, 2316-2324, doi:10.1172/JCI33655. 
210. Park, S.J.; Ahmad, F.; Um, J.H.; Brown, A.L.; Xu, X.; Kang, H.; Ke, H.; Feng, X.; Ryall, J.; Philp, A., et al. Specific Sirt1 Activator-mediated Improvement in Glucose Homeostasis Requires Sirt1-Independent Activation of AMPK. EBioMedicine 2017, 18, 128-138, doi:10.1016/j.ebiom.2017.03.019.

211. Park, S.Y.; Kim, G.S.; Hwang, H.J.; Nam, T.H.; Park, H.S.; Song, J.; Jang, T.H.; Lee, Y.C.; Kim, J.S. Structural basis of the specific interaction of SMRT corepressor with histone deacetylase 4. Nucleic Acids Res 2018, 46, 11776-11788, doi:10.1093/nar/gky926.

212. Parra, M. Class IIa HDACs - new insights into their functions in physiology and pathology. FEBS J 2015, 282, 1736-1744, doi:10.1111/febs.13061.

213. Peng, Y.; Zhang, G.; Tang, H.; Dong, L.; Gao, C.; Yang, X.; Peng, Y.; Xu, Y. Influence of SIRT1 polymorphisms for diabetic foot susceptibility and severity. Medicine (Baltimore) 2018, 97, e11455, doi:10.1097/MD.0000000000011455.

214. Pillai, V.B.; Kanwal, A.; Fang, Y.H.; Sharp, W.W.; Samant, S.; Arbiser, J.; Gupta, M.P. Honokiol, an activator of Sirtuin-3 (SIRT3) preserves mitochondria and protects the heart from doxorubicin-induced cardiomyopathy in mice. Oncotarget 2017, 8, 34082-34098, doi:10.18632/oncotarget.16133.

215. Pinho, A.V.; Bensellam, M.; Wauters, E.; Rees, M.; Giry-Laterriere, M.; Mawson, A.; Ly le, Q.; Biankin, A.V.; Wu, J.; Laybutt, D.R., et al. Pancreas-Specific Sirt1-Deficiency in Mice Compromises Beta-Cell Function without Development of Hyperglycemia. PLoS One 2015, 10, e0128012, doi:10.1371/journal.pone.0128012.

216. Pinney, S.E.; Simmons, R.A. Epigenetic mechanisms in the development of type 2 diabetes. Trends Endocrinol Metab 2010, 21, 223-229, doi:10.1016/j.tem.2009.10.002.

217. Plaisance, V.; Rolland, L.; Gmyr, V.; Annicotte, J.S.; Kerr-Conte, J.; Pattou, F.; Abderrahmani, A. The class I histone deacetylase inhibitor MS-275 prevents pancreatic beta cell death induced by palmitate. J Diabetes Res 2014, 2014, 195739, doi:10.1155/2014/195739.

218. Prud'homme, G.J. Treatment of human pancreatic beta cells with a combination of gammaaminobutyric acid (GABA) and GLP-1 ameliorates cell survival and proliferation. . Journal of Diabetes \& Metabolism 2017, 8, doi:10.4172/2155-6156-C1-065.

219. Qin, K.; Zhang, N.; Zhang, Z.; Nipper, M.; Zhu, Z.; Leighton, J.; Xu, K.; Musi, N.; Wang, P. SIRT6-mediated transcriptional suppression of Txnip is critical for pancreatic beta cell function and survival in mice. Diabetologia 2018, 61, 906-918, doi:10.1007/s00125-0174542-6.

220. Qin, R.; Zhang, L.; Lin, D.; Xiao, F.; Guo, L. Sirt1 inhibits HG-induced endothelial injury: Role of Mff-based mitochondrial fission and Factin homeostasis-mediated cellular migration. Int J Mol Med 2019, 44, 89-102, doi:10.3892/ijmm.2019.4185.

221. Rabadiya, S.; Bhadada, S.; Dudhrejiya, A.; Vaishnav, D.; Patel, B. Magnesium valproate ameliorates type 1 diabetes and cardiomyopathy in diabetic rats through estrogen receptors. Biomed Pharmacother 2018, 97, 919-927, doi:10.1016/j.biopha.2017.10.137.

222. Rahnasto-Rilla, M.; Tyni, J.; Huovinen, M.; Jarho, E.; Kulikowicz, T.; Ravichandran, S.; V, A.B.; Ferrucci, L.; Lahtela-Kakkonen, M.; Moaddel, R. Natural polyphenols as sirtuin 6 modulators. Sci Rep 2018, 8, 4163, doi:10.1038/s41598-018-22388-5.

223. Raichur, S.; Teh, S.H.; Ohwaki, K.; Gaur, V.; Long, Y.C.; Hargreaves, M.; McGee, S.L.; Kusunoki, J. Histone deacetylase 5 regulates glucose uptake and insulin action in muscle cells. J Mol Endocrinol 2012, 49, 203-211, doi:10.1530/JME-12-0095.

224. Ramakrishnan, G.; Davaakhuu, G.; Kaplun, L.; Chung, W.C.; Rana, A.; Atfi, A.; Miele, L.; Tzivion, G. Sirt2 deacetylase is a novel AKT binding partner critical for AKT activation by insulin. J Biol Chem 2014, 289, 6054-6066, doi:10.1074/jbc.M113.537266.

225. Ramesh, S.; Govindarajulu, M.; Lynd, T.; Briggs, G.; Adamek, D.; Jones, E.; Heiner, J.; Majrashi, M.; Moore, T.; Amin, R., et al. SIRT3 activator Honokiol attenuates beta-Amyloid by modulating amyloidogenic pathway. PLoS One 2018, 13, e0190350, doi:10.1371/journal.pone.0190350.

226. Raychaudhuri, N.; Raychaudhuri, S.; Thamotharan, M.; Devaskar, S.U. Histone code modifications repress glucose transporter 4 expression in the intrauterine growth-restricted offspring. J Biol Chem 2008, 283, 13611-13626, doi:10.1074/jbc.M800128200. 
227. Rehan, M.K. Epigenetics and diabetes mellitus. The Egyptian Journal of Internal Medicine 2016, 28, 39-51, doi:10.4103/1110-7782.193890.

228. Remsberg, J.R.; Ediger, B.N.; Ho, W.Y.; Damle, M.; Li, Z.; Teng, C.; Lanzillotta, C.; Stoffers, D.A.; Lazar, M.A. Deletion of histone deacetylase 3 in adult beta cells improves glucose tolerance via increased insulin secretion. Mol Metab 2017, 6, 30-37, doi:10.1016/j.molmet.2016.11.007.

229. Rivera-Mancía, S., Trujillo, J., Chaverri, J.P. Utility of curcumin for the treatment of diabetes mellitus: evidence from preclinical and clinical studies. Journal of Nutrition \& Intermediary Metabolism 2018, 14, 29-41.

230. Rizk, S.M.; El-Maraghy, S.A.; Nassar, N.N. A novel role for SIRT-1 in L-arginine protection against STZ induced myocardial fibrosis in rats. PLoS One 2014, 9, e114560, doi:10.1371/journal.pone.0114560.

231. Roder, P.V.; Wu, B.; Liu, Y.; Han, W. Pancreatic regulation of glucose homeostasis. Exp Mol Med 2016, 48, e219, doi:10.1038/emm.2016.6.

232. Sadhukhan, S.; Liu, X.; Ryu, D.; Nelson, O.D.; Stupinski, J.A.; Li, Z.; Chen, W.; Zhang, S.; Weiss, R.S.; Locasale, J.W., et al. Metabolomics-assisted proteomics identifies succinylation and SIRT5 as important regulators of cardiac function. Proc Natl Acad Sci U S A 2016, 113, 4320-4325, doi:10.1073/pnas.1519858113.

233. Salas, E.; Rabhi, N.; Froguel, P.; Annicotte, J.S. Role of Ink4a/Arf locus in beta cell mass expansion under physiological and pathological conditions. J Diabetes Res 2014, 2014, 873679, doi:10.1155/2014/873679.

234. Sampley, M.L.; Ozcan, S. Regulation of insulin gene transcription by multiple histone acetyltransferases. DNA Cell Biol 2012, 31, 8-14, doi:10.1089/dna.2011.1336.

235. Sanchez, R.; Meslamani, J.; Zhou, M.M. The bromodomain: from epigenome reader to druggable target. Biochim Biophys Acta 2014, 1839, 676-685, doi:10.1016/j.bbagrm.2014.03.011.

236. Sathishkumar, C.; Prabu, P.; Balakumar, M.; Lenin, R.; Prabhu, D.; Anjana, R.M.; Mohan, V.; Balasubramanyam, M. Augmentation of histone deacetylase 3 (HDAC3) epigenetic signature at the interface of proinflammation and insulin resistance in patients with type 2 diabetes. Clin Epigenetics 2016, 8, 125, doi:10.1186/s13148-016-0293-3.

237. Schartner, E., Saleh, A., Da Silva, R.V., Chowdhury, S.R., Smith, D., Fernyhough, P. SIRT2 is Required for Axon Regeneration in Adult Sensory Neurons and High Glucose Concentration Reduces its Expression in Diabetic Neuropathy. Canadian Journal of Diabetes 2014, 38, S62.

238. Schartner, E.; Sabbir, M.G.; Saleh, A.; Silva, R.V.; Roy Chowdhury, S.; Smith, D.R.; Fernyhough, P. High glucose concentration suppresses a SIRT2 regulated pathway that enhances neurite outgrowth in cultured adult sensory neurons. Exp Neurol 2018, 309, 134147, doi:10.1016/j.expneurol.2018.08.001.

239. Schütz, L.F., Park, M. H., Choudhury, M. HDACs in diabetes: a new era of epigenetic drug. Nutritional and Therapeutic Interventions for Diabetes and Metabolic Syndrome 2018, 475486.

240. Seidel, C.; Schnekenburger, M.; Dicato, M.; Diederich, M. Histone deacetylase modulators provided by Mother Nature. Genes Nutr 2012, 7, 357-367, doi:10.1007/s12263-012-0283-9.

241. Shakespear, M.R.; Halili, M.A.; Irvine, K.M.; Fairlie, D.P.; Sweet, M.J. Histone deacetylases as regulators of inflammation and immunity. Trends Immunol 2011, 32, 335-343, doi:10.1016/j.it.2011.04.001.

242. Shanak, S.; Saad, B.; Zaid, H. Metabolic and Epigenetic Action Mechanisms of Antidiabetic Medicinal Plants. Evid Based Complement Alternat Med 2019, 2019, 3583067, doi:10.1155/2019/3583067.

243. Sharma, S.; Taliyan, R. Histone deacetylase inhibitors: Future therapeutics for insulin resistance and type 2 diabetes. Pharmacol Res 2016, 113, 320-326, doi:10.1016/j.phrs.2016.09.009.

244. Shen, J.; Ma, W.; Liu, Y. Deacetylase SIRT6 deaccelerates endothelial senescence. Cardiovasc Res 2013, 97, 391-392, doi:10.1093/cvr/cvs421.

245. Shi, J.X.; Wang, Q.J.; Li, H.; Huang, Q. SIRT4 overexpression protects against diabetic 
nephropathy by inhibiting podocyte apoptosis. Exp Ther Med 2017, 13, 342-348, doi:10.3892/etm.2016.3938.

246. Shi, X.; Pi, L.; Zhou, S.; Li, X.; Min, F.; Wang, S.; Liu, Z.; Wu, J. Activation of Sirtuin 1 Attenuates High Glucose-Induced Neuronal Apoptosis by Deacetylating p53. Front Endocrinol (Lausanne) 2018, 9, 274, doi:10.3389/fendo.2018.00274.

247. Shin, J.S.; Min, B.H.; Lim, J.Y.; Kim, B.K.; Han, H.J.; Yoon, K.H.; Kim, S.J.; Park, C.G. Novel culture technique involving an histone deacetylase inhibitor reduces the marginal islet mass to correct streptozotocin-induced diabetes. Cell Transplant 2011, 20, 1321-1332, doi:10.3727/096368910X557146.

248. Sociali, G.; Magnone, M.; Ravera, S.; Damonte, P.; Vigliarolo, T.; Von Holtey, M.; Vellone, V.G.; Millo, E.; Caffa, I.; Cea, M., et al. Pharmacological Sirt6 inhibition improves glucose tolerance in a type 2 diabetes mouse model. FASEB J 2017, 31, 3138-3149, doi:10.1096/fj.201601294R.

249. Song, J.; Yang, B.; Jia, X.; Li, M.; Tan, W.; Ma, S.; Shi, X.; Feng, L. Distinctive Roles of Sirtuins on Diabetes, Protective or Detrimental? Front Endocrinol (Lausanne) 2018, 9, 724, doi:10.3389/fendo.2018.00724.

250. Song, M.Y.; Wang, J.; Ka, S.O.; Bae, E.J.; Park, B.H. Insulin secretion impairment in Sirt6 knockout pancreatic beta cells is mediated by suppression of the FoxO1-Pdx1-Glut2 pathway. Sci Rep 2016, 6, 30321, doi:10.1038/srep30321.

251. Spaeth, J.M.; Walker, E.M.; Stein, R. Impact of Pdx1-associated chromatin modifiers on islet beta-cells. Diabetes Obes Metab 2016, 18 Suppl 1, 123-127, doi:10.1111/dom.12730.

252. Spallotta, F.; Cencioni, C.; Straino, S.; Nanni, S.; Rosati, J.; Artuso, S.; Manni, I.; Colussi, C.; Piaggio, G.; Martelli, F., et al. A nitric oxide-dependent cross-talk between class I and III histone deacetylases accelerates skin repair. J Biol Chem 2013, 288, 11004-11012, doi:10.1074/jbc.M112.441816.

253. Srivastava, S.P.; Li, J.; Kitada, M.; Fujita, H.; Yamada, Y.; Goodwin, J.E.; Kanasaki, K.; Koya, D. SIRT3 deficiency leads to induction of abnormal glycolysis in diabetic kidney with fibrosis. Cell Death Dis 2018, 9, 997, doi:10.1038/s41419-018-1057-0.

254. Stiehl, D.P.; Fath, D.M.; Liang, D.; Jiang, Y.; Sang, N. Histone deacetylase inhibitors synergize p300 autoacetylation that regulates its transactivation activity and complex formation. Cancer Res 2007, 67, 2256-2264, doi:10.1158/0008-5472.CAN-06-3985.

255. Sulaiman, M.; Matta, M.J.; Sunderesan, N.R.; Gupta, M.P.; Periasamy, M.; Gupta, M. Resveratrol, an activator of SIRT1, upregulates sarcoplasmic calcium ATPase and improves cardiac function in diabetic cardiomyopathy. Am J Physiol Heart Circ Physiol 2010, 298, H833-843, doi:10.1152/ajpheart.00418.2009.

256. Sun, L.; Marin de Evsikova, C.; Bian, K.; Achille, A.; Telles, E.; Pei, H.; Seto, E. Programming and Regulation of Metabolic Homeostasis by HDAC11. EBioMedicine 2018, 33, 157-168, doi:10.1016/j.ebiom.2018.06.025.

257. Sun, X.Y.; Qin, H.J.; Zhang, Z.; Xu, Y.; Yang, X.C.; Zhao, D.M.; Li, X.N.; Sun, L.K. Valproate attenuates diabetic nephropathy through inhibition of endoplasmic reticulum stressinduced apoptosis. Mol Med Rep 2016, 13, 661-668, doi:10.3892/mmr.2015.4580.

258. Susick, L.; Senanayake, T.; Veluthakal, R.; Woster, P.M.; Kowluru, A. A novel histone deacetylase inhibitor prevents IL-1beta induced metabolic dysfunction in pancreatic betacells. J Cell Mol Med 2009, 13, 1877-1885, doi:10.1111/j.1582-4934.2009.00672.x.

259. Suzuki, T.; Muto, N.; Bando, M.; Itoh, Y.; Masaki, A.; Ri, M.; Ota, Y.; Nakagawa, H.; Iida, S.; Shirahige, K., et al. Design, synthesis, and biological activity of NCC149 derivatives as histone deacetylase 8-selective inhibitors. ChemMedChem 2014, 9, 657-664, doi: $10.1002 / \mathrm{cmdc} .201300414$.

260. Tan, H.W.; Sim, A.Y.; Huang, S.L.; Leng, Y.; Long, Y.C. HC toxin (a HDAC inhibitor) enhances IRS1-Akt Signaling and metabolism in mouse myotubes. J Mol Endocrinol 2015, 55, 197-207, doi:10.1530/JME-15-0140.

261. Tang, J.; Yan, H.; Zhuang, S. Histone deacetylases as targets for treatment of multiple diseases. Clin Sci (Lond) 2013, 124, 651-662, doi:10.1042/CS20120504.

262. Tang, W.; Fan, Y. SIRT6 as a potential target for treating insulin resistance. Life Sci 2019, 231, 116558, doi:10.1016/j.lfs.2019.116558. 
263. Tate, M., Willis, A.M., Deo, M., De Blasio, M.J., Prakoso, D., Kiriazis, H., Du, X.-J., Qian, H.-W., McGee, S., Gregorevic, P., Ritchie, R.H. Cardiac-selective targeting of histone deacetylase 4 to limit experimental diabetic cardiomyopathy. European Heart Journa 2018, 39, 2841.

264. Thandavarayan, R.A.; Garikipati, V.N.; Joladarashi, D.; Suresh Babu, S.; Jeyabal, P.; Verma, S.K.; Mackie, A.R.; Khan, M.; Arumugam, S.; Watanabe, K., et al. Sirtuin-6 deficiency exacerbates diabetes-induced impairment of wound healing. Exp Dermatol 2015, 24, 773-778, doi:10.1111/exd.12762.

265. Trisciuoglio, D.; Di Martile, M.; Del Bufalo, D. Emerging Role of Histone Acetyltransferase in Stem Cells and Cancer. Stem Cells Int 2018, 2018, 8908751, doi:10.1155/2018/8908751.

266. Vincent Wai-Sun Wong, M.T.-S.M., Alfred Sze-Lok Cheng. Handbook of Nutrition, Diet, and Epigenetics; Springer, Cham: 2017; https://doi.org/10.1007/978-3-319-31143-2_23-1.

267. Wagner, F.F.; Lundh, M.; Kaya, T.; McCarren, P.; Zhang, Y.L.; Chattopadhyay, S.; Gale, J.P.; Galbo, T.; Fisher, S.L.; Meier, B.C., et al. An Isochemogenic Set of Inhibitors To Define the Therapeutic Potential of Histone Deacetylases in beta-Cell Protection. ACS Chem Biol 2016, 11, 363-374, doi:10.1021/acschembio.5b00640.

268. Wang, B.; Yang, Q.; Sun, Y.Y.; Xing, Y.F.; Wang, Y.B.; Lu, X.T.; Bai, W.W.; Liu, X.Q.; Zhao, Y.X. Resveratrol-enhanced autophagic flux ameliorates myocardial oxidative stress injury in diabetic mice. J Cell Mol Med 2014, 18, 1599-1611, doi:10.1111/jcmm.12312.

269. Wang, F.; Shang, Y.; Zhang, R.; Gao, X.; Zeng, Q. A SIRT1 agonist reduces cognitive decline in type 2 diabetic rats through antioxidative and antiinflammatory mechanisms. Mol Med Rep 2019, 19, 1040-1048, doi:10.3892/mmr.2018.9699.

270. Wang, J.; Wang, K.; Huang, C.; Lin, D.; Zhou, Y.; Wu, Y.; Tian, N.; Fan, P.; Pan, X.; Xu, D., et al. SIRT3 Activation by Dihydromyricetin Suppresses Chondrocytes Degeneration via Maintaining Mitochondrial Homeostasis. Int J Biol Sci 2018, 14, 1873-1882, doi:10.7150/ijbs.27746.

271. Wang, L.; Beier, U.H.; Akimova, T.; Dahiya, S.; Han, R.; Samanta, A.; Levine, M.H.; Hancock, W.W. Histone/protein deacetylase inhibitor therapy for enhancement of Foxp3+ Tregulatory cell function posttransplantation. Am J Transplant 2018, 18, 1596-1603, doi:10.1111/ajt.14749.

272. Wang, R.H.; Xu, X.; Kim, H.S.; Xiao, Z.; Deng, C.X. SIRT1 deacetylates FOXA2 and is critical for Pdx1 transcription and beta-cell formation. Int J Biol Sci 2013, 9, 934-946, doi:10.7150/ijbs.7529.

273. Wang, S.; Wang, J.; Zhao, A.; Li, J. SIRT1 activation inhibits hyperglycemia-induced apoptosis by reducing oxidative stress and mitochondrial dysfunction in human endothelial cells. Mol Med Rep 2017, 16, 3331-3338, doi:10.3892/mmr.2017.7027.

274. Wang, W.; Shang, C.; Zhang, W.; Jin, Z.; Yao, F.; He, Y.; Wang, B.; Li, Y.; Zhang, J.; Lin, R. Hydroxytyrosol NO regulates oxidative stress and NO production through SIRT1 in diabetic mice and vascular endothelial cells. Phytomedicine 2019, 52, 206-215, doi:10.1016/j.phymed.2018.09.208.

275. Wang, X., Wei, X., Pang, Q., Yi, F. Histone deacetylases and their inhibitors: molecular mechanisms and therapeutic implications in diabetes mellitus. Acta Pharmaceutica Sinica B 2012, 2, 387-395.

276. Wang, X.; Liu, J.; Zhen, J.; Zhang, C.; Wan, Q.; Liu, G.; Wei, X.; Zhang, Y.; Wang, Z.; Han, $\mathrm{H}$, et al. Histone deacetylase 4 selectively contributes to podocyte injury in diabetic nephropathy. Kidney Int 2014, 86, 712-725, doi:10.1038/ki.2014.111.

277. Wang, Y.; Zhao, X.; Shi, D.; Chen, P.; Yu, Y.; Yang, L.; Xie, L. Overexpression of SIRT1 promotes high glucose-attenuated corneal epithelial wound healing via p53 regulation of the IGFBP3/IGF-1R/AKT pathway. Invest Ophthalmol Vis Sci 2013, 54, 3806-3814, doi:10.1167/iovs.13-12091.

278. Watanabe, H.; Inaba, Y.; Kimura, K.; Matsumoto, M.; Kaneko, S.; Kasuga, M.; Inoue, H. Sirt2 facilitates hepatic glucose uptake by deacetylating glucokinase regulatory protein. Nat Commun 2018, 9, 30, doi:10.1038/s41467-017-02537-6.

279. Wilkin, T.J. Changing perspectives in diabetes: their impact on its classification. Diabetologia 2007, 50, 1587-1592, doi:10.1007/s00125-007-0665-5. 
280. Winkler, R.; Benz, V.; Clemenz, M.; Bloch, M.; Foryst-Ludwig, A.; Wardat, S.; Witte, N.; Trappiel, M.; Namsolleck, P.; Mai, K., et al. Histone deacetylase 6 (HDAC6) is an essential modifier of glucocorticoid-induced hepatic gluconeogenesis. Diabetes 2012, 61, 513-523, doi: $10.2337 / \mathrm{db} 11-0313$.

281. Wong, C.K.; Wade-Vallance, A.K.; Luciani, D.S.; Brindle, P.K.; Lynn, F.C.; Gibson, W.T. The p300 and CBP Transcriptional Coactivators Are Required for beta-Cell and alpha-Cell Proliferation. Diabetes 2018, 67, 412-422, doi:10.2337/db17-0237.

282. Wu, H.; Wu, J.; Zhou, S.; Huang, W.; Li, Y.; Zhang, H.; Wang, J.; Jia, Y. SRT2104 attenuates diabetes-induced aortic endothelial dysfunction via inhibition of P53. J Endocrinol 2018, 237, 1-14, doi:10.1530/JOE-17-0672.

283. Wu, J.; Jiang, Z.; Zhang, H.; Liang, W.; Huang, W.; Zhang, H.; Li, Y.; Wang, Z.; Wang, J.; Jia, Y., et al. Sodium butyrate attenuates diabetes-induced aortic endothelial dysfunction via P300-mediated transcriptional activation of Nrf2. Free Radic Biol Med 2018, 124, 454-465, doi:10.1016/j.freeradbiomed.2018.06.034.

284. Wu, S.Y.; Liang, J.; Yang, B.C.; Leung, P.S. SIRT1 Activation Promotes beta-Cell Regeneration by Activating Endocrine Progenitor Cells via AMPK Signaling-Mediated Fatty Acid Oxidation. Stem Cells 2019, 37, 1416-1428, doi:10.1002/stem.3073.

285. Wu, Y.; Leng, Y.; Meng, Q.; Xue, R.; Zhao, B.; Zhan, L.; Xia, Z. Suppression of Excessive Histone Deacetylases Activity in Diabetic Hearts Attenuates Myocardial Ischemia/Reperfusion Injury via Mitochondria Apoptosis Pathway. J Diabetes Res 2017, 2017, 8208065, doi:10.1155/2017/8208065.

286. Xie, M.; Tian, J.; Luo, Y.; Wei, L.; Lin, S.; Tang, S. Effects of 5-aza-2'-deoxycytidine and trichostatin A on high glucose- and interleukin-1beta-induced secretory mediators from human retinal endothelial cells and retinal pigment epithelial cells. Mol Vis 2014, 20, 1411-1421.

287. Xie, R.; Carrano, A.C.; Sander, M. A systems view of epigenetic networks regulating pancreas development and beta-cell function. Wiley Interdiscip Rev Syst Biol Med 2015, 7, 1-11, doi:10.1002/wsbm.1287.

288. Xu, J.; Jackson, C.W.; Khoury, N.; Escobar, I.; Perez-Pinzon, M.A. Brain SIRT1 Mediates Metabolic Homeostasis and Neuroprotection. Front Endocrinol (Lausanne) 2018, 9, 702, doi:10.3389/fendo.2018.00702.

289. Xu, Z.; Tong, Q.; Zhang, Z.; Wang, S.; Zheng, Y.; Liu, Q.; Qian, L.B.; Chen, S.Y.; Sun, J.; Cai, L. Inhibition of HDAC3 prevents diabetic cardiomyopathy in OVE26 mice via epigenetic regulation of DUSP5-ERK1/2 pathway. Clin Sci (Lond) 2017, 131, 1841-1857, doi:10.1042/CS20170064.

290. Yamato, E. High dose of histone deacetylase inhibitors affects insulin secretory mechanism of pancreatic beta cell line. Endocr Regul 2018, 52, 21-26, doi:10.2478/enr-2018-0004.

291. Yang, F., Zhao, N., Ge, D., Chen, Y. Next-generation of selective histone deacetylase inhibitors. . RSC Advances 2019, 9, 19571-19583.

292. Yanginlar, C.; Logie, C. HDAC11 is a regulator of diverse immune functions. Biochim Biophys Acta Gene Regul Mech 2018, 1861, 54-59, doi:10.1016/j.bbagrm.2017.12.002.

293. Yao, X.H.; Nguyen, K.H.; Nyomba, B.L. Reversal of glucose intolerance in rat offspring exposed to ethanol before birth through reduction of nuclear skeletal muscle HDAC expression by the bile acid TUDCA. Physiol Rep 2014, 2, doi:10.14814/phy2.12195.

294. Ye, X.; Li, M.; Hou, T.; Gao, T.; Zhu, W.G.; Yang, Y. Sirtuins in glucose and lipid metabolism. Oncotarget 2017, 8, 1845-1859, doi:10.18632/oncotarget.12157.

295. Yerra, V.G.; Kalvala, A.K.; Kumar, A. Isoliquiritigenin reduces oxidative damage and alleviates mitochondrial impairment by SIRT1 activation in experimental diabetic neuropathy. J Nutr Biochem 2017, 47, 41-52, doi:10.1016/j.jnutbio.2017.05.001.

296. Ying, Y.; Jiang, C.; Zhang, M.; Jin, J.; Ge, S.; Wang, X. Phloretin protects against cardiac damage and remodeling via restoring SIRT1 and anti-inflammatory effects in the streptozotocin-induced diabetic mouse model. Aging (Albany NY) 2019, 11, 2822-2835, doi:10.18632/aging.101954.

297. Yoshimatsu, G.; Kunnathodi, F.; Saravanan, P.B.; Shahbazov, R.; Chang, C.; Darden, C.M.; Zurawski, S.; Boyuk, G.; Kanak, M.A.; Levy, M.F., et al. Pancreatic beta-Cell-Derived IP10/CXCL10 Isletokine Mediates Early Loss of Graft Function in Islet Cell Transplantation. 
Diabetes 2017, 66, 2857-2867, doi:10.2337/db17-0578.

298. Yu, J.; Qin, B.; Wu, F.; Qin, S.; Nowsheen, S.; Shan, S.; Zayas, J.; Pei, H.; Lou, Z.; Wang, L. Regulation of Serine-Threonine Kinase Akt Activation by NAD(+)-Dependent Deacetylase SIRT7. Cell Rep 2017, 18, 1229-1240, doi:10.1016/j.celrep.2017.01.009.

299. Yu, L.; Chen, J.F.; Shuai, X.; Xu, Y.; Ding, Y.; Zhang, J.; Yang, W.; Liang, X.; Su, D.; Yan, C. Artesunate protects pancreatic beta cells against cytokine-induced damage via SIRT1 inhibiting NF-kappaB activation. J Endocrinol Invest 2016, 39, 83-91, doi:10.1007/s40618015-0328-1.

300. Yu, W.; Gao, B.; Li, N.; Wang, J.; Qiu, C.; Zhang, G.; Liu, M.; Zhang, R.; Li, C.; Ji, G., et al. Sirt3 deficiency exacerbates diabetic cardiac dysfunction: Role of Foxo3A-Parkin-mediated mitophagy. Biochim Biophys Acta Mol Basis Dis 2017, 1863, 1973-1983, doi:10.1016/j.bbadis.2016.10.021.

301. Yu, W.C.; Chen, Y.L.; Hwang, P.A.; Chen, T.H.; Chou, T.C. Fucoidan ameliorates pancreatic beta-cell death and impaired insulin synthesis in streptozotocin-treated beta cells and mice via a Sirt-1-dependent manner. Mol Nutr Food Res 2017, 61, doi:10.1002/mnfr.201700136.

302. Yu, X.; Zhang, L.; Yang, X.; Huang, H.; Huang, Z.; Shi, L.; Zhang, H.; Du, G. Salvianolic acid A protects the peripheral nerve function in diabetic rats through regulation of the AMPKPGC1alpha-Sirt3 axis. Molecules 2012, 17, 11216-11228, doi:10.3390/molecules170911216.

303. Yuan, H.; Li, H.; Yu, P.; Fan, Q.; Zhang, X.; Huang, W.; Shen, J.; Cui, Y.; Zhou, W. Involvement of HDAC6 in ischaemia and reperfusion-induced rat retinal injury. BMC Ophthalmol 2018, 18, 300, doi:10.1186/s12886-018-0951-7.

304. Yuan, Q.; Zhan, L.; Zhou, Q.Y.; Zhang, L.L.; Chen, X.M.; Hu, X.M.; Yuan, X.C. SIRT2 regulates microtubule stabilization in diabetic cardiomyopathy. Eur J Pharmacol 2015, 764, 554-561, doi:10.1016/j.ejphar.2015.07.045.

305. Yuan, Y.; Shi, M.; Li, L.; Liu, J.; Chen, B.; Chen, Y.; An, X.; Liu, S.; Luo, R.; Long, D., et al. Mesenchymal stem cell-conditioned media ameliorate diabetic endothelial dysfunction by improving mitochondrial bioenergetics via the Sirt1/AMPK/PGC-1alpha pathway. Clin Sci (Lond) 2016, 130, 2181-2198, doi:10.1042/CS20160235.

306. Yuen, D.A.; Zhang, Y.; Thai, K.; Spring, C.; Chan, L.; Guo, X.; Advani, A.; Sivak, J.M.; Gilbert, R.E. Angiogenic dysfunction in bone marrow-derived early outgrowth cells from diabetic animals is attenuated by SIRT1 activation. Stem Cells Transl Med 2012, 1, 921-926, doi:10.5966/sctm.2012-0026.

307. Yuriy K Bashmakov, I.M.P. Old Drug Acquires New Target: Metformin and Sirt1. Journal of Diabetes \& Metabolism 2011, 2, 1000107e, doi:http://dx.doi.org/10.4172/21556156.1000107e.

308. Zeng, H.; He, X.; Hou, X.; Li, L.; Chen, J.X. Apelin gene therapy increases myocardial vascular density and ameliorates diabetic cardiomyopathy via upregulation of sirtuin 3. Am J Physiol Heart Circ Physiol 2014, 306, H585-597, doi:10.1152/ajpheart.00821.2013.

309. Zeng, Z.; Liao, R.; Yao, Z.; Zhou, W.; Ye, P.; Zheng, X.; Li, X.; Huang, Y.; Chen, S.; Chen, $\mathrm{Q}$. Three single nucleotide variants of the HDAC gene are associated with type 2 diabetes mellitus in a Chinese population: a community-based case-control study. Gene 2014, 533, 427-433, doi:10.1016/j.gene.2013.09.123.

310. Zhang, J.; Xu, Z.; Gu, J.; Jiang, S.; Liu, Q.; Zheng, Y.; Freedman, J.H.; Sun, J.; Cai, L. HDAC3 inhibition in diabetic mice may activate Nrf2 preventing diabetes-induced liver damage and FGF21 synthesis and secretion leading to aortic protection. Am J Physiol Endocrinol Metab 2018, 315, E150-E162, doi:10.1152/ajpendo.00465.2017.

311. Zhang, L.; Du, J.; Yano, N.; Wang, H.; Zhao, Y.T.; Dubielecka, P.M.; Zhuang, S.; Chin, Y.E.; Qin, G.; Zhao, T.C. Sodium Butyrate Protects -Against High Fat Diet-Induced Cardiac Dysfunction and Metabolic Disorders in Type II Diabetic Mice. J Cell Biochem 2017, 118, 2395-2408, doi:10.1002/jcb.25902.

312. Zhang, M.; Pan, Y.; Dorfman, R.G.; Yin, Y.; Zhou, Q.; Huang, S.; Liu, J.; Zhao, S. Sirtinol promotes PEPCK1 degradation and inhibits gluconeogenesis by inhibiting deacetylase SIRT2. Sci Rep 2017, 7, 7, doi:10.1038/s41598-017-00035-9.

313. Zhang, M.; Wang, S.; Cheng, Z.; Xiong, Z.; Lv, J.; Yang, Z.; Li, T.; Jiang, S.; Gu, J.; Sun, D., et al. Polydatin ameliorates diabetic cardiomyopathy via Sirt3 activation. Biochem Biophys 
Res Commun 2017, 493, 1280-1287, doi:10.1016/j.bbrc.2017.09.151.

314. Zhang, X.; Yang, S.; Chen, J.; Su, Z. Unraveling the Regulation of Hepatic Gluconeogenesis. Front Endocrinol (Lausanne) 2018, 9, 802, doi:10.3389/fendo.2018.00802.

315. Zhang, Z.; Ding, X.; Zhou, Z.; Qiu, Z.; Shi, N.; Zhou, S.; Du, L.; Zhu, X.; Wu, Y.; Yin, X., et al. Sirtuin 1 alleviates diabetic neuropathic pain by regulating synaptic plasticity of spinal dorsal horn neurons. Pain 2019, 160, 1082-1092, doi:10.1097/j.pain.0000000000001489.

316. Zhao, B.; Yuan, Q.; Hou, J.B.; Xia, Z.Y.; Zhan, L.Y.; Li, M.; Jiang, M.; Gao, W.W.; Liu, L. Inhibition of HDAC3 Ameliorates Cerebral Ischemia Reperfusion Injury in Diabetic Mice In Vivo and In Vitro. J Diabetes Res 2019, 2019, 8520856, doi:10.1155/2019/8520856.

317. Zhao, H.; Ma, T.; Fan, B.; Yang, L.; Han, C.; Luo, J.; Kong, L. Protective effect of trans-deltaviniferin against high glucose-induced oxidative stress in human umbilical vein endothelial cells through the SIRT1 pathway. Free Radic Res 2016, 50, 68-83, doi:10.3109/10715762.2015.1108412.

318. Zhao, Y.; Wei, J.; Hou, X.; Liu, H.; Guo, F.; Zhou, Y.; Zhang, Y.; Qu, Y.; Gu, J.; Zhou, Y., et al. SIRT1 rs10823108 and FOXO1 rs17446614 responsible for genetic susceptibility to diabetic nephropathy. Sci Rep 2017, 7, 10285, doi:10.1038/s41598-017-10612-7.

319. Zheng, J.; Shi, L.; Liang, F.; Xu, W.; Li, T.; Gao, L.; Sun, Z.; Yu, J.; Zhang, J. Sirt3 Ameliorates Oxidative Stress and Mitochondrial Dysfunction After Intracerebral Hemorrhage in Diabetic Rats. Front Neurosci 2018, 12, 414, doi:10.3389/fnins.2018.00414.

320. Zhong, F.; Jiang, Y. Endogenous Pancreatic beta Cell Regeneration: A Potential Strategy for the Recovery of beta Cell Deficiency in Diabetes. Front Endocrinol (Lausanne) 2019, 10, 101, doi:10.3389/fendo.2019.00101.

321. Zhong, Q.; Kowluru, R.A. Role of histone acetylation in the development of diabetic retinopathy and the metabolic memory phenomenon. J Cell Biochem 2010, 110, 1306-1313, doi:10.1002/jcb.22644.

322. Zhou, C.H.; Zhang, M.X.; Zhou, S.S.; Li, H.; Gao, J.; Du, L.; Yin, X.X. SIRT1 attenuates neuropathic pain by epigenetic regulation of mGluR $1 / 5$ expressions in type 2 diabetic rats. Pain 2017, 158, 130-139, doi:10.1097/j.pain.0000000000000739.

323. Zhou, S.; Chen, H.Z.; Wan, Y.Z.; Zhang, Q.J.; Wei, Y.S.; Huang, S.; Liu, J.J.; Lu, Y.B.; Zhang, Z.Q.; Yang, R.F., et al. Repression of P66Shc expression by SIRT1 contributes to the prevention of hyperglycemia-induced endothelial dysfunction. Circ Res 2011, 109, 639-648, doi:10.1161/CIRCRESAHA.111.243592.

324. Zhu, Y.; Liu, Q.; Zhou, Z.; Ikeda, Y. PDX1, Neurogenin-3, and MAFA: critical transcription regulators for beta cell development and regeneration. Stem Cell Res Ther 2017, 8, 240, doi:10.1186/s13287-017-0694-Z.

325. Zorrilla-Zubilete, M.A.; Yeste, A.; Quintana, F.J.; Toiber, D.; Mostoslavsky, R.; Silberman, D.M. Epigenetic control of early neurodegenerative events in diabetic retinopathy by the histone deacetylase SIRT6. J Neurochem 2018, 144, 128-138, doi:10.1111/jnc.14243.

\section{Legends to Figures-}

Fig. 1. RMtiple biological actions of HDAC inhibitors (HDACi) on progenitor. cell lineage. and embryonic stem cells.

Fig. 2. A) When glucose levels are high, acetylation of histone $\mathrm{H} 4$ is increased in the insulin promoter due to interaction of PDX1 with HAT p300; B) when glucose levels are low, PDX 1 recruits HDAC 1 and HDAC 2 to the insulin promoter so that $\mathrm{H} 4$ can no longer be acetylated and led to the shutdown of insulin production; C) NeuD1 role in insulin gene expression through p300- 
associated factor (PCAF) acetylation, MafA phosphorylation when glucose levels are high.

Fig. 3. HDACs in glucose homeostasis: PI3K-Akt signaling regulation through IRS1 substrate phosphorylation and it effects on GLUT4 receptor in generating insulin resistance (adipocytes and muscles) through HDACs and also its action on PDX through HDAC1 to regulate insulin secretion.

Fig. 4. Importance of HDAC1s in mediating the increase in hepatic glucose production in obesity and diabetes

Fig. 5. HDAC3 and 5 inhibition and insulin resistance through PPAR $\gamma$ under neuroinflammation. Decrease in HDAC 3/5 activity results in increased GLUT 4 expression, and prevents lead insulin resistance.

Fig. 6. Diabetic nephropathy: In diabetes if HDAC2 get inhibited with HADCi in renal cells-induce the expression of DNA binding/ differentiation 2 (Id2) and bone-morphogenic protein 7 (BMP7) to inhibit TGF- $\beta 1$ Signaling. Eventually downregulate fibronectin, collagen $1, \alpha-$ SMA, and Ecadherin and provides the protection either from diabetic nephropathy or nephromegaly.

Fig. 7. HDAC inhibition and $\beta$ - cell protection by HDACi through STAT1-SERCA2 viz CHOP \& HSP-70 to show modulatory effects on Bcl-2. 
Table 1. Localization, expression, and functions of different HDACs in their respective classes.

\begin{tabular}{|c|c|c|c|c|}
\hline Classes & Members & Localizations & Expressions & Functions \\
\hline $\begin{array}{l}\text { Class I } \\
\text { (Zn }{ }^{2+-d e p e n d e n t)}\end{array}$ & HDAC 1, 2, 3, 8 & $\begin{array}{l}\text { Nucleus of all types of } \\
\text { tissues. }\end{array}$ & Ubiquitous & $\begin{array}{l}\text { Promotes proliferation, IFN signalling, and } \\
\text { HIF1 } \alpha \text { function. Contrary, it represses } \\
\text { MTA1 \& NF-KB functions. }\end{array}$ \\
\hline $\begin{array}{l}\text { Class II } \\
\text { (Zn²+-dependent) }\end{array}$ & $\begin{array}{l}\text { HDAC4, 5, 6, 7, } \\
9,10\end{array}$ & $\begin{array}{l}\text { Nucleus and cytoplasm of } \\
\text { brain, heart, skeletal muscle, } \\
\text { pancreas, liver, kidney, and } \\
\text { placenta. }\end{array}$ & Specific & $\begin{array}{l}\text { Promotes HIF1 } \alpha \text { function and HSP } 90 \\
\text { function (chaperone). It represses II5 } \\
\text { promoter and inhibits Foxp3 and Treg } \\
\text { function }\end{array}$ \\
\hline $\begin{array}{l}\text { Class III } \\
\text { (NAD+-dependent) }\end{array}$ & SIRT1-7 & $\begin{array}{l}\text { Mitochondria, nucleus, and } \\
\text { cytoplasm. Brain, and in all } \\
\text { the oncogenic tissues. }\end{array}$ & Ubiquitous & $\begin{array}{l}\text { Promotes immune function across various } \\
\text { types synapses by NAD+-dependent } \\
\text { mechanism through SIRT1. }\end{array}$ \\
\hline $\begin{array}{l}\text { Class IV } \\
\text { (Zn²+-dependent) }\end{array}$ & HDAC11 & $\begin{array}{l}\text { Cytoplasm and nucleus of } \\
\text { heart, brain, kidney, and } \\
\text { skeletal muscle. }\end{array}$ & Ubiquitous & Inhibits II5 promoter activity in APCs. \\
\hline
\end{tabular}


Table 2. Specific roles of different HDACs in Glucose metabolism and Diabetes.

\begin{tabular}{|c|c|c|}
\hline HDACs classes & HDAC Member & Specific function in Glucose metabolism and Diabetes \\
\hline \multirow{4}{*}{ Class I HDACs } & HDAC1 & Acts as repressor for the transcription of GLUT4 \\
\hline & HDAC2 & $\begin{array}{l}\text { Binds to IRS-1 leading to reduced acetylation and decreased Insulin receptor mediated tyrosine phosphorylation of } \\
\text { IRS-1 }\end{array}$ \\
\hline & HDAC3 & Stimulates Glucose production by FOXO transcription factor. \\
\hline & HDAC8 & Upregulated in obese mice models and promotes Insulin resistance. \\
\hline \multirow{4}{*}{ Class Ila HDACs } & HDAC4 & $\begin{array}{l}\text { Repress transcription of GLUT4, involved in recruitment of class I HDAC3 to liver and stimulation of glucose } \\
\text { production. }\end{array}$ \\
\hline & HDAC5 & $\begin{array}{l}\text { Repress transcription of GLUT4, involved in recruitment of class I HDAC3 to liver and stimulation of glucose } \\
\text { production. }\end{array}$ \\
\hline & HDAC7 & $\begin{array}{l}\text { Levels of HDAC7 are elevated in islets of T2D patients, elevated levels of HDAC7 lead to impairment in Insulin } \\
\text { secretion and increased } \beta \text {-cell apoptosis invitro }\end{array}$ \\
\hline & HDAC9 & Suppression of HDAC9 expression leads to improvement in Insulin sensitivity and glucose tolerance \\
\hline Class IIb HDACs & HDAC6 & Stimulates glucocorticoid-stimulated glucose production and contributes to hyperglycemia and glucose intolerance. \\
\hline SIRTUINS & SIRT2 and SIRT4 & SIRT2 and SIRT4 impair insulin signaling and may contribute to pathogenesis of T2D \\
\hline
\end{tabular}




\section{Graphical Abstract}

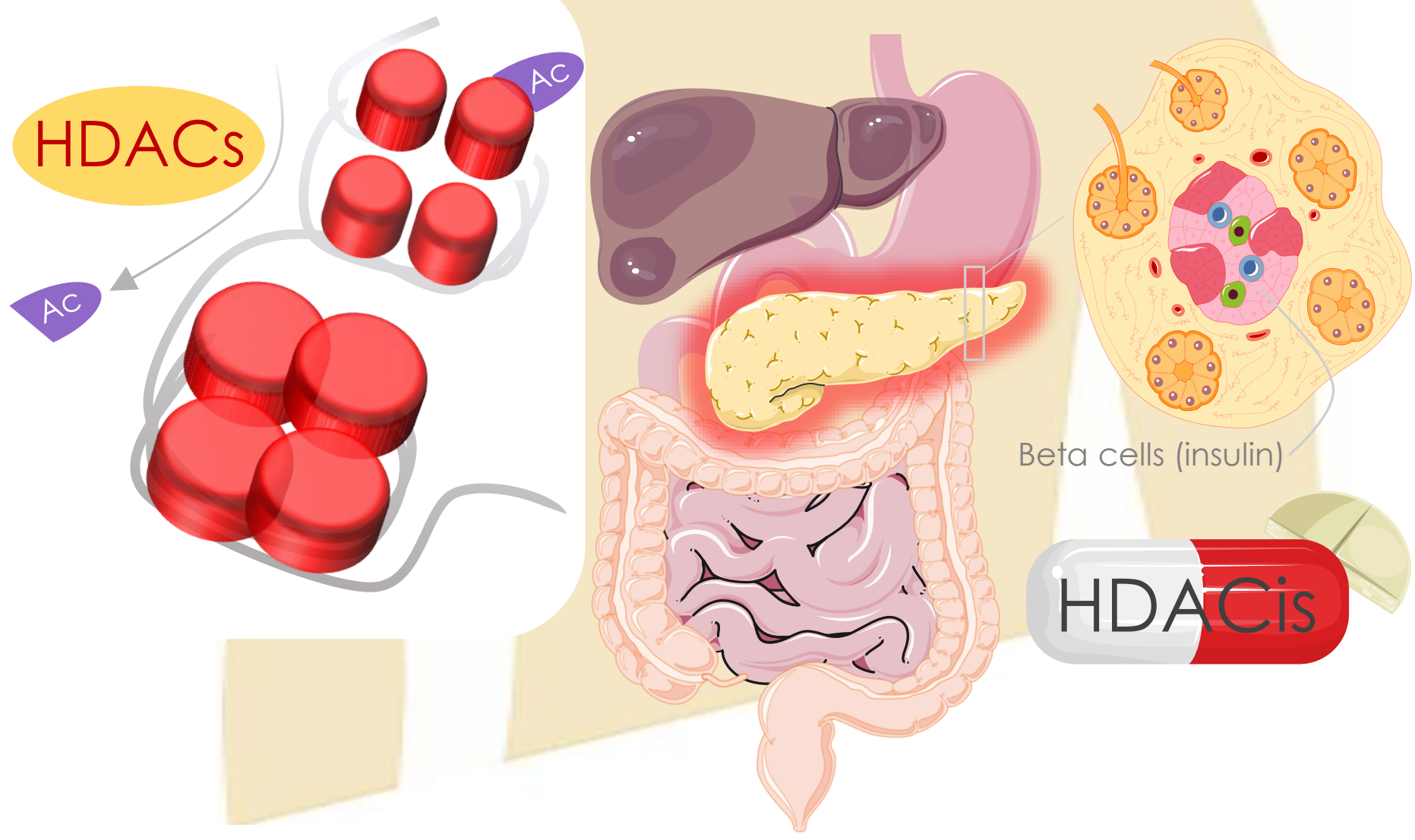




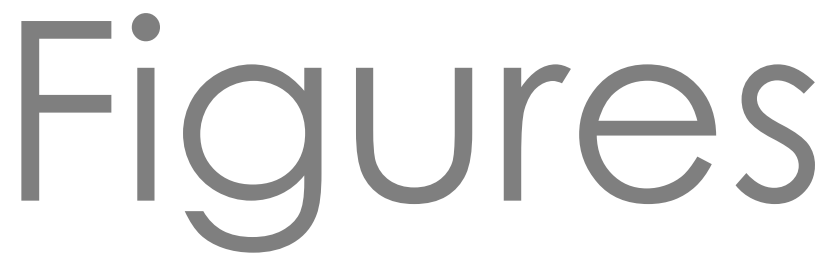




\section{rIg.}

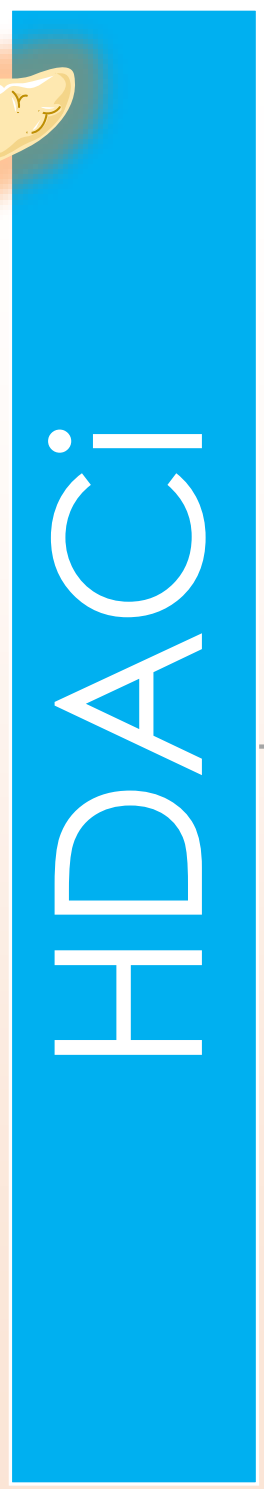

Enhance the expression of NGN- endocrine progenitor cells ( )

Enhance differentiation into $\beta / \delta$ cell lineage

Enhance embryonic stem cells' differentiation into insulin producing cells

Enhance to express insulin, glucagon and somatostatin viz. embryonic stem cells

Enhance the pool of $\beta$ and $\delta$ cells (pancreatic endocrine cells) 
A
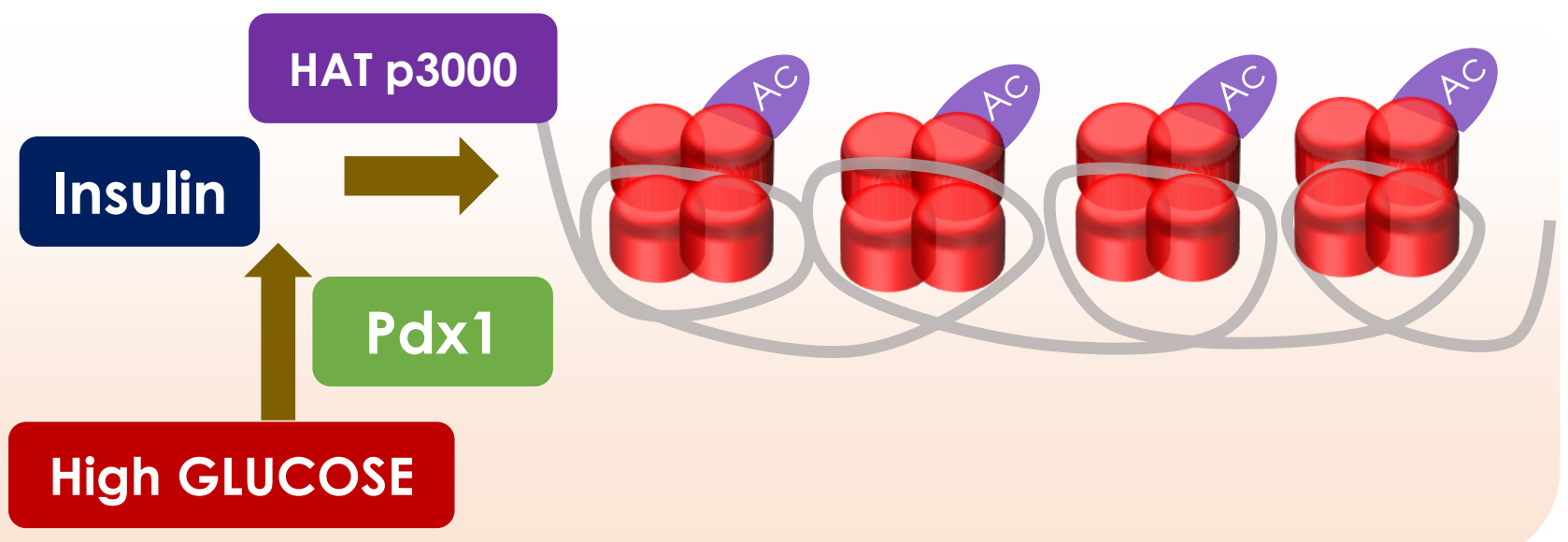

\section{High GLUCOSE}

B
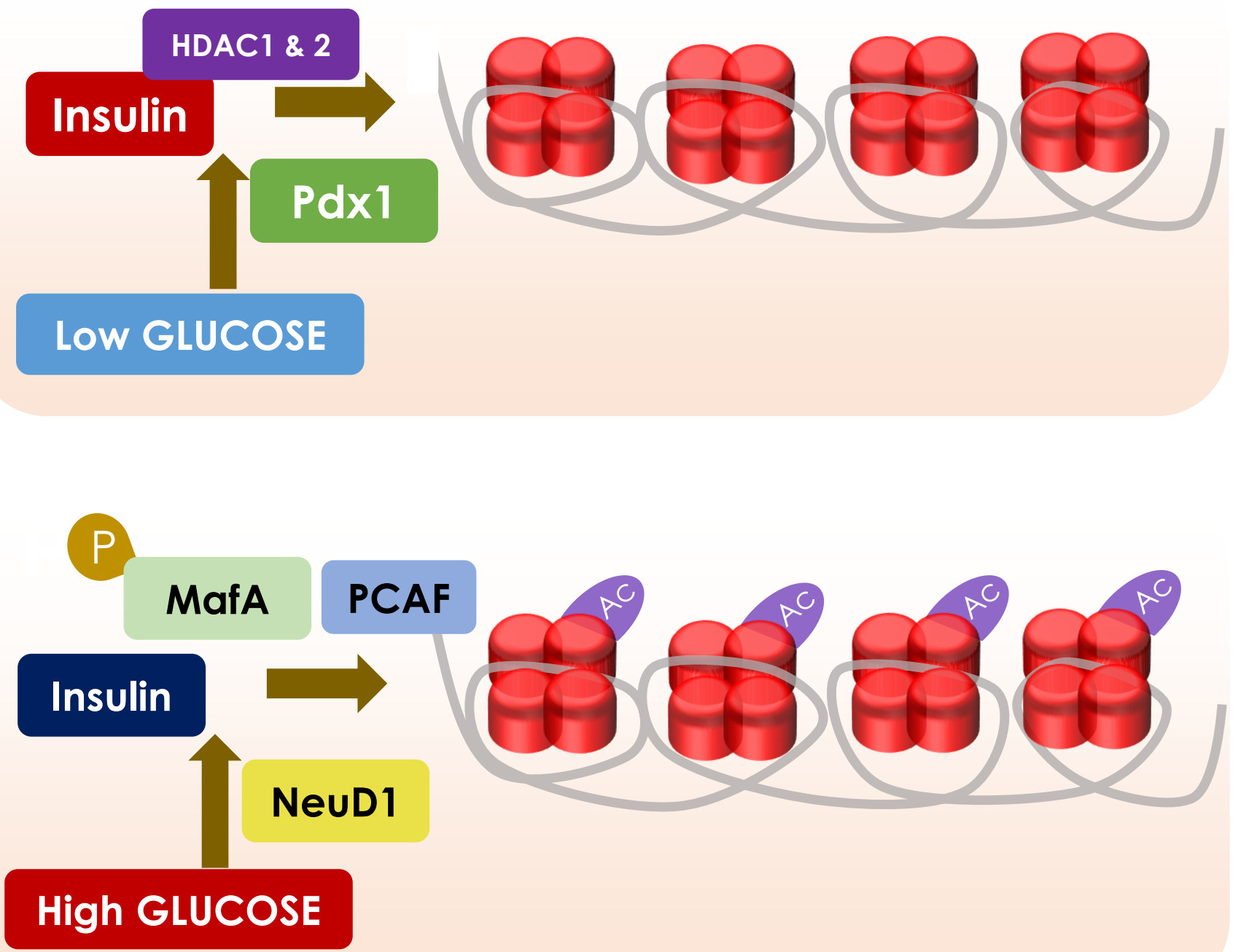

\section{High GLUCOSE}




\section{rIg. 3}
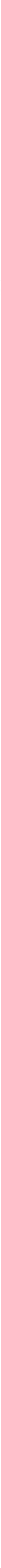


\section{rIg. 4}

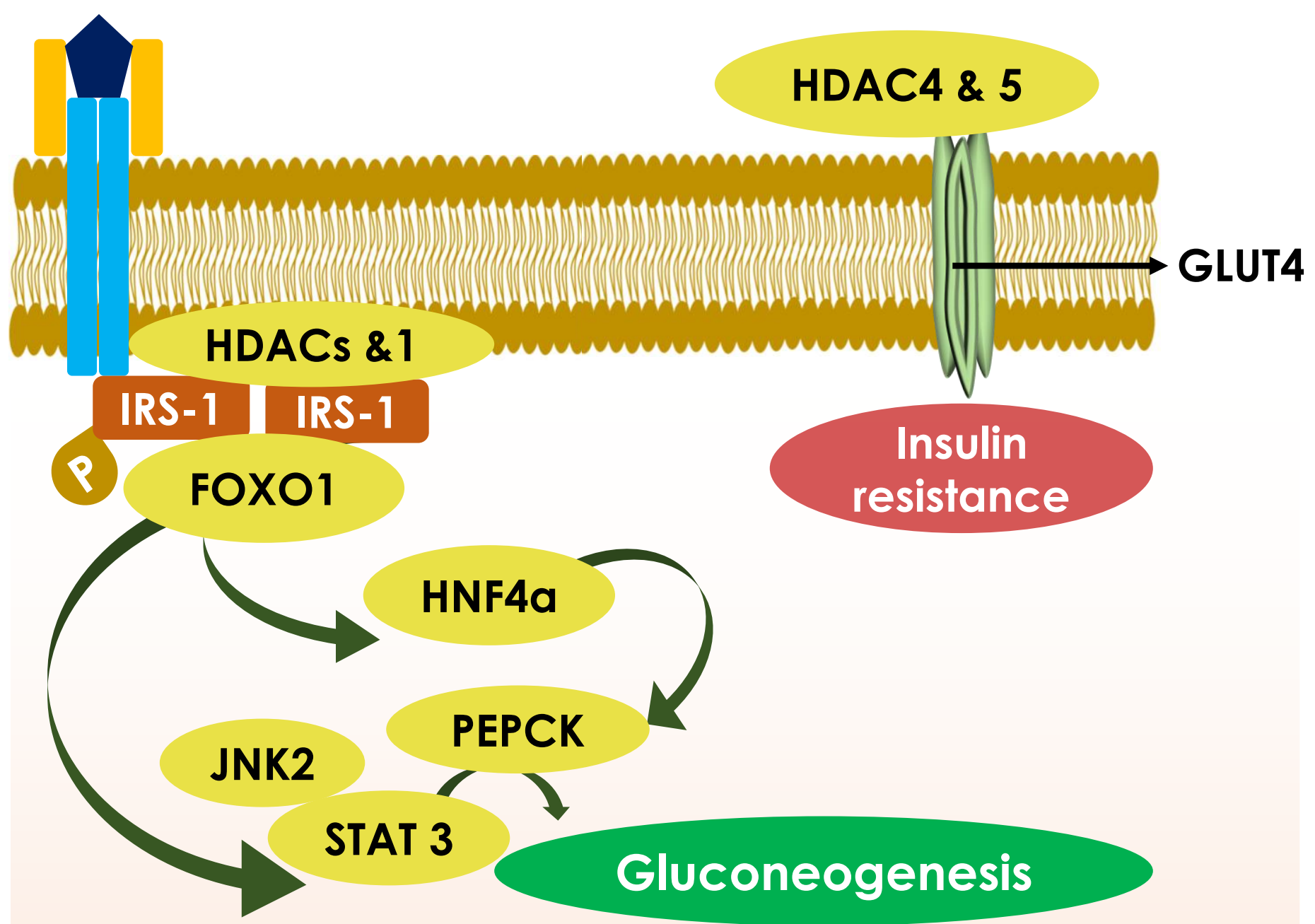




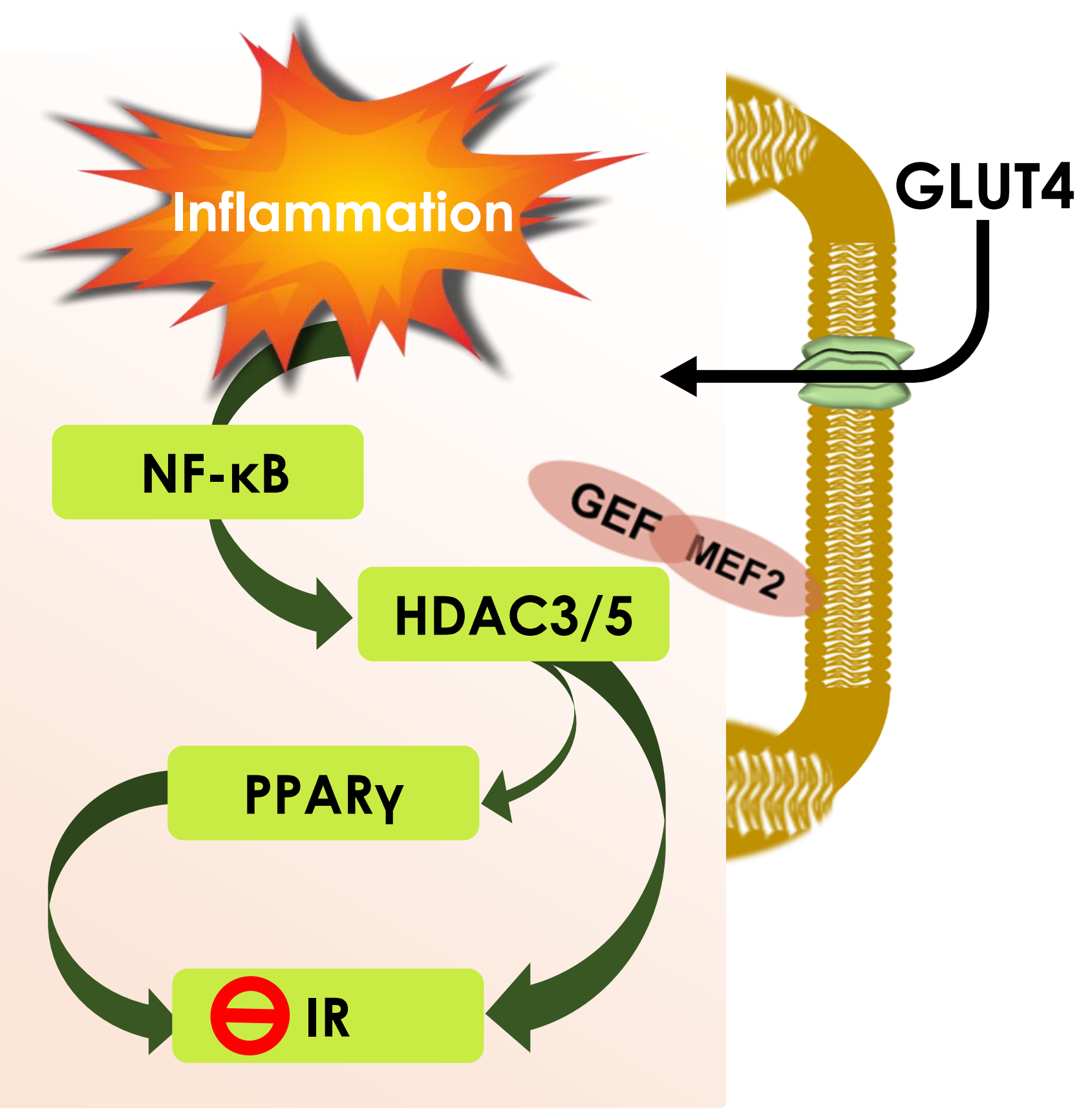




\section{Diabetes}

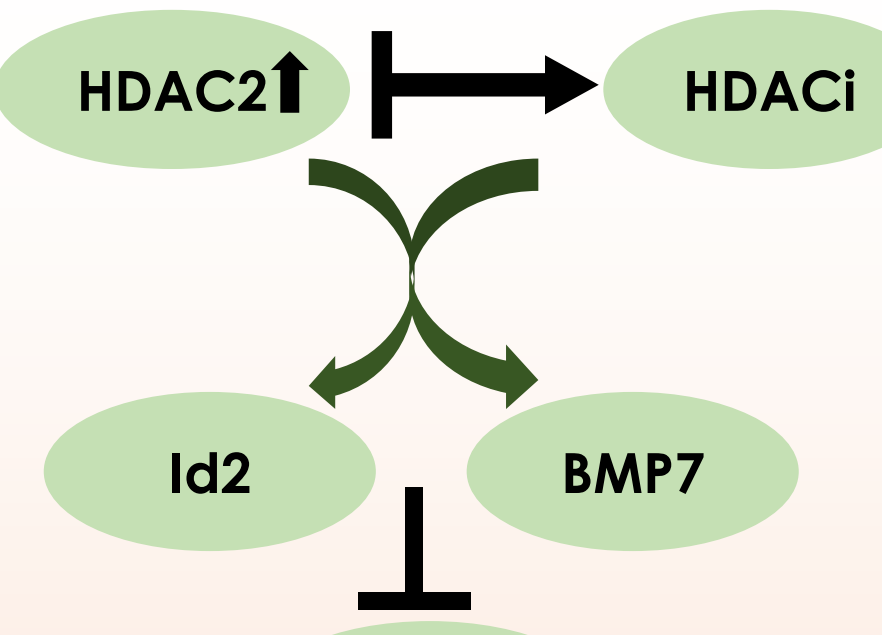

\section{TGF- $\beta 1$}

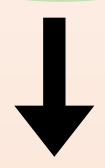

Flbronectin, collagen 1, a-SMA,

and $\mathrm{E}$ - cadherin 


\section{Cytokines}

\section{STAT1}

\section{CHOP}

\section{SERCA2}

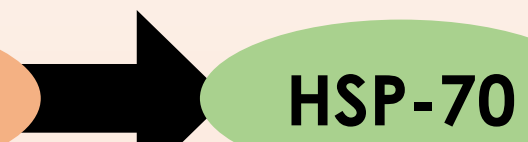

